\title{
Let There Be Light: \\ Discovering Communication in Collaboration
}

\author{
Fabian Jesus Garcia \\ Dallas, Texas
}

Bachelor of Arts in Theatre Technical, West Texas A\&M University, 2014 Associate of Science in Theatre, Grayson County College, 2012

\begin{abstract}
A Thesis presented to the Graduate Faculty of the University of Virginia in Candidacy for the Degree of Master of Fine Arts

Department of Drama
\end{abstract}

Faculty Advisers:

R. Lee Kennedy, MFA

Theresa M. Davis, MFA

University of Virginia

May, 2017 


\section{Acknowledgments}

To my mentor, R. Lee Kennedy, words cannot express how grateful I am to have studied under your guidance for three years here at the University of Virginia. You have help me discover my artistic abilities as a designer and have helped shape me into a better collaborator.

To my favorite director, Theresa M. Davis, thank you for letting me work with you these past three years. Your guidance has helped nurture my confidence in theatre. You challenged me to step back and take different approaches to my work as a designer.

Para mi familia, gracias por estar conmigo todos estos años de estudio. No estaría aquí

graduandome sin ustedes apoyándome a ser el mejor estudiante que puedo ser. En el tiempo que e estado fuera de casa, e aprendido lo importante que es la familia para mi. Los quiero much.

To my graduate colleagues, Steven P. Spera and Matthew J. Ishee, I would like to thank you for collaborating with me these three years in graduate school. I have learned so much from working with each of you. It has been fun and I look forward to the next step of our professional careers.

To my friends, Jenny Barrett, Chelsea Dickens, Michael Giovinco, Katie and Clay Tillman, and Stan Standly, I could not have gotten to this point in my life without you all. No matter where life takes me, I am grateful to have every single one of you in my life. Thank you. 
Every sentence begins with a word. Every story begins with a draft. Every collaboration begins with an idea. In theatre, a group of artists comes together to explore storytelling. They journey through a process to discover the message and secrets the story holds. Ideas, images, and facts come together as the team finds meaning in the story. These same individuals collaborate to create a work of art that shapes the minds and spirits of the people who watch the story unfold onstage. Their opinions and choices help give life to the play. In order to create a cohesive and finalized theatrical production, the design team must be able to engage in clear and effective communication.

Collaboration is an essential ingredient in the theatrical production process. Great theatre is created when audience members can look at a show and see a harmonious product through the artistic choices within the areas of scenery, costumes, lighting, sound, and other elements. A unified production comes from a successful collaboration that originates in the beginning stages of the production and that is carried through the rest of the process until opening night. Like any great work of art, however, achieving this level of collaboration does not come easy.

I started my graduate studies with a primary goal: to learn how to communicate effectively in design meetings as a Lighting Designer. It is a Lighting Designer's responsibility to visualize the production as a whole and evaluate how lighting can create atmosphere, match the mood of the show, and enhance the plot. The Lighting Designer should also be capable of anticipating future challenges that others on the design team may overlook and should be capable drawing effective solutions to these challenges. The designer analyzes the script to discover clues to about location, time of day, atmospheric effects, and emotional intent. In addition, the Lighting Designer shifts emphasis from one stage area to another, supports the style of the production and balances the visual elements onstage into a cohesive whole. Collaborating with 
different people in theatre is a skill that develops over time through a communication process. My three years of training at The University of Virginia's Department of Drama has shined a light on how important communication is when practicing successful collaboration.

An open channel of communication between all of the different departments in a production is crucial. Discussing new ideas with the entire creative team will ensure that everyone is in agreement with the direction of the production and that no surprises occur later in the process that could potentially cause problems. There are a number of different qualities that make for successful communication. Active listening is key when collaborating with others because one must be able to embrace ideas, viewpoints, even non-verbal cues from other collaborators. Respect and trust in the lighting team and design colleagues will establish a professional atmosphere. Being knowledgeable about the designer's role and the needs of the production and understanding personalities will also help ease the process of collaboration. Finally, having an open-mind and being flexible while collaborating is crucial to foster a safe and creative environment where the free exchange of ideas can occur.

On 8:30A.M. Thursday October $6^{\text {th }}, 2016$, I began a twenty-week intensive journey of self-discovery through which my skills, knowledge, and creativity were put to the test on a production of Blood Wedding by Federico García Lorca, translated by Langston Hughes and adapted by Melia Bensussen. Blood Wedding was hands-down one of the most challenging shows I have had to design in graduate school. It was to be my first mainstage design in the Culbreth Theatre, which is a 520-seat proscenium theatre. Blood Wedding is a rural tragedy in three acts. The plot follows two families whose children are getting married. Their wedding is a joyous occasion in the community that unfortunately turns ugly when the bride runs away with her old sweetheart Leonardo before her wedding night. This event triggers a manhunt for the 
bride and leads to the demise and death of the both the bridegroom and Leonardo. The story has supernatural elements including the personification of Death as a beggar woman, and the Moon as a "masculine, cold and blood-thirsty world." ${ }^{1}$ Each propels the action forward and helps the audience understand the external forces in play that lead to the demise of the characters.

The first design meeting for this production was held in October. The Director started the meeting with his thoughts on the play. He started by saying that "the Langston Hughes translation allows for a more American version of the play to be done." He also wanted to bring out a different story than the traditional poetic presentation, and then he went on to talk about the themes of "premature death and destruction." The Director saw "a society where young men are susceptible to violence," and he described the community as being on "the outskirts of town, where urban decay meets a rural population.” This concept was not congruent with my initial ideas. He wanted to have an open space and therefore requested a minimal set, and he wanted to incorporate contemporary elements into the original script, which was written in 1932 and performed in 1933, so that the production would be relatable to today's audience. The Director wanted to create what he called an "expressive environment," rather than a "realistic or naturalistic" one. To me, this particular statement meant I could explore the emotional aspect of the story and so I began my research for the next step of the collaboration.

At the next meeting the Scenic and Costume Designers presented their initial research. Both designers gravitated toward the idea of decay that stemmed from the Director's initial comments (see fig. 1). The Scenic Designer wanted to explore the idea of decay through layers of dirt, brick, mortar, plaster, cement, and vines. He also suggested a raked stage that would

\footnotetext{
${ }^{1}$ Lgp. "Meaning and Symbolism in Lorca's Blood Wedding." Little Girl Productions. N.p., 10 May 2014. Web. 26 Apr. 2017.
} 
extend over the apron into the house to create a more dynamic space for the actors (see fig. 2). The Costume Designer suggested dyeing a gradient to the shirts, pants, skirts, and other costume pieces. The gradient would increase throughout the play to convey to the audience that the dirt from the ground was creeping up onto the characters as if the ground was enveloping them (see fig. 3-7). In the first meetings, the Sound Designer was so moved by the poetic language of the script that he wanted to incorporate the use of violins and melody throughout the show. Through the process, however, the sound score would ultimately develop into a scape "of bizarre sound" and subtle tone shifts, leaning away from the original intent. Throughout these conversations, I tried my best to keep an open mind. It was a challenge for me to grasp the idea of decay as a metaphor for this play. With my initial reading of the script, I had found the play's language to be bold and poetic, featuring elements of Romanticism, Symbolism, and Expressionism. I could envision these elements translating visually into the final product of our show, but the concept of decay was one I could not. I was unsure at this point how I was going idea of decay would fit into the lighting design when it is difficult enough sometimes to convey realistic ideas such as time of day or passage of time. Incorporating decay into the lighting was a big challenge for me because lights cannot actually decay on stage, in the literal sense of the word. I did not say this to the team; instead I accepted the idea and put it in the back of my mind. I let the rest of the design team continue with the design process and I hoped that listening to their discussion would help me figure out a direction for the lighting design. 


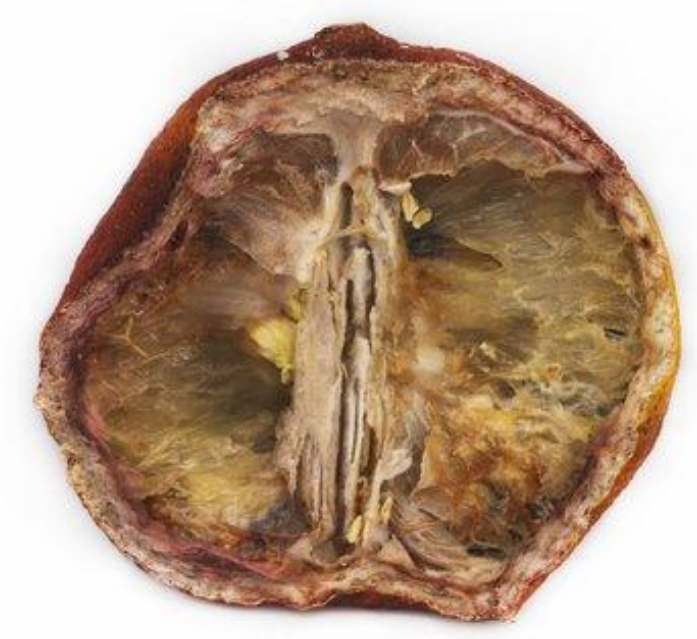

Figure 1. An image from the Scenic Designer's initial research. ${ }^{2}$

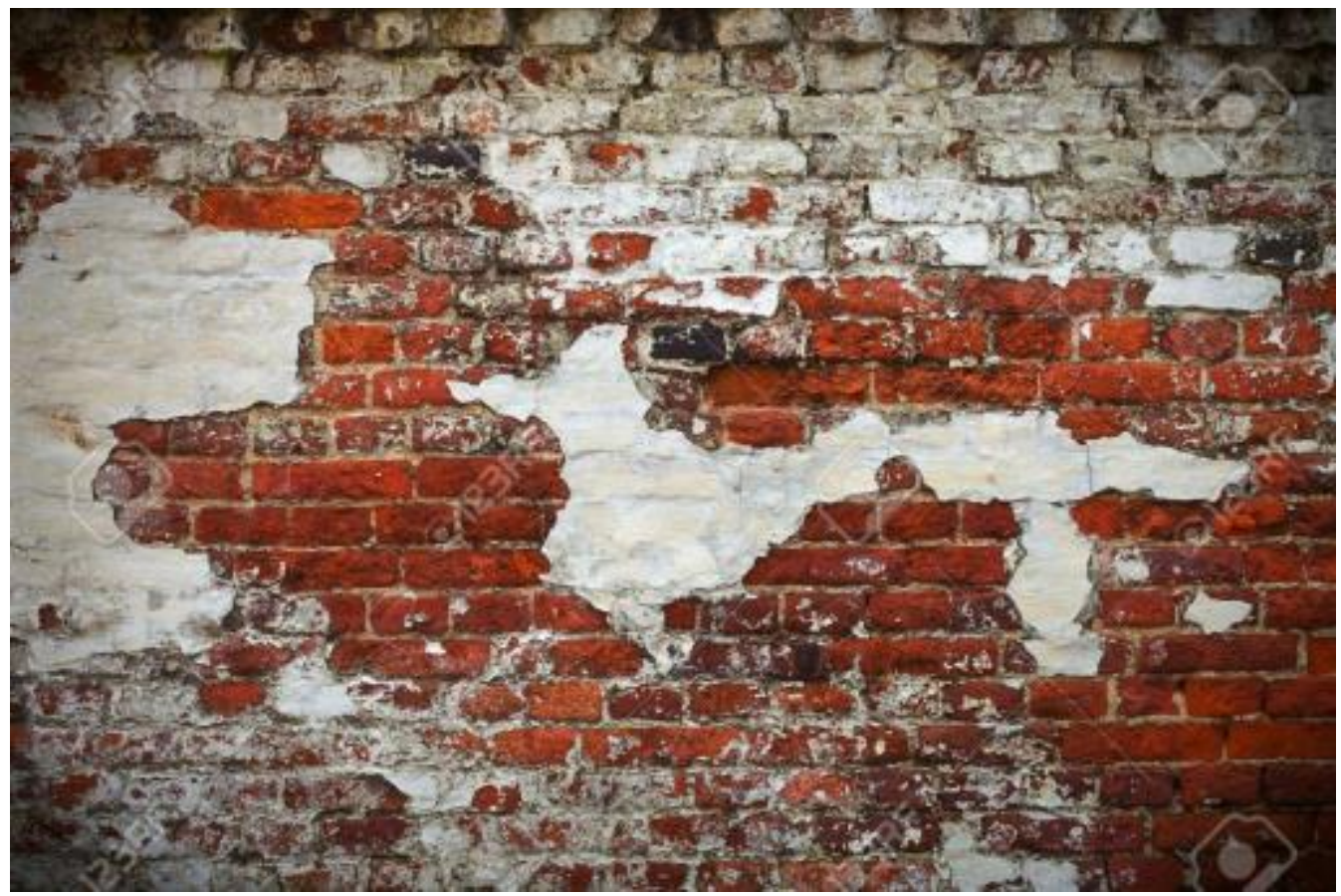

Figure 2. An image from the Scenic Designer's initial research. ${ }^{3}$

2 2012, Nan Shartel June 6. "San Diego Reader." Rotting Fruit. N.p., n.d. Web. 27 Apr. 2017. <http://www.sandiegoreader.com/weblogs/poetry/2012/jun/06/rotting-fruit/>. 


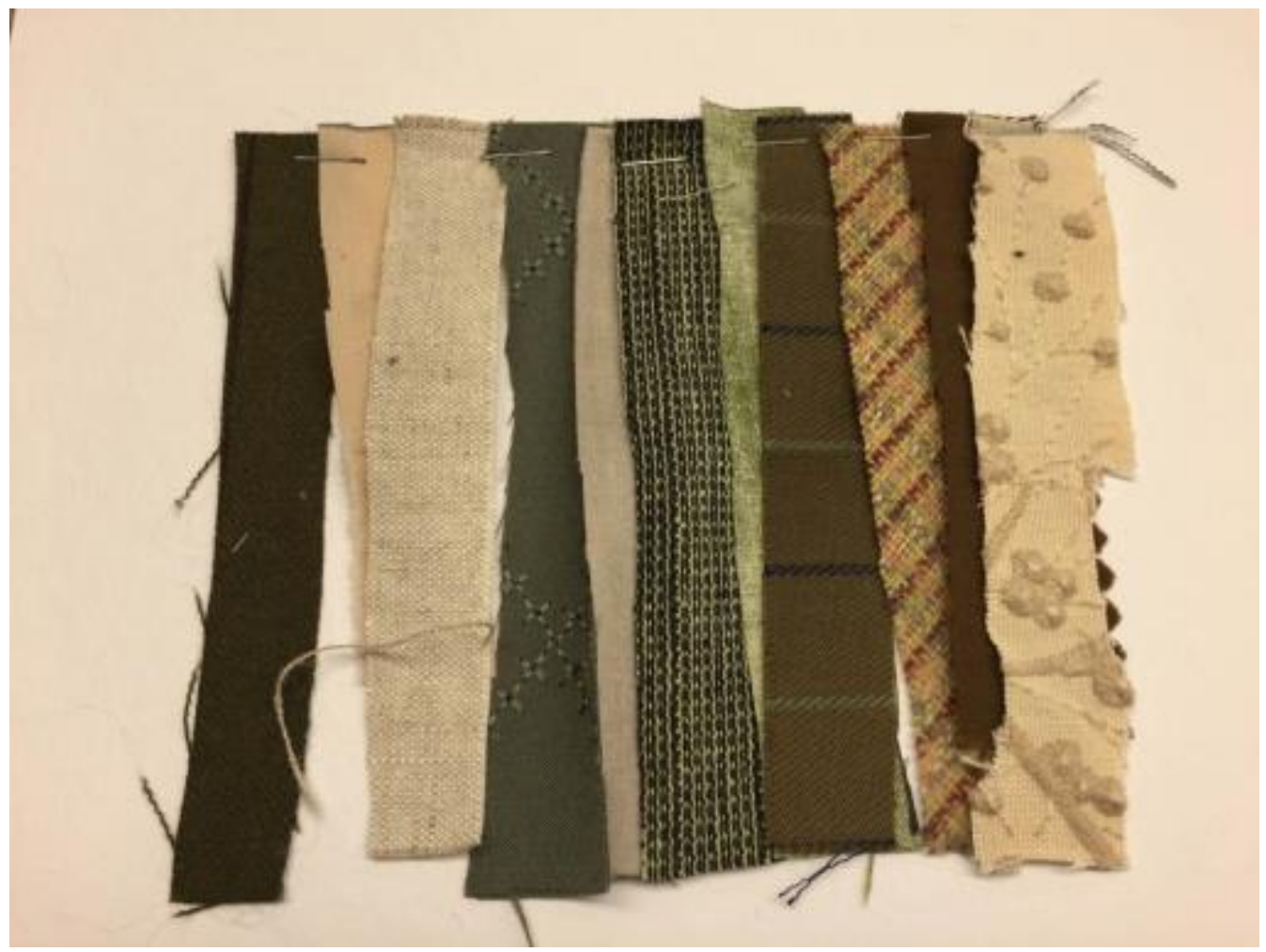

Figure 3. Color swatch from the Costume Designer.

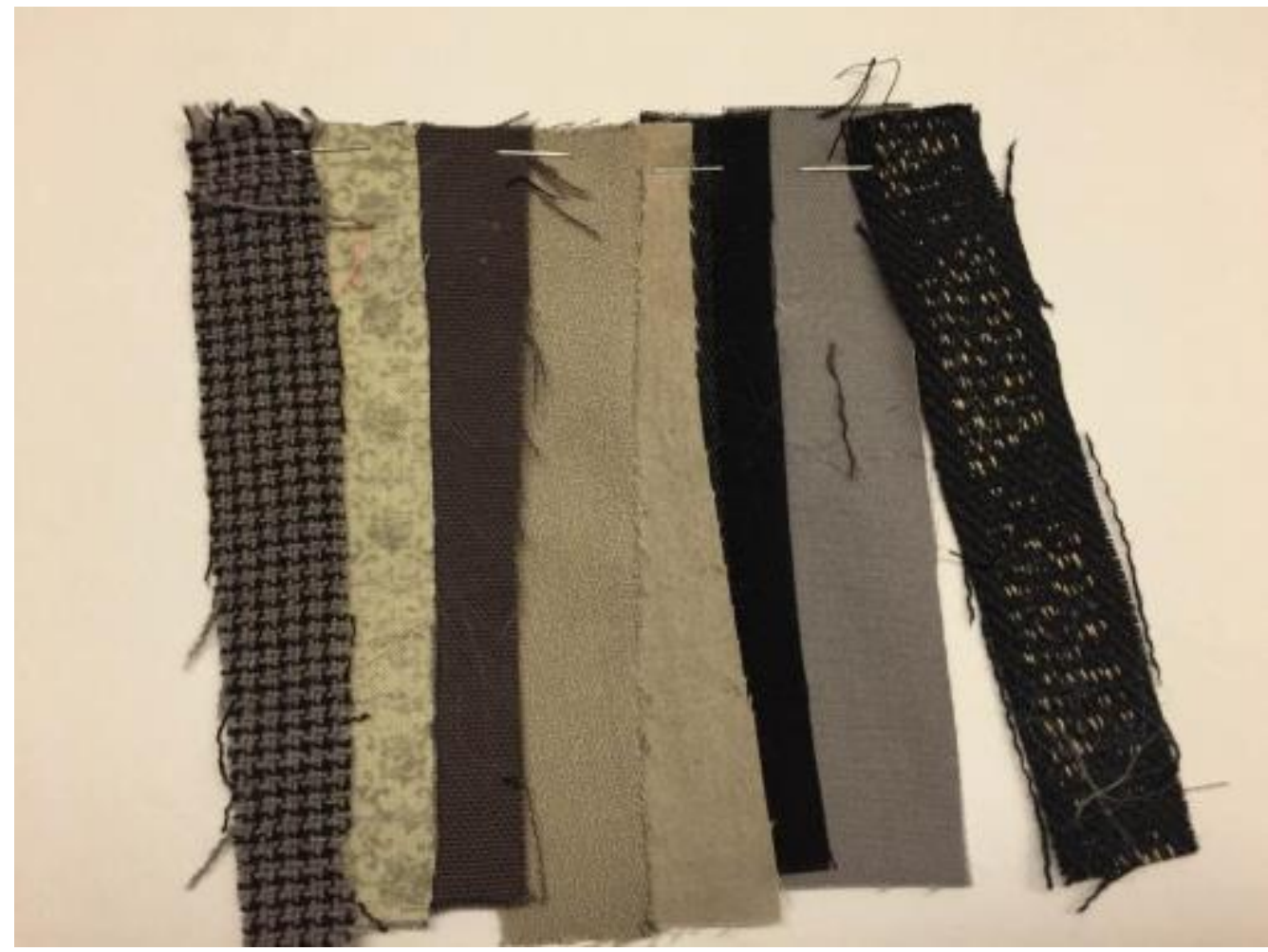

Figure 4. Color swatch from the Costume Designer.

3 "Grunge red brick wall texture with remaining plaster (stucco)." 123RF Stock Photos. N.p., n.d. Web. 27 Apr. 2017. <https://www.123rf.com/photo_6168766_grunge-red-brick-wall-texture-with-remaining-plaster-stucco.html>. 


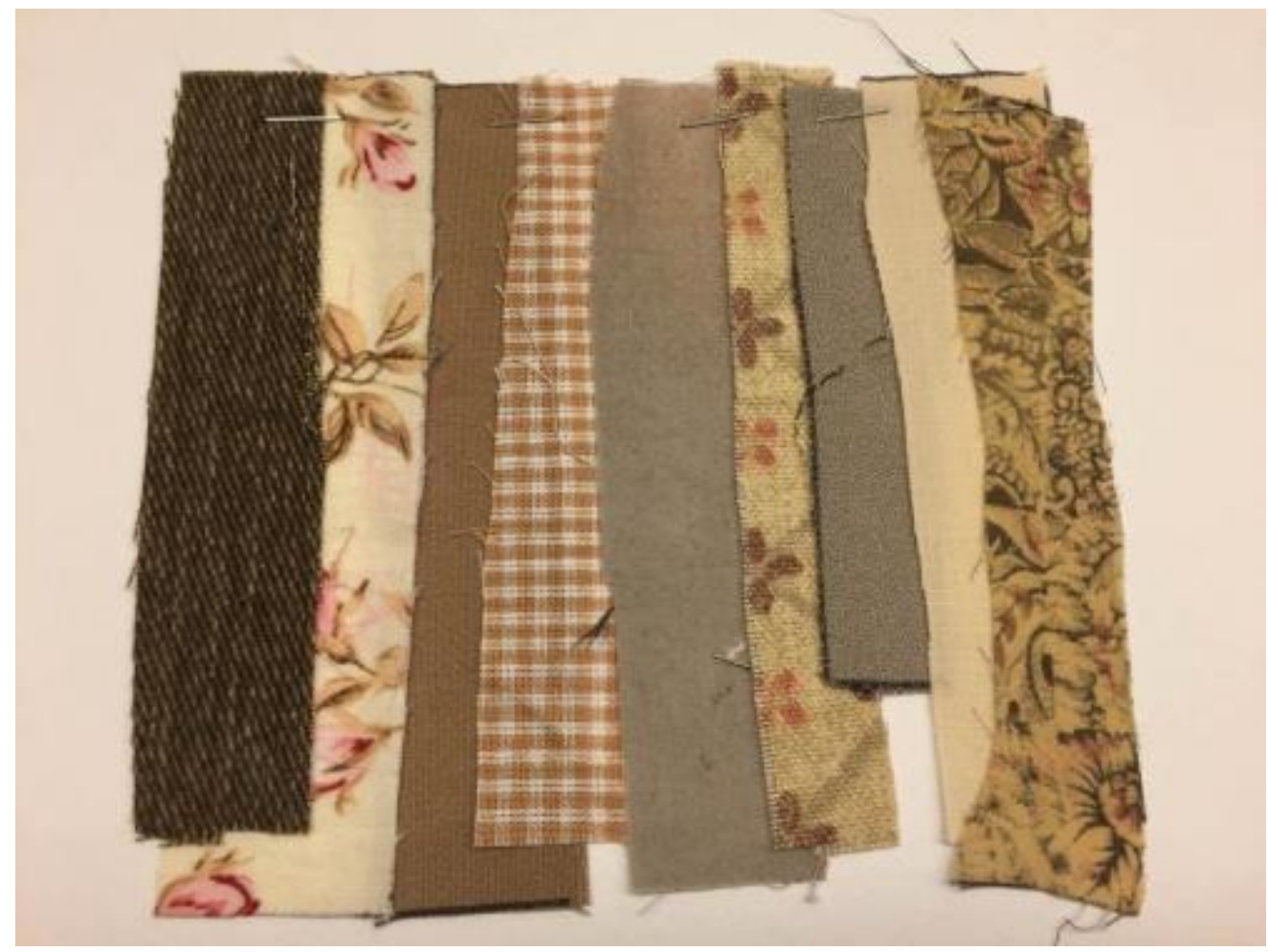

Figure 5. Color swatch from the Costume Designer.

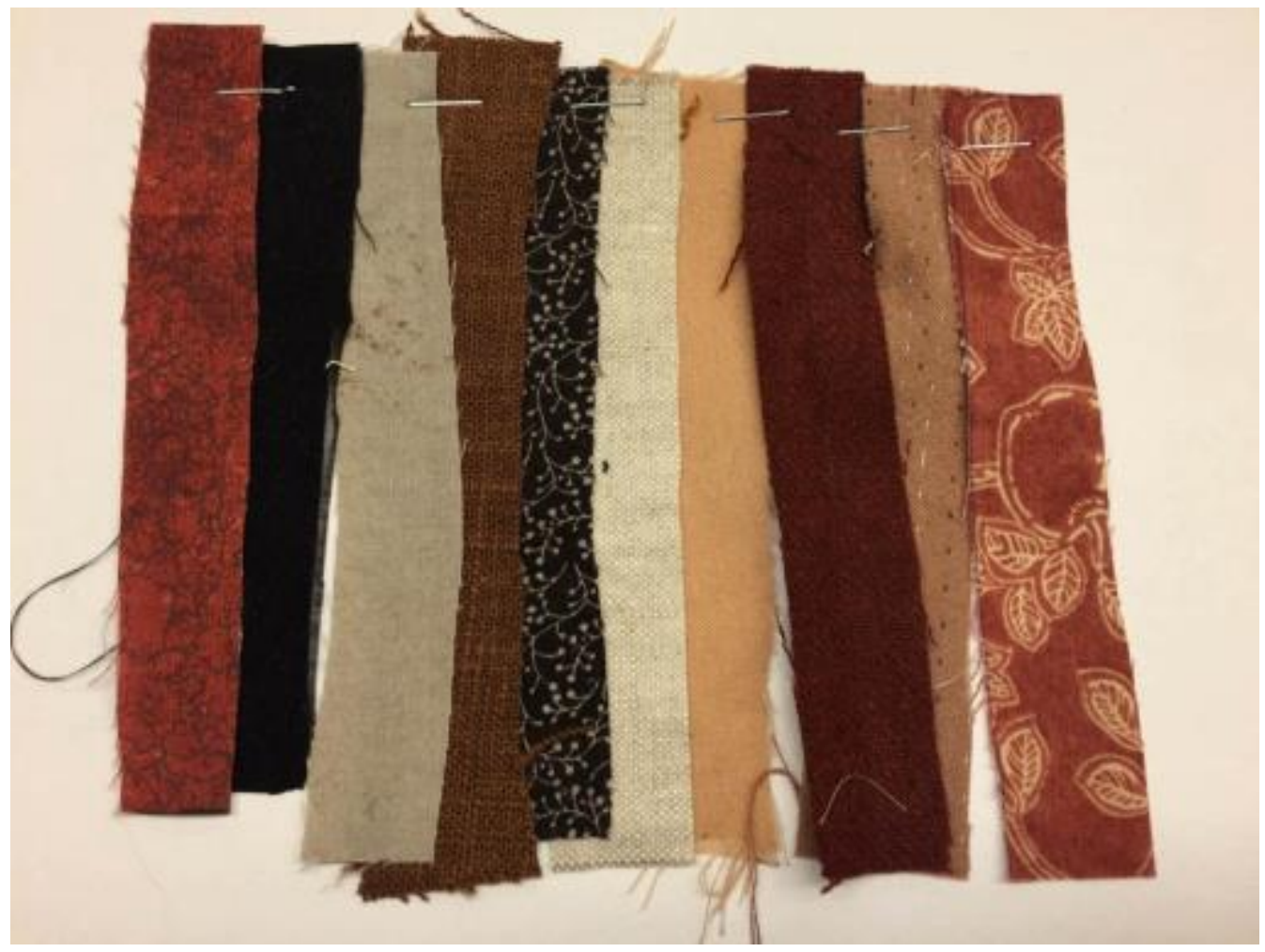

Figure 6. Color swatch from the Costume Designer. 


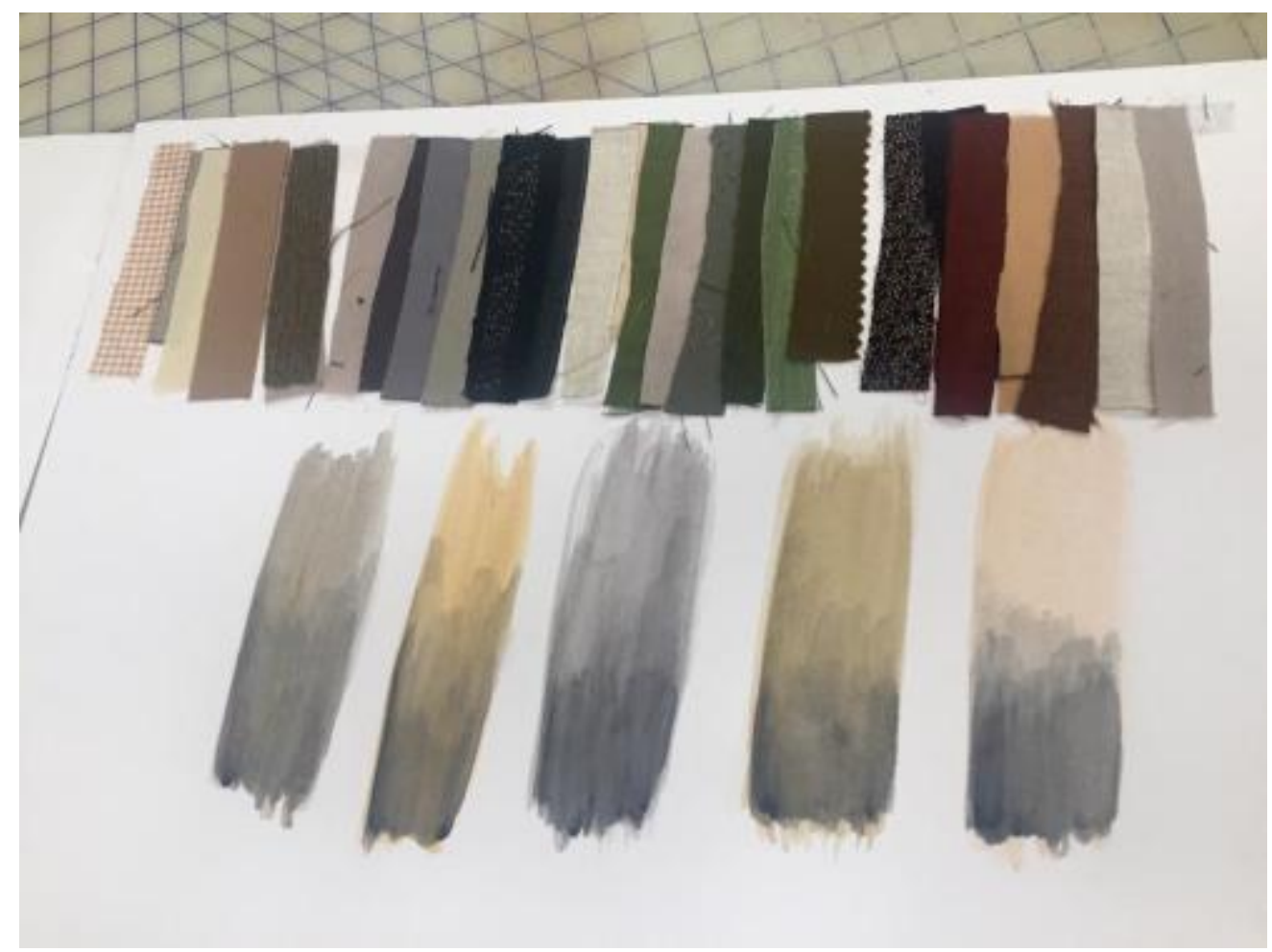

Figure 7. Color swatch with gradient paint swatch from the Costume Designer.

After a few more design meetings, the designs for the set and costumes had progressed enough that I could start envisioning the lighting in more specific terms. The scenic design developed into a raked stage that came out to the audience and had a twenty-foot-high wall that would break open for Act Three. When I saw how open the stage would be for the show, I got excited because I could easily imagine beautiful and poetic lighting in that open space that would bring the play to life and that would allow me to express Lorca's poetic language through the lighting. My initial idea was that I would design the show as if I were designing a dance. Dance has always played a big role in my development as a Lighting Designer. The ability to create powerful lighting imagery in a movement piece that highlights dancers and sculpts them beautifully is a skill I have been developing since I started designing. This show presented a great opportunity to explore how dance-style lighting could work in a straight play. With this new inspiration, I took one of the first steps in my design process to find research to present to 
the design team.

Research is an important step as a Lighting Designer. It is the main way I communicate with the design team about the direction and ideas I want to explore in the production. I started my search with dramatic dance lighting images I found online. All my research usually comes from the internet because of how accessible it is. I picked a wide range of dance images that I believed showed all the different possibilities I could explore with lighting the show. I found images with single source lighting to show how dramatic and isolated we could create on stage, but I also showed images with lots of dancers using the space to show I could also light a group of actors (see fig. 8-13). I made sure to choose images that reflected a range of color possibilities from no color white to very saturated primary colors, making sure that everyone understood that this was not necessarily a final color palette (see fig. 14-18). Finally, I found images that showed the shape of the lighting beams in a hazy atmosphere so that the team could visualize how adding haze to the show would add to the final visual quality of the production (see fig. 19-22).

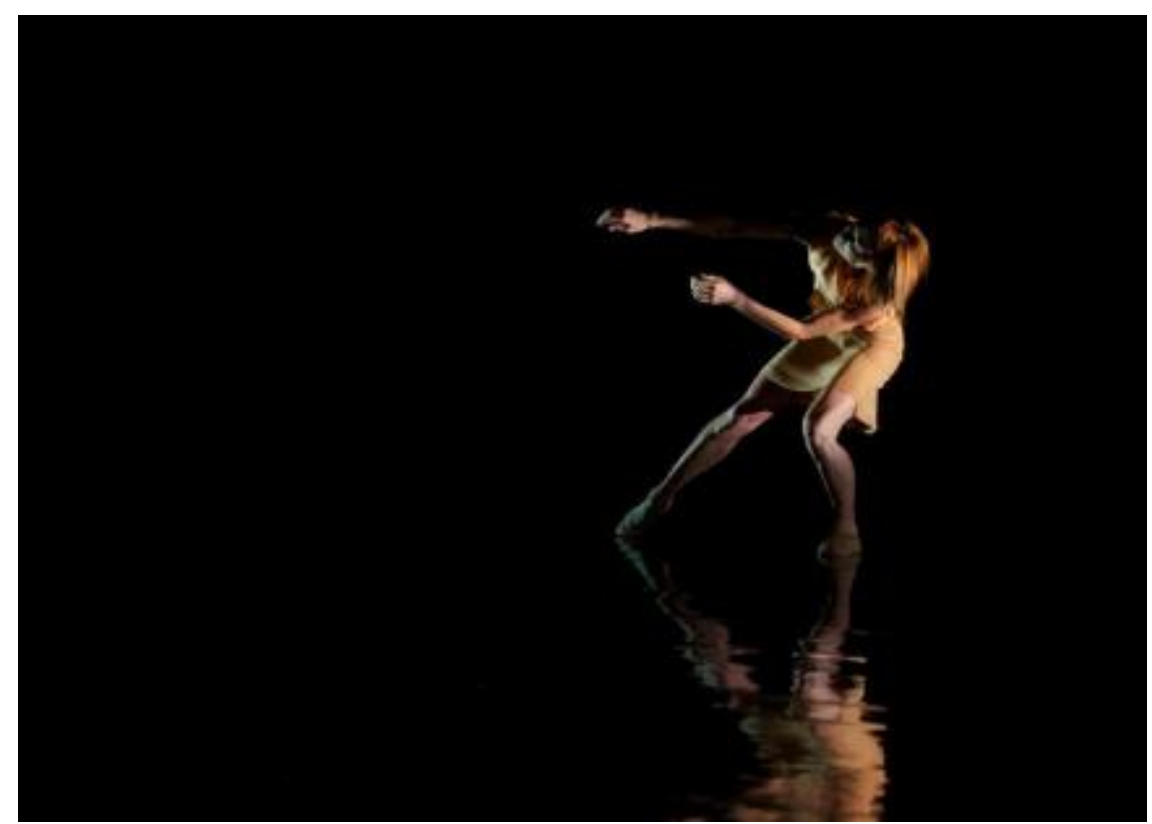

Figure 8. Initial research from the Lighting Designer. ${ }^{4}$

\footnotetext{
${ }^{4}$ Figure 8. Alfa img - Showing > Creative Dancers. N.p., n.d. Web. 27 Apr. 2017. <http://alfa-
} 


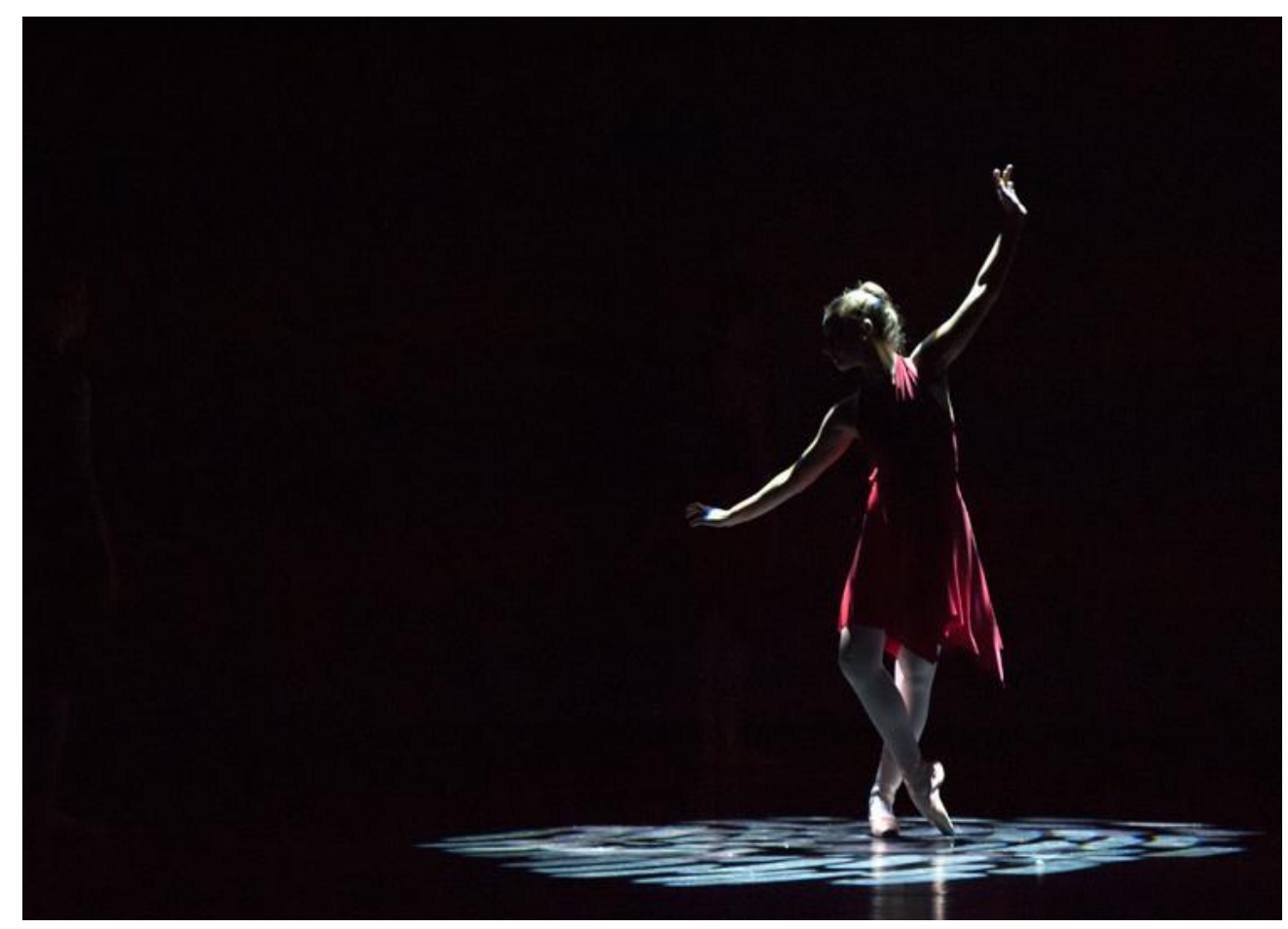

Figure 9. Initial research from the Lighting Designer. ${ }^{5}$

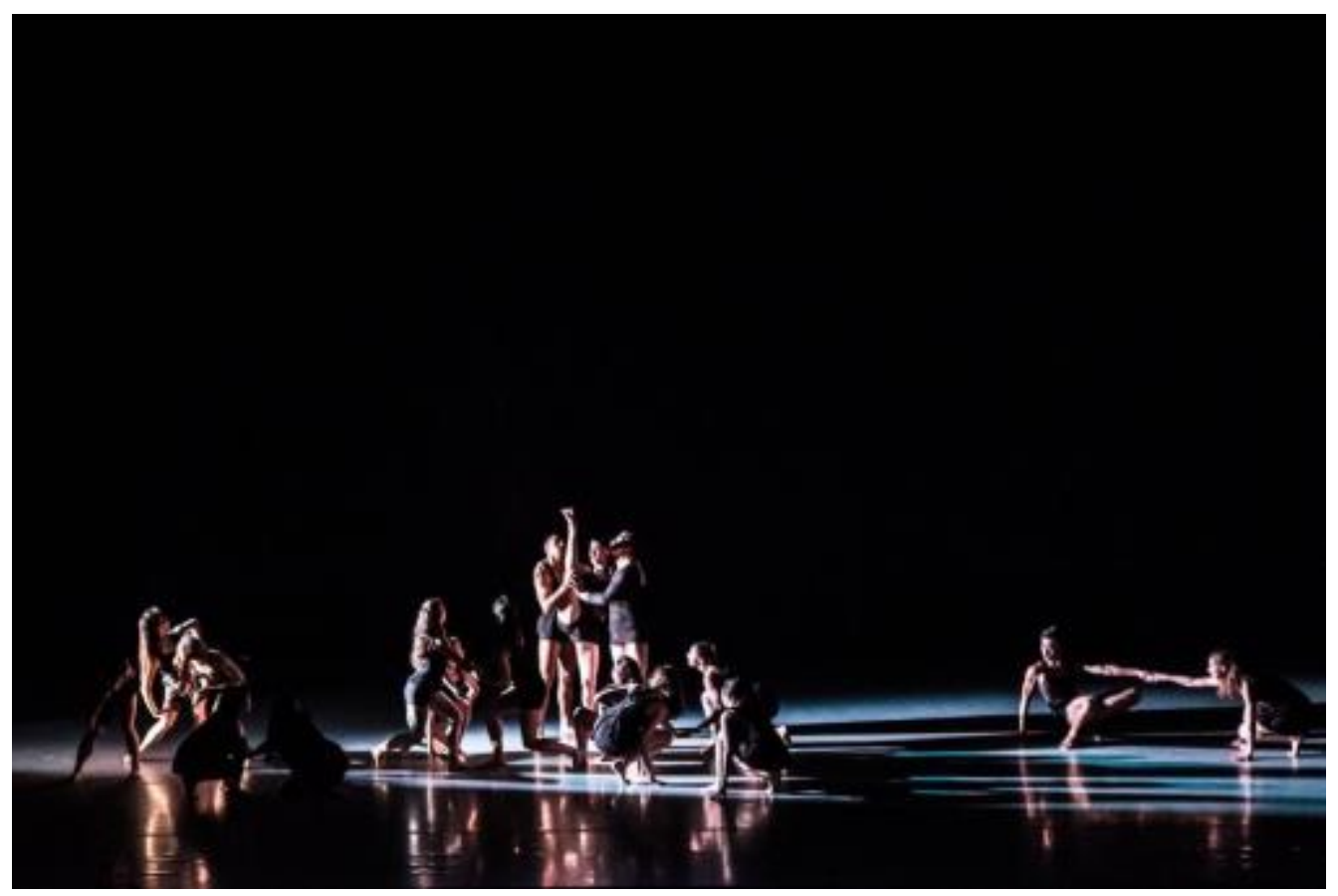

Figure 10. Initial research from the Lighting Designer. ${ }^{6}$

img.com/show/creative-dancers.html>.

5 "Photographing Dance." C.L.Roughgarden. N.p., 06 Nov. 2011. Web. 27 Apr. 2017.

$<$ https://clroughgarden.wordpress.com/2011/11/06/photographing-dance/>.

6 "Nick Saiki Lighting Design - Home Version 2." Nick Saiki Lighting Design. N.p., n.d. Web. 27 Apr. 2017. 


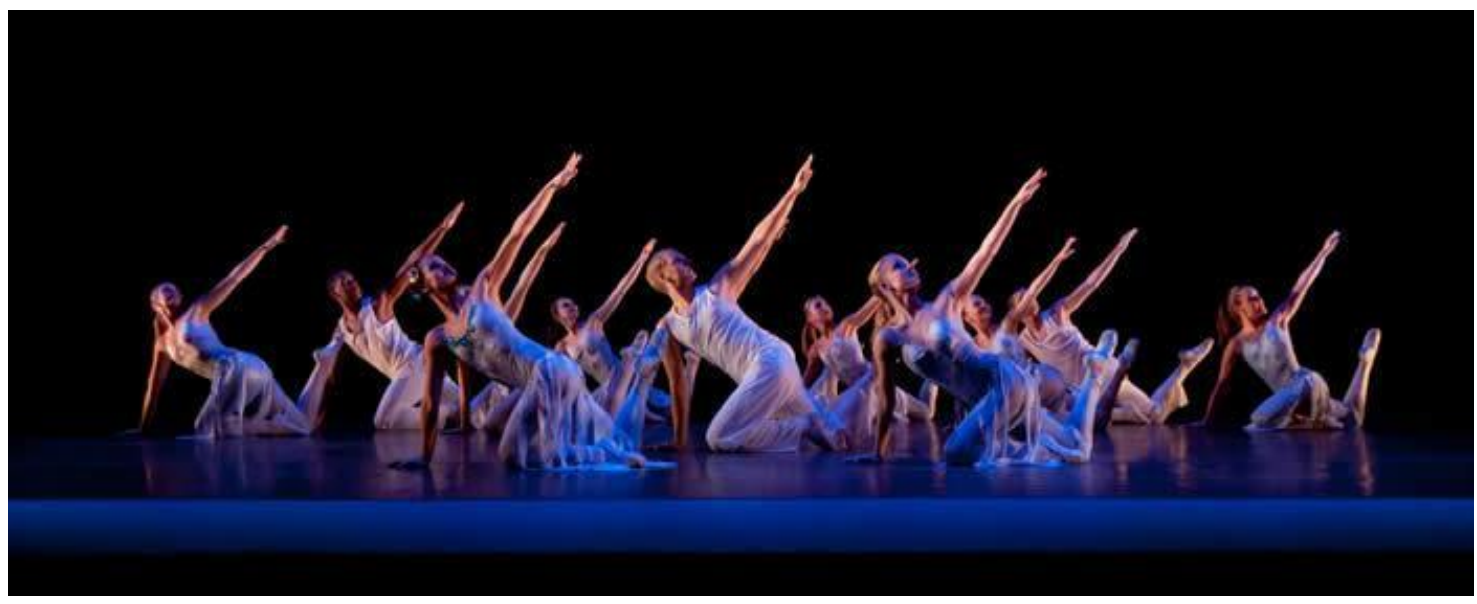

Figure 11. Initial research from the Lighting Designer. ${ }^{7}$

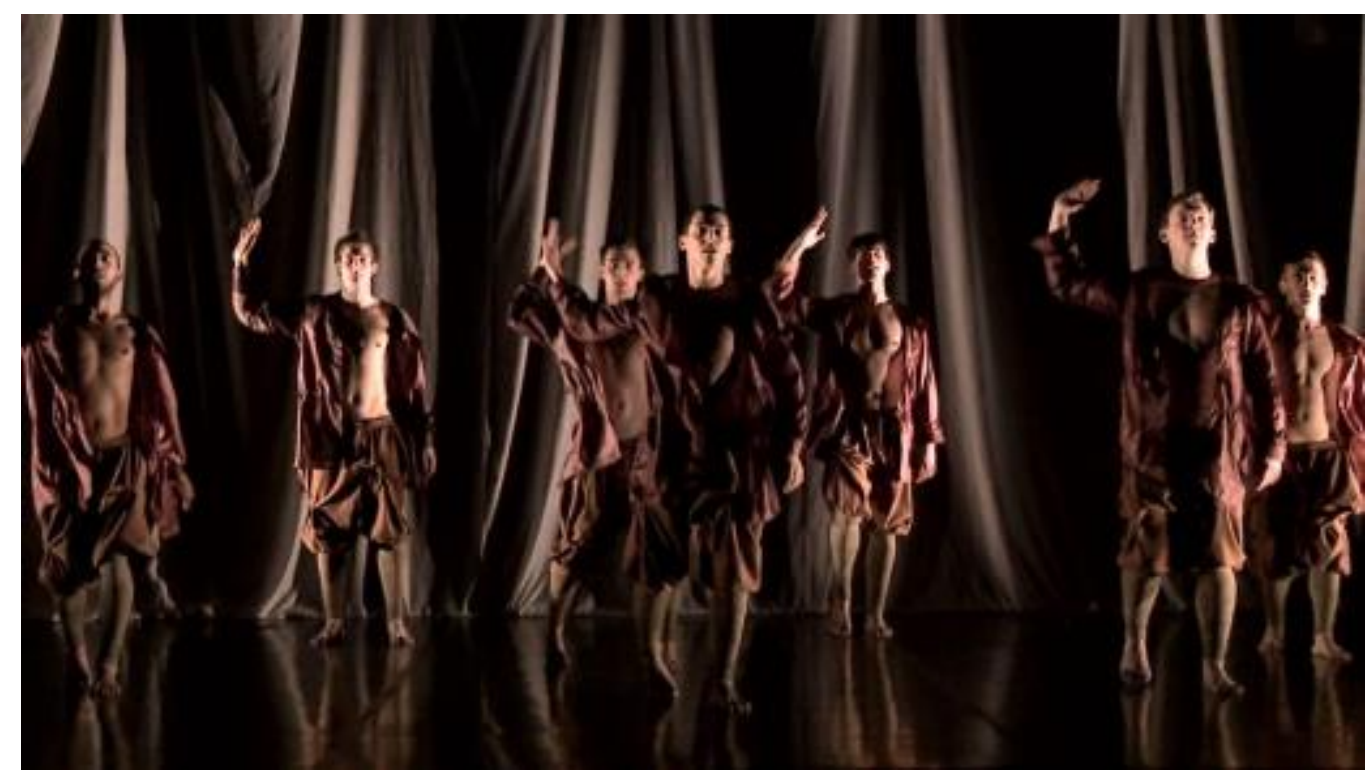

Figure 12. Initial research from the Lighting Designer. ${ }^{8}$

<http://nicksaikidesign.com/home/>.

7 Szekely, Andie. "Lughnasa (Lighting Design Fall 2014)." Pinterest. N.p., 22 Sept. 2014. Web. 27 Apr. 2017. <https://www.pinterest.com/pin/29906785001072906/>.

8 "Ballet Boyz." Modern Dance Videos. N.p., n.d. Web. 27 Apr. 2017.

<http://moderndancevideos.com/category/ballet-boyz/>. 


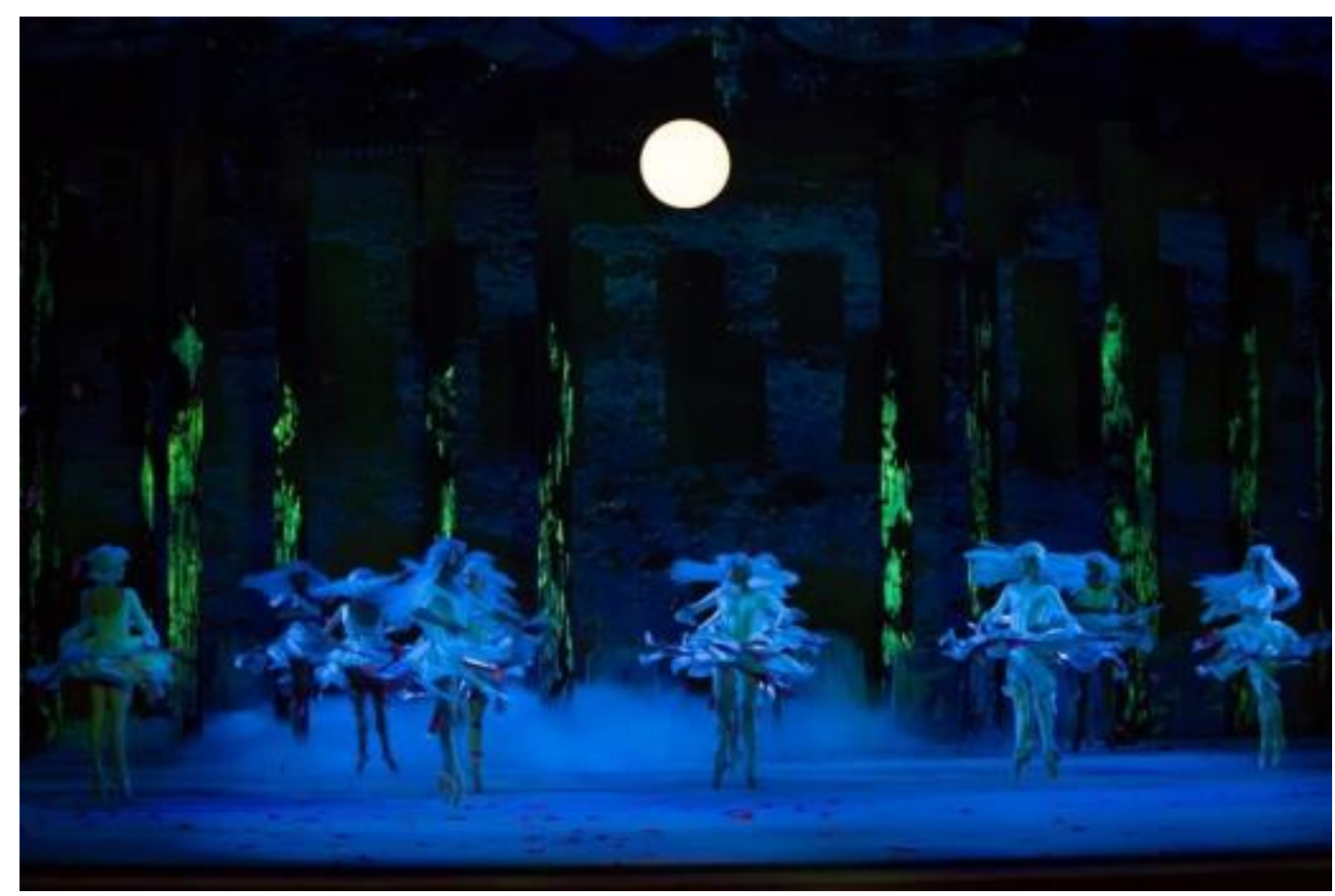

Figure 13. Initial research from the Lighting Designer. ${ }^{9}$

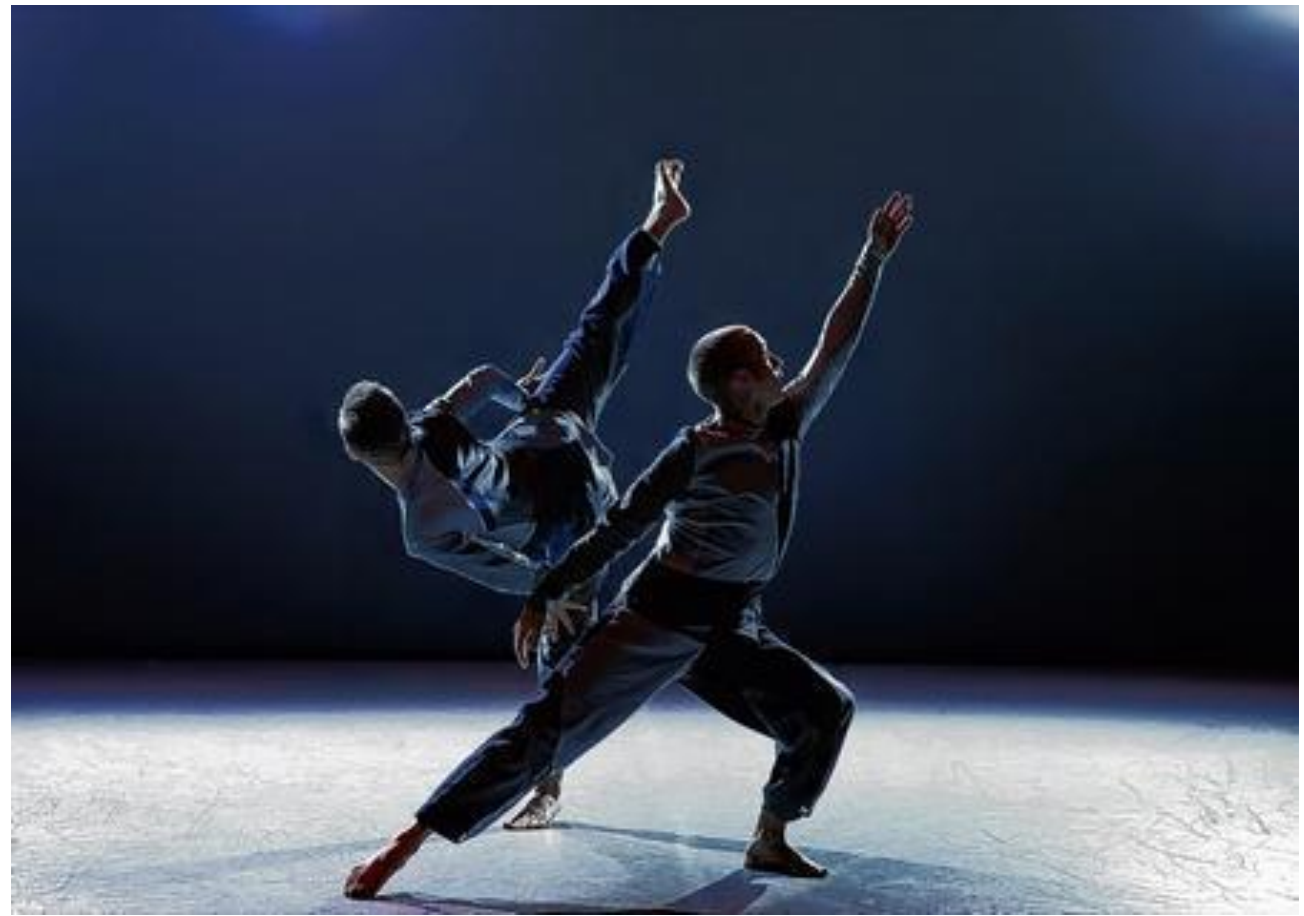

Figure 14. Initial research from the Lighting Designer. ${ }^{10}$

\footnotetext{
${ }^{9}$ Bailey, Wes. "Taylor and Washington Ballet Choose 4Wall DC for 'Sleepy Hollow'" 4Wall Entertainment. N.p., n.d. Web. 27 Apr. 2017. <https://www.4wall.com/about/press/taylor-and-washington-ballet-choose-4wall-dc-forsleepy-hollow>.

10 "Performing art." Kent Online. N.p., 26 Mar. 2012. Web. 27 Apr. 2017.
} 


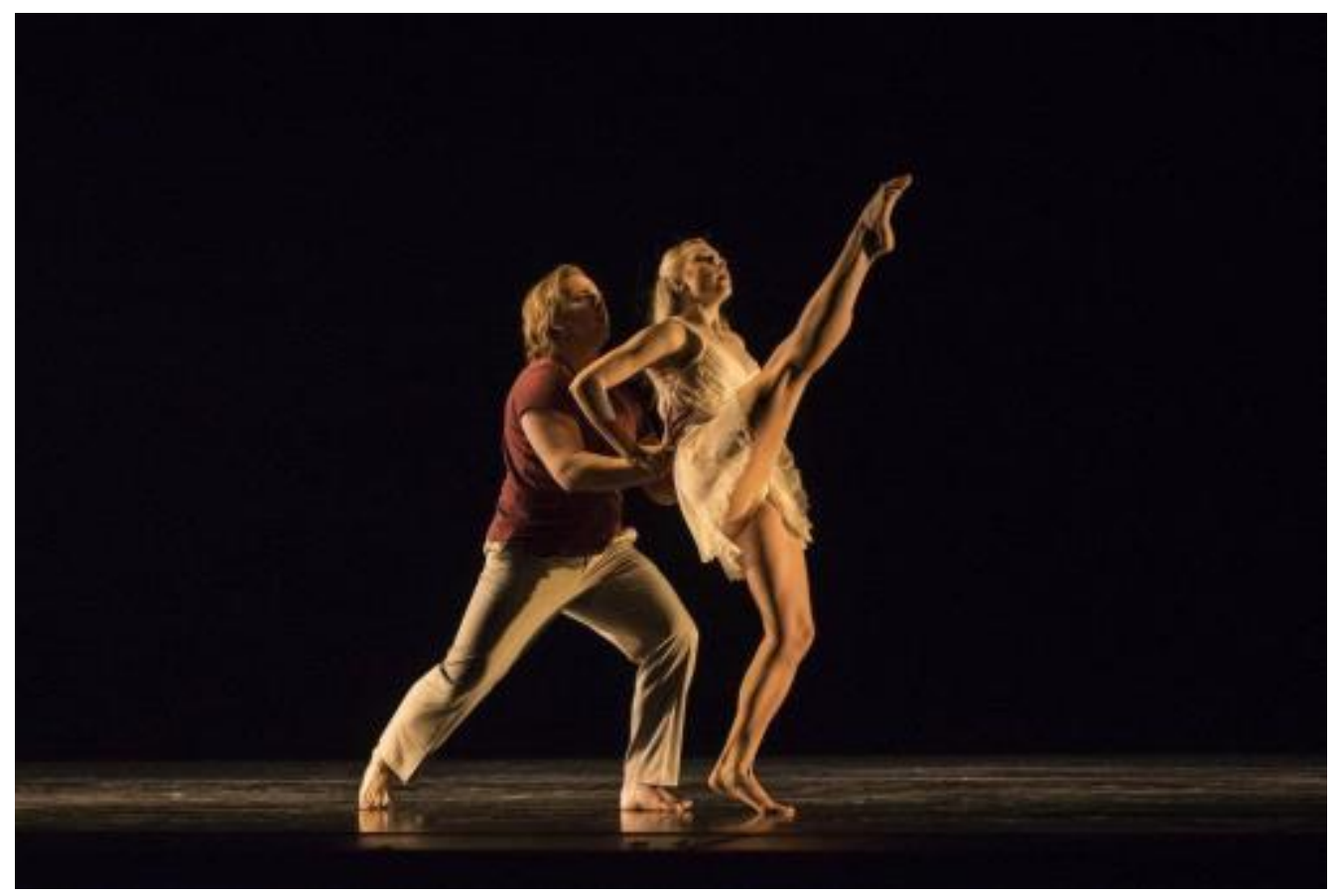

Figure 15. Initial research from the Lighting Designer. ${ }^{11}$

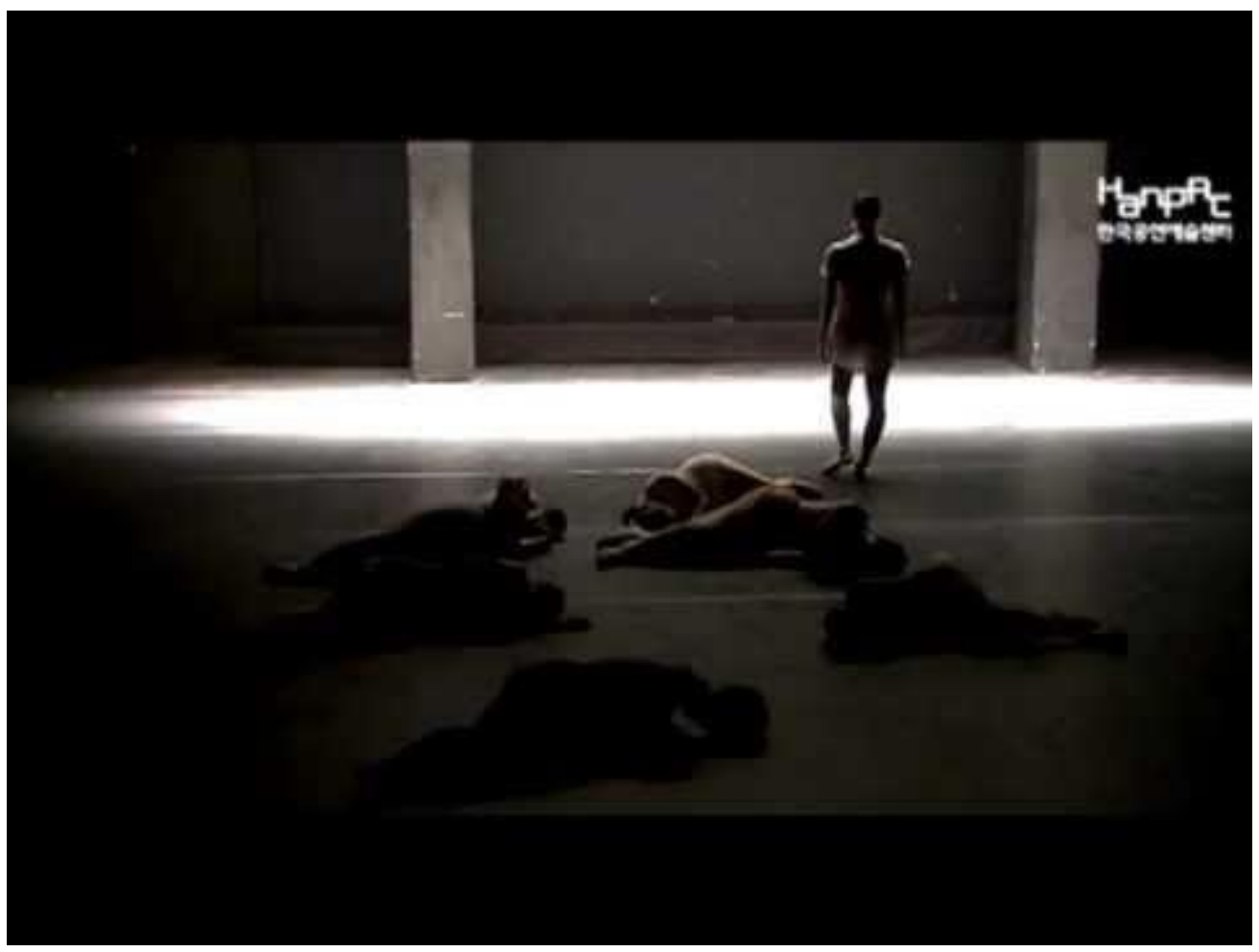

Figure 16. Initial research from the Lighting Designer. ${ }^{12}$

<http://www.kentonline.co.uk/kent/news/performing-art-a65927/>.

11 "Lighting Design by Jesse Belsky." Pinterest. N.p., n.d. Web. 27 Apr. 2017.

<https://www.pinterest.com/jessebelsky/lighting-design-by-jesse-belsky/>. 


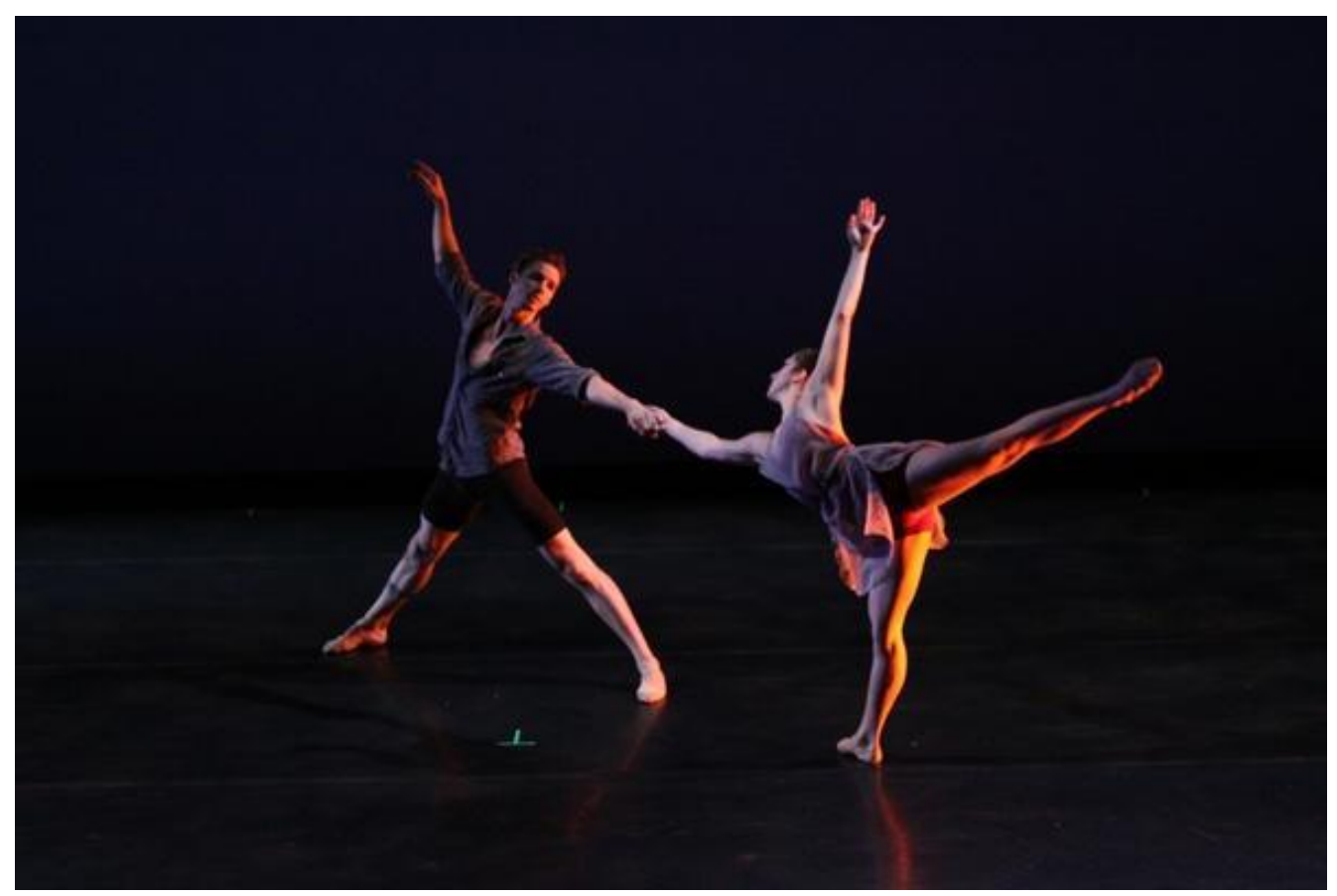

Figure 17. Initial research from the Lighting Designer. ${ }^{13}$

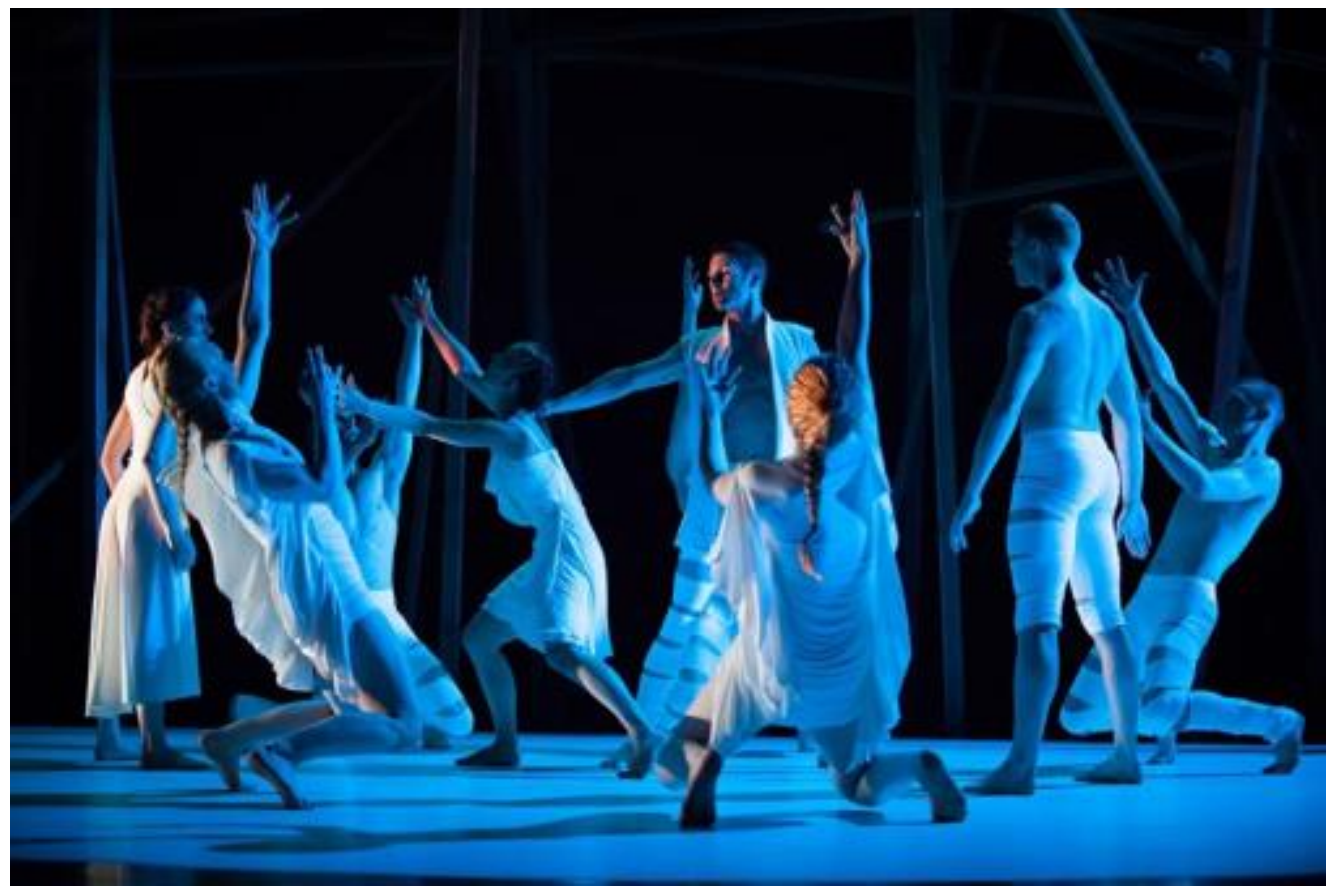

Figure 18. Initial research from the Lighting Designer. ${ }^{14}$

12 Darkcirclescontemp. "'Talking in your Sleep' by Hyunsang Cho, Dark Circles Contemporary Dance." YouTube. YouTube, 29 Oct. 2012. Web. 27 Apr. 2017. <https://www.youtube.com/watch?v=DxMPA0Kc0II>.

13 Anthony, Laura. "Lighting Stuff." Pinterest. N.p., 22 Feb. 2013. Web. 27 Apr. 2017.

<https://www.pinterest.com/pin/247275835762672331/>.

14 "Photos of Pascal Rioult’s "Iphigenia."' Rioult.wordpress.com. N.p., 07 June 2013. Web. 27 Apr. 2017. 


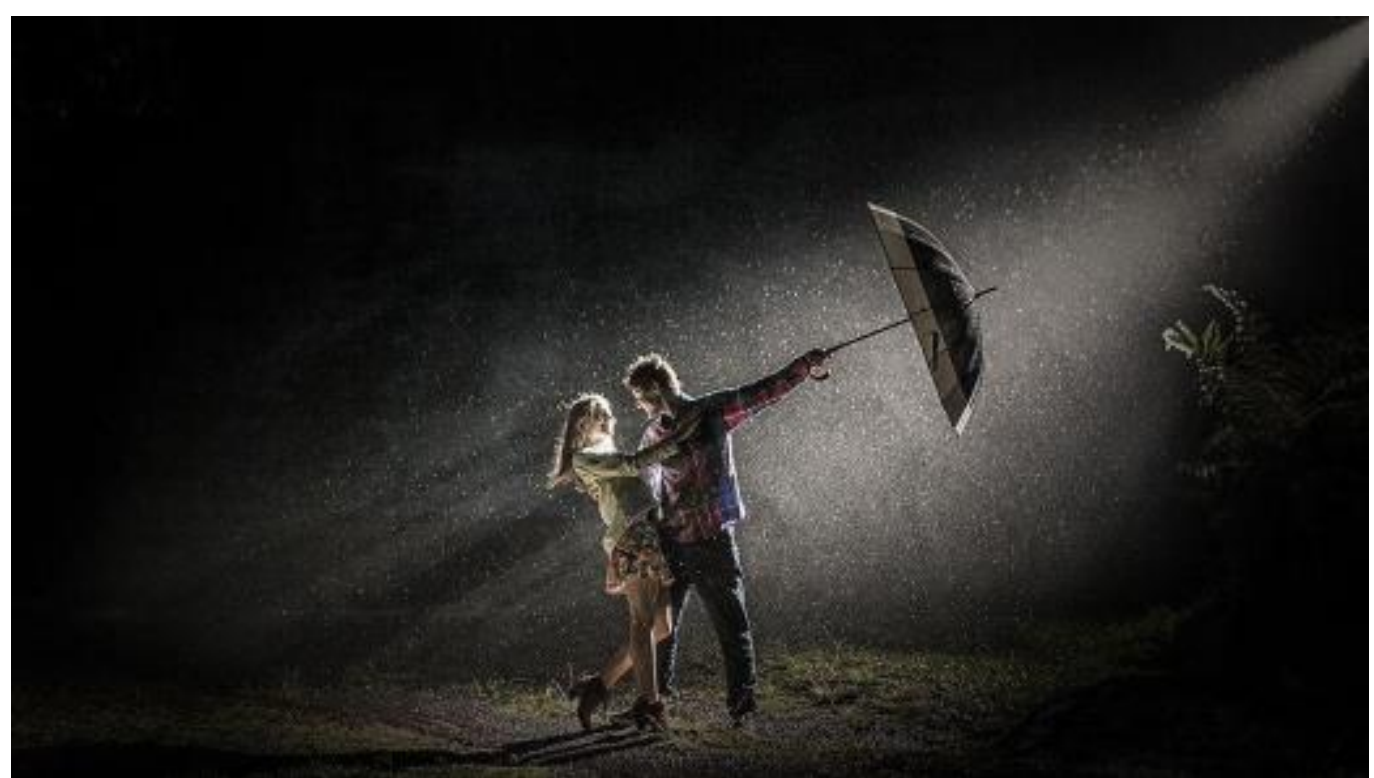

Figure 19. Initial research from the Lighting Designer. ${ }^{15}$

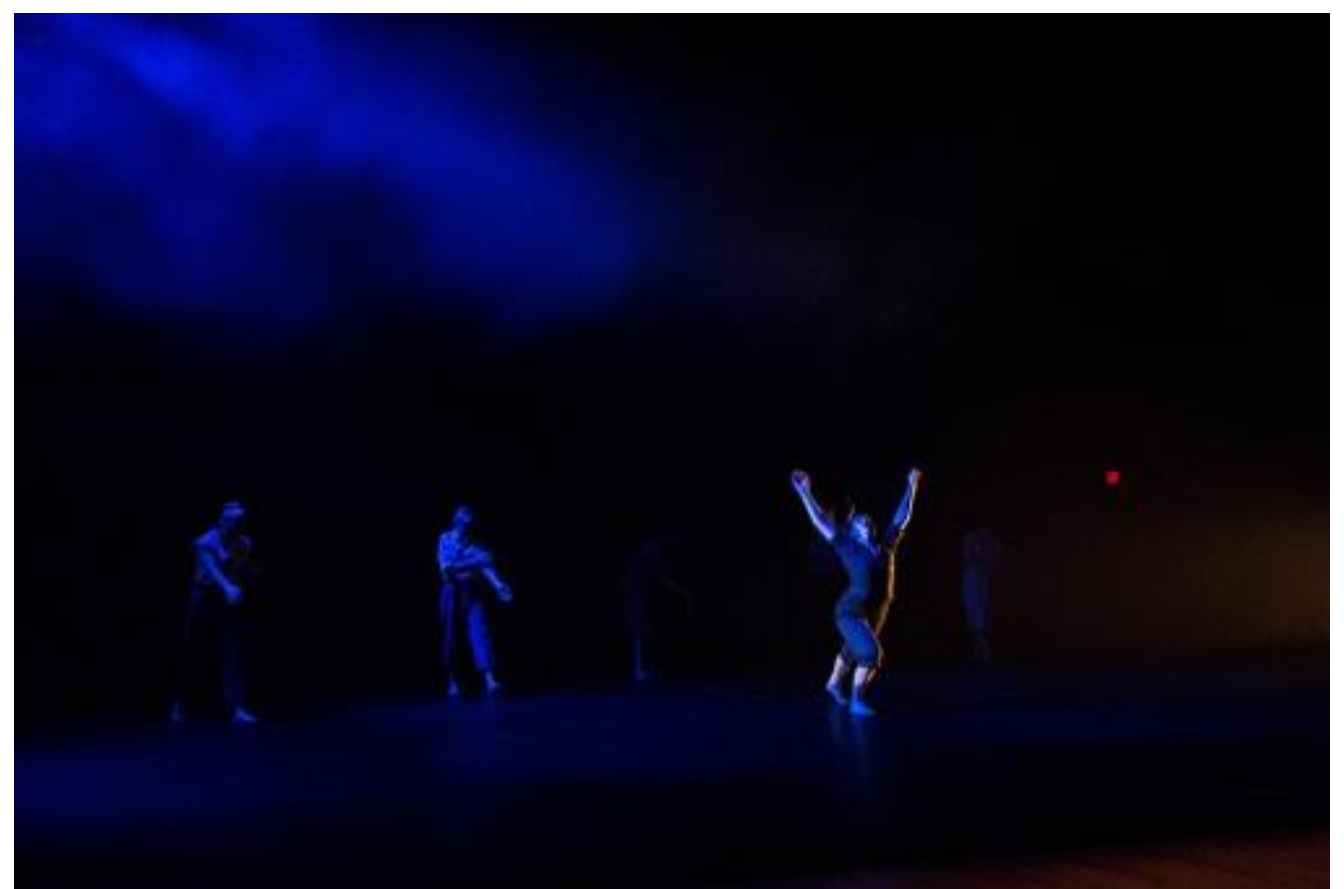

Figure 20. Initial research from the Lighting Designer. ${ }^{16}$

<https://rioult.wordpress.com/2013/06/07/photos-of-pascal-rioults-iphigenia/>.

15 "JVKovacs - fotógrafo de casamento florianópolis, fotografia de casamento." Jvkovacs.com.br. N.p., n.d. Web. 27 Apr. 2017. <http://jvkovacs.com.br/blog/inicio/>.

16 "No Armisitice - University of Iowa Dance - Space Place Theatre." Lucas Ingram Design. N.p., 18 Oct. 2015. Web. 27 Apr. 2017. <https://lucasingramdesign.com/2014/12/04/no-armisitice/>. 


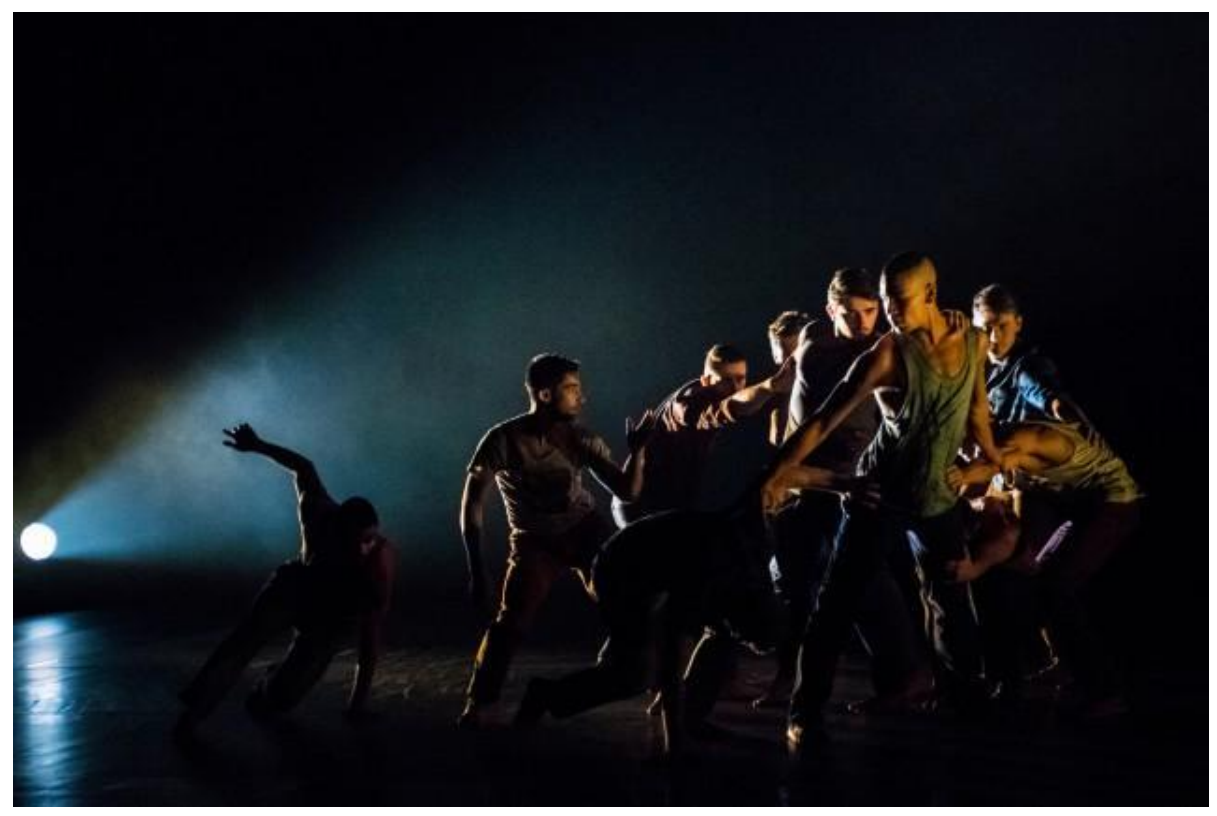

Figure 21. Initial research from the Lighting Designer. ${ }^{17}$

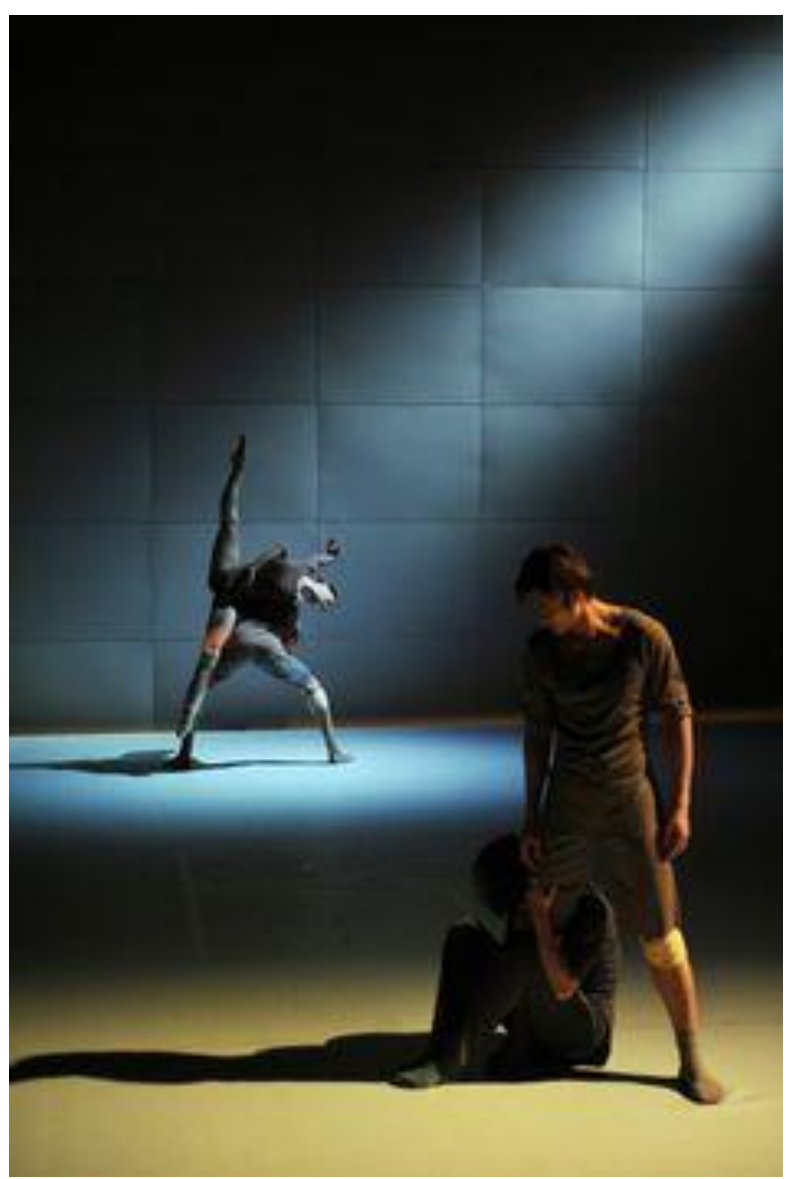

Figure 22. Initial research from the Lighting Designer. ${ }^{18}$

17 "Review: Balletboyz the TALENT - Linbury Studio Theatre, Royal Opera House." LondonDance. N.p., n.d. Web. 27 Apr. 2017. <http://londondance.com/articles/reviews/balletboyz-the-talent-linbury-roh/>. 
After compiling all of my initial research, I decided not to put it in a collage format, as I have on many past productions, because I wanted to show off each image one by one. I believed this would allow the team to absorb and process the images without getting overwhelmed with a visually complex composition that might result in a negative initial response. A few concerns arose after I presented my research. The Director was open to exploring the idea of lighting this show in a fashion similar to dance, but when he heard the word dance, all he really heard was that the design would be just heavy side light. To me, his words seemed to express concern over the visibility of the actors' faces. I put his worry at ease by explaining that while sidelight is predominantly important in dance, I could find different angles to light the actors adequately. I also pointed out that one of the dance qualities I wanted to explore was finding other nontraditional ways to the light actors. Thankfully, he understood some of what I was saying and trusted that I knew what I was doing and gave me the green light to keep moving forward with my ideas.

Running with the idea of a dance-heavy design using multiple sidelight angles, I had to work closely with the Scenic Designer to come up with appropriate masking for the show. I was not sure where the lights specifically would hang, but I wanted to keep as many options available as possible. I made it clear that twenty-one foot booms as lighting positions would be important for the show and would have to be placed to accommodate for actor entrances. In an outside meeting, the Scenic Designer and I sat down and looked at the groundplan (see fig. 23). We talked about wing space and where the booms could be located. Eight booms would be used with four on each side of the stage, and the masking would be left open at first in order to create the feeling of a grand open space. Then we negotiated space overstage because I needed a lighting

18 "City Contemporary Dance Company - Blind Chance - Hong Kong." DanceTabs. N.p., 09 May 2012. Web. 27 Apr. 2017. <http://dancetabs.com/2012/04/city-contemporary-dance-company-blind-chance-hong-kong/>. 
position upstage near the wall. I explained that by not having an electric far upstage, I could not light the eight-foot space in front of the wall. The Scenic Designer also requested that I consider lighting the dirt that was downstage of the wall because he was interested in exploring how that visual element could be used to frame the show. It had never occurred to me that it could be used that way, and I let him know that I would keep it in mind going forward. After the meeting, the Scenic Designer took what we talked about and made the appropriate changes to the groundplan (see fig. 24).

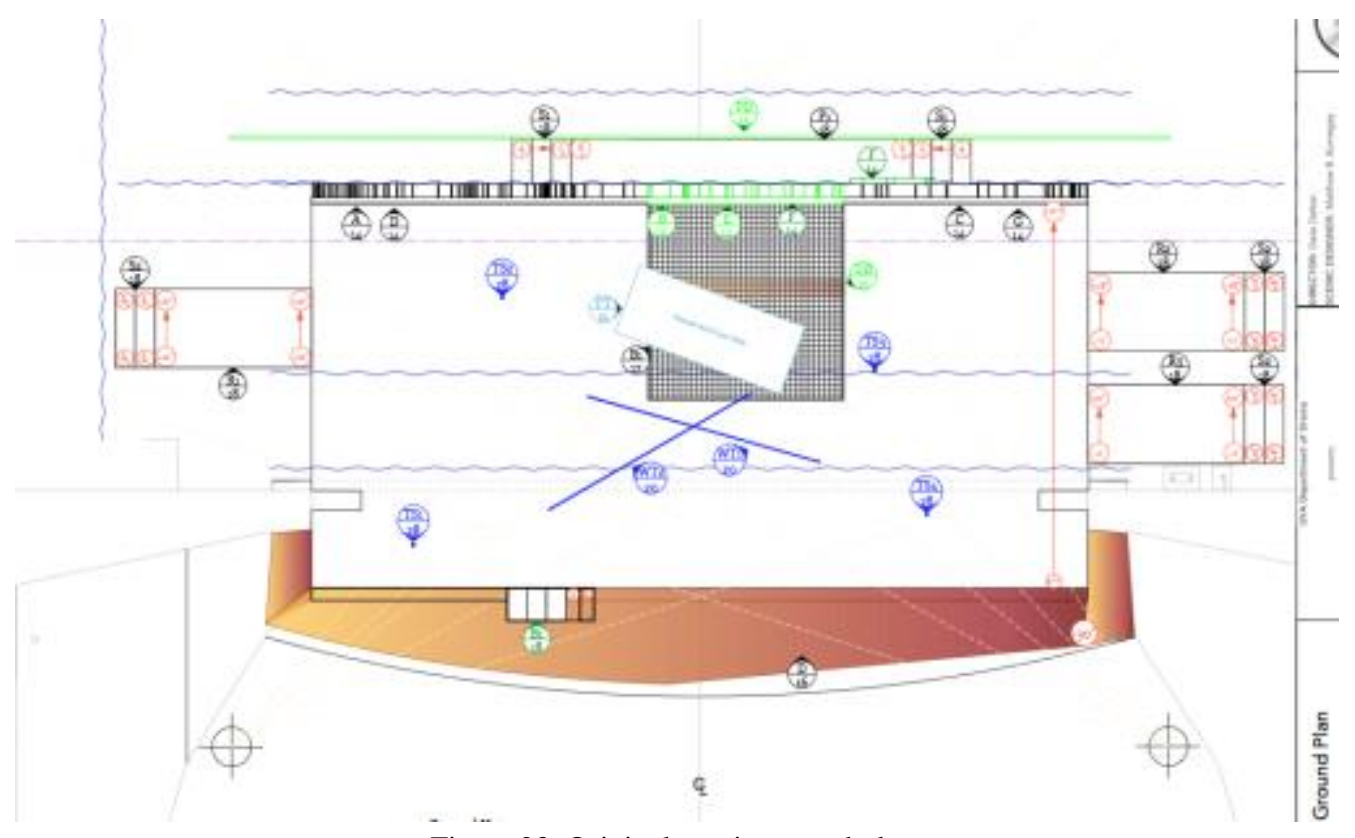

Figure 23. Original scenic ground plan. 


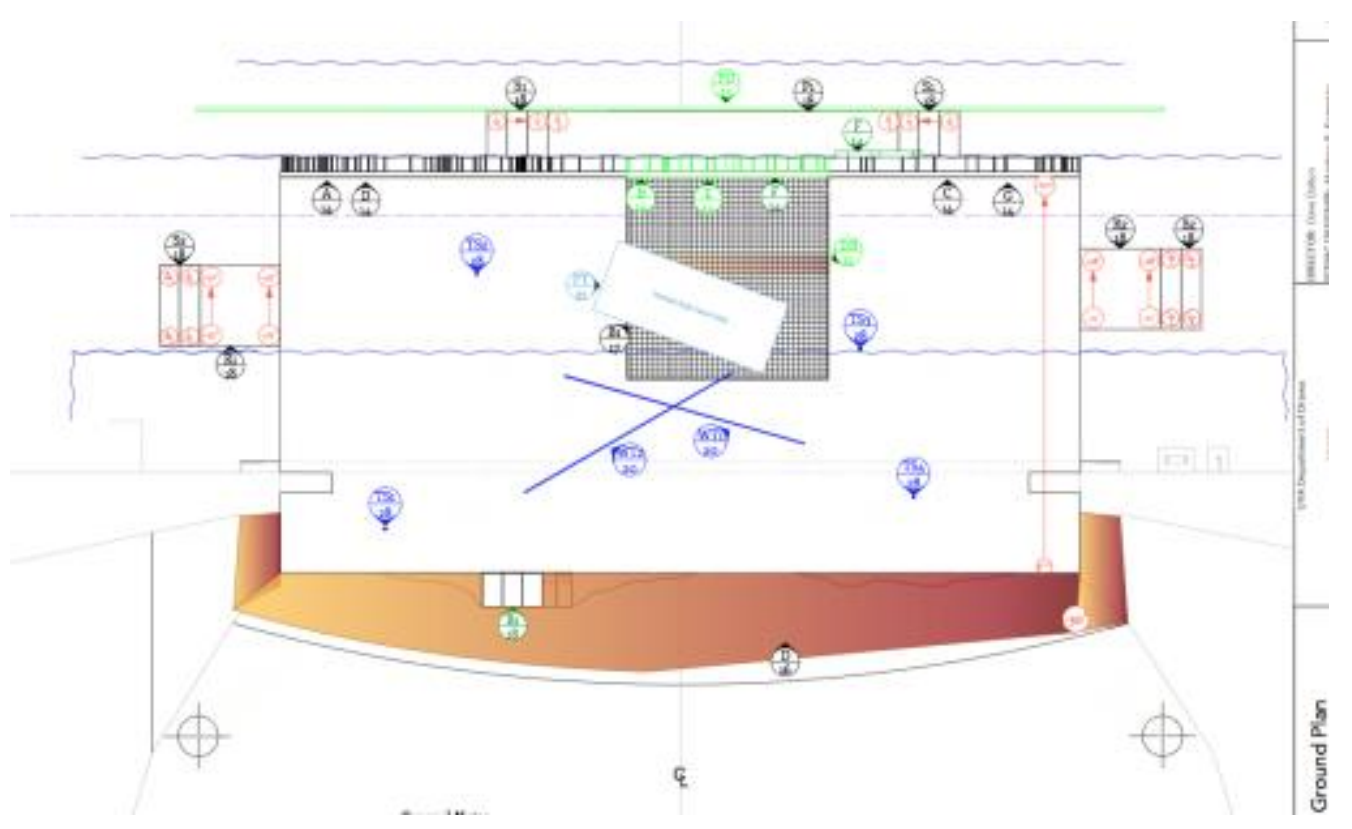

Figure 24. Updated scenic ground plan.

At this point, the end of the semester was upon us. This meant that I had to create the light plot during the winter break and have everything decided by the time classes resumed since hang would start immediately. I still had no specific idea of how the lighting would fit into the world of the play other than my idea of a beautiful dramatic dance feel. I decided to take a huge risk and see how far I could push the limits of my design.

One night while working, I began to consider the properties of decay: multiple colors, rotting smell, and deterioration. These properties can be found in rust, a process where steel or iron is oxidized leading to the creation of interesting colors and patterns. I began researching what rust looked like to get an idea for colors when I stumbled upon a beautifully striking image of a vibrantly blue colored rust (see fig. 25). This discovery led me to research more vibrant images of rust (see fig. 26-28), which ultimately ended up as the beautiful color palette for the show. I compiled different images and then placed them in a collage (see fig. 29) and presented it to the Director in an individual meeting. He did not understand how it particularly fit the show conceptually but liked how vibrant the color palette was. We talked about some of the different 
looks he was expecting to see in the design and I talked about the through-line I wanted to explore with color. I described a vibrant and colorful show that slowly lost color as the show progressed. The Director felt that was the wrong direction. He instead wanted the show to start dim and get brighter in order to set up the audience as if the show would have a happy ending but then crush their hopes at the end of Act Two. I was completely thrown off when the Director explained this idea. It was like starting all over, and I had no idea how to move ahead, but I told the Director that I would modify the design to accommodate his request.

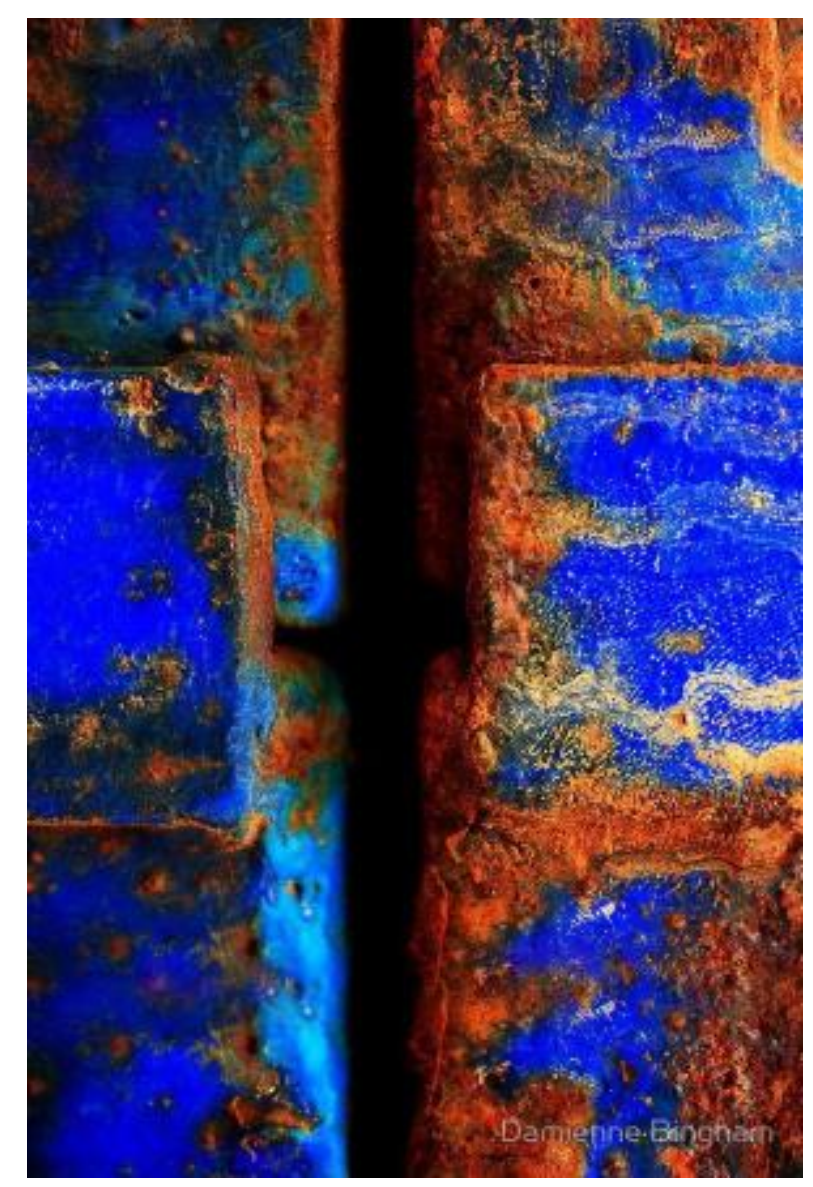

Figure 25. Color and theme research from the Lighting Designer. ${ }^{19}$

19 "GD122." Pinterest. N.p., n.d. Web. 27 Apr. 2017. <https://www.pinterest.com/M4DM3L/gd122/>. 


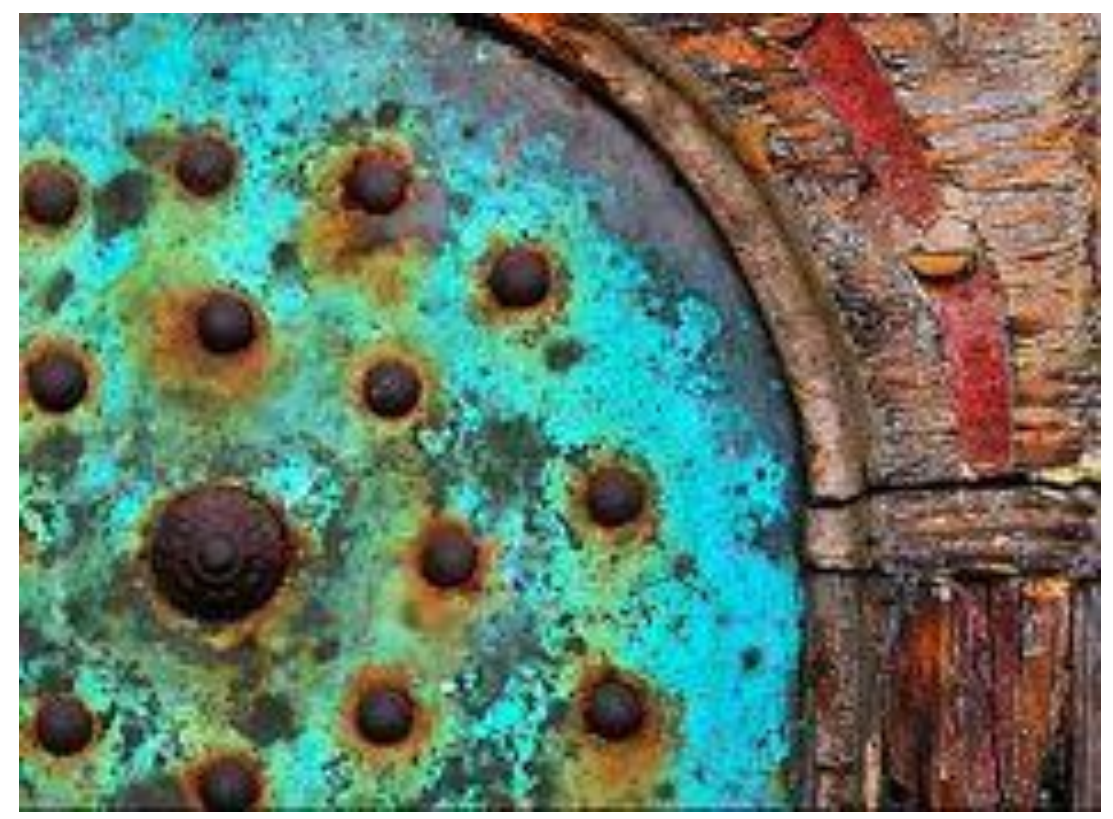

Figure 26. Color and theme research from the Lighting Designer. ${ }^{20}$

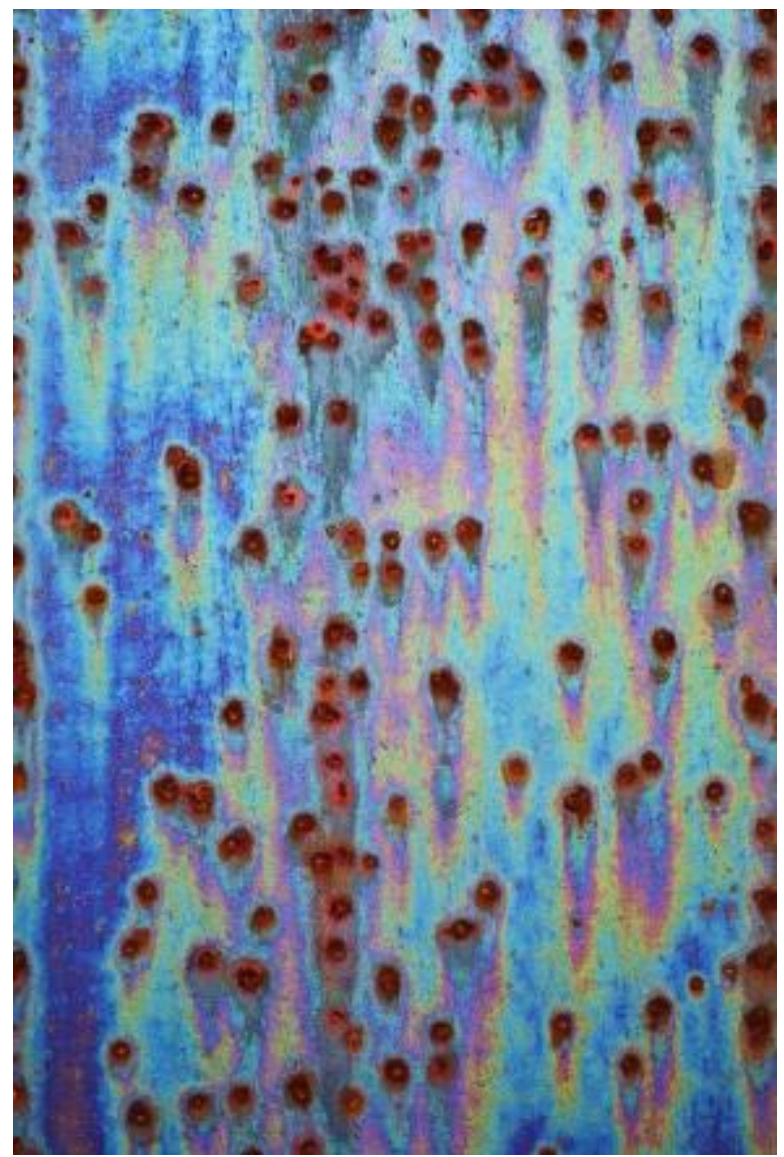

Figure 27. Color and theme research from the Lighting Designer. ${ }^{21}$

${ }^{20}$ McKenzie, Fiona. "Rust." Pinterest. N.p., 20 Feb. 2017. Web. 27 Apr. 2017. $<$ https://es.pinterest.com/pin/337699672044766713/>. 


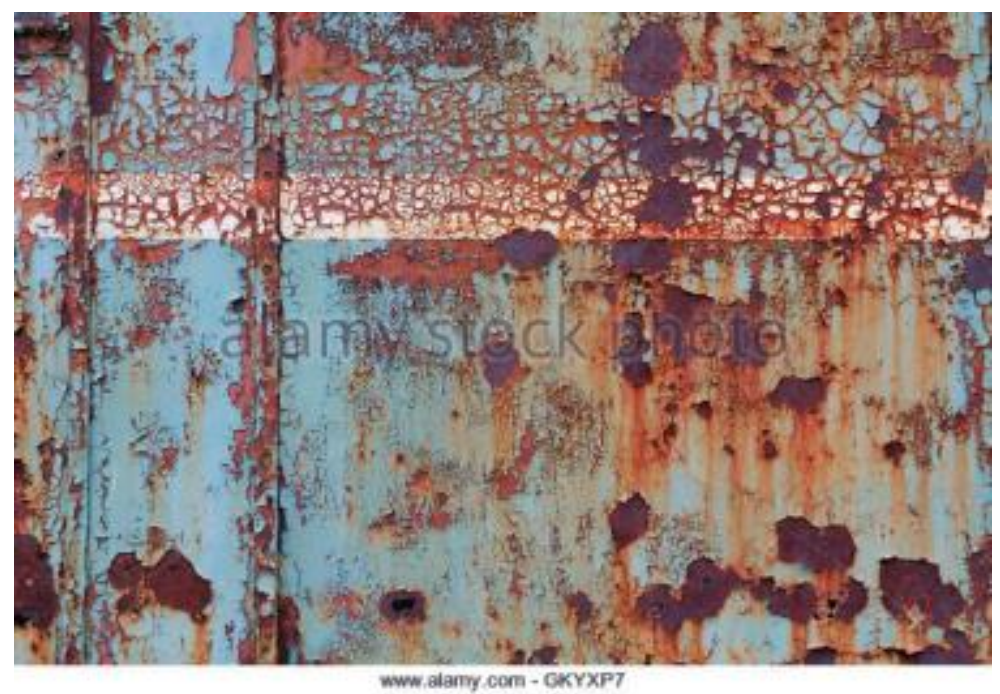

Figure 28. Color and theme research from the Lighting Designer. ${ }^{22}$

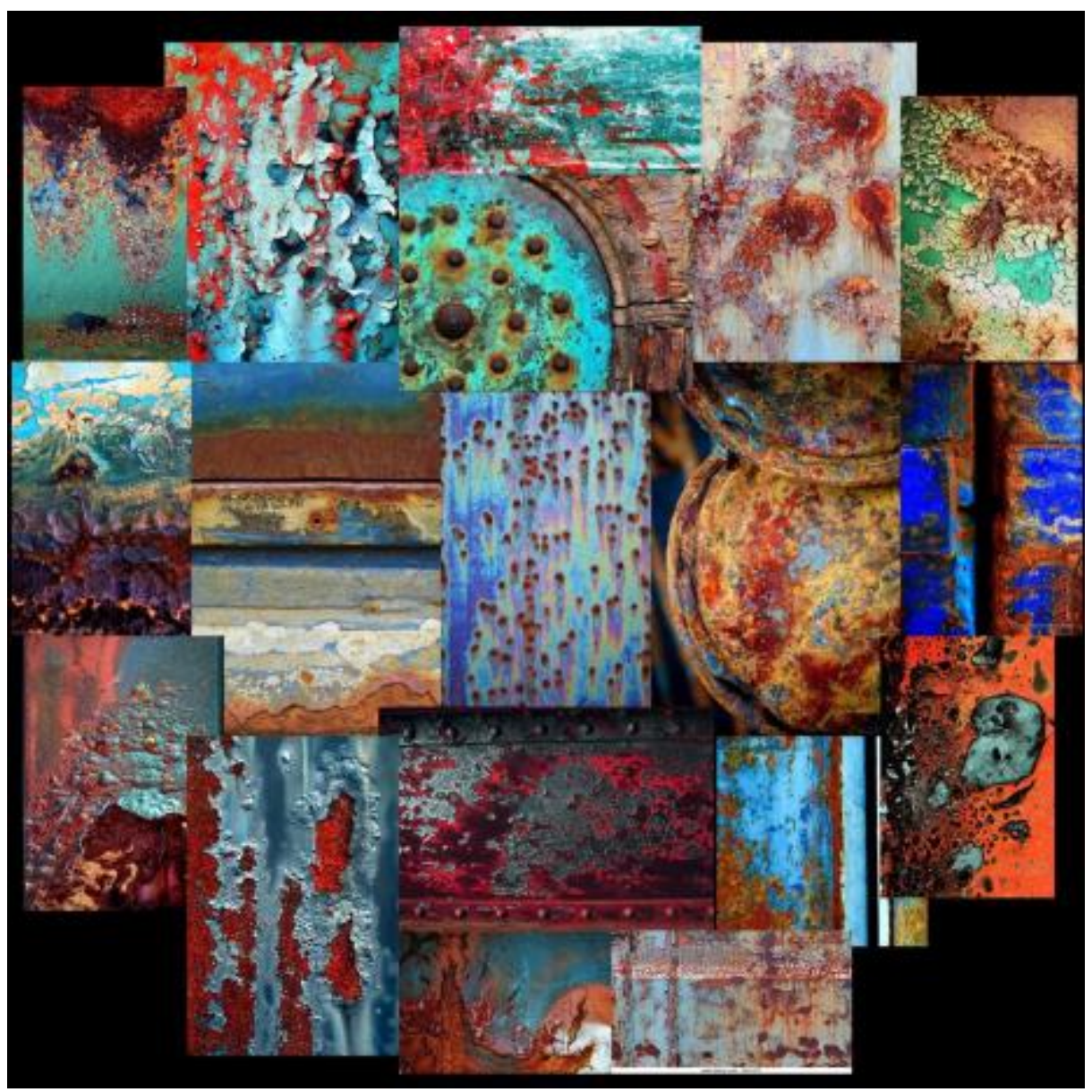

Figure 29. Color and theme research collage from the Lighting Designer.

\footnotetext{
${ }^{21}$ A, Esmeralda García. "Encaústica." Pinterest. N.p., 27 Oct. 2015. Web. 27 Apr. 2017. <https://www.pinterest.com/pin/299630181437957103/>.

22 "Corroded Iron Stock Photos and Images." Alamy Stock Photos. N.p., n.d. Web. 27 Apr. 2017. <http://www.alamy.com/stock-photo/corroded-iron.html>.
} 
Winter break rolled around the corner, and I felt completely lost. I struggled with not only trying to understand what world the design team was creating, but I felt like I had lost my eye for design. I was frustrated and felt like my creativity had been drained and I had no idea how to get it back. I spent days locked in my house just staring at a blank Vectorworks file. Nothing. I decided to try and stop thinking and just do something. I ultimately went back to the basics of drafting plot systems. A base of a show can be broken down into front, top, back and side light systems, along with specials (see fig. 30-31). The angle and degrees vary by show but I knew I could at least start with these basic systems. I wanted to do something completely different in systems but I could not figure out what, so I just relied on standard ones.

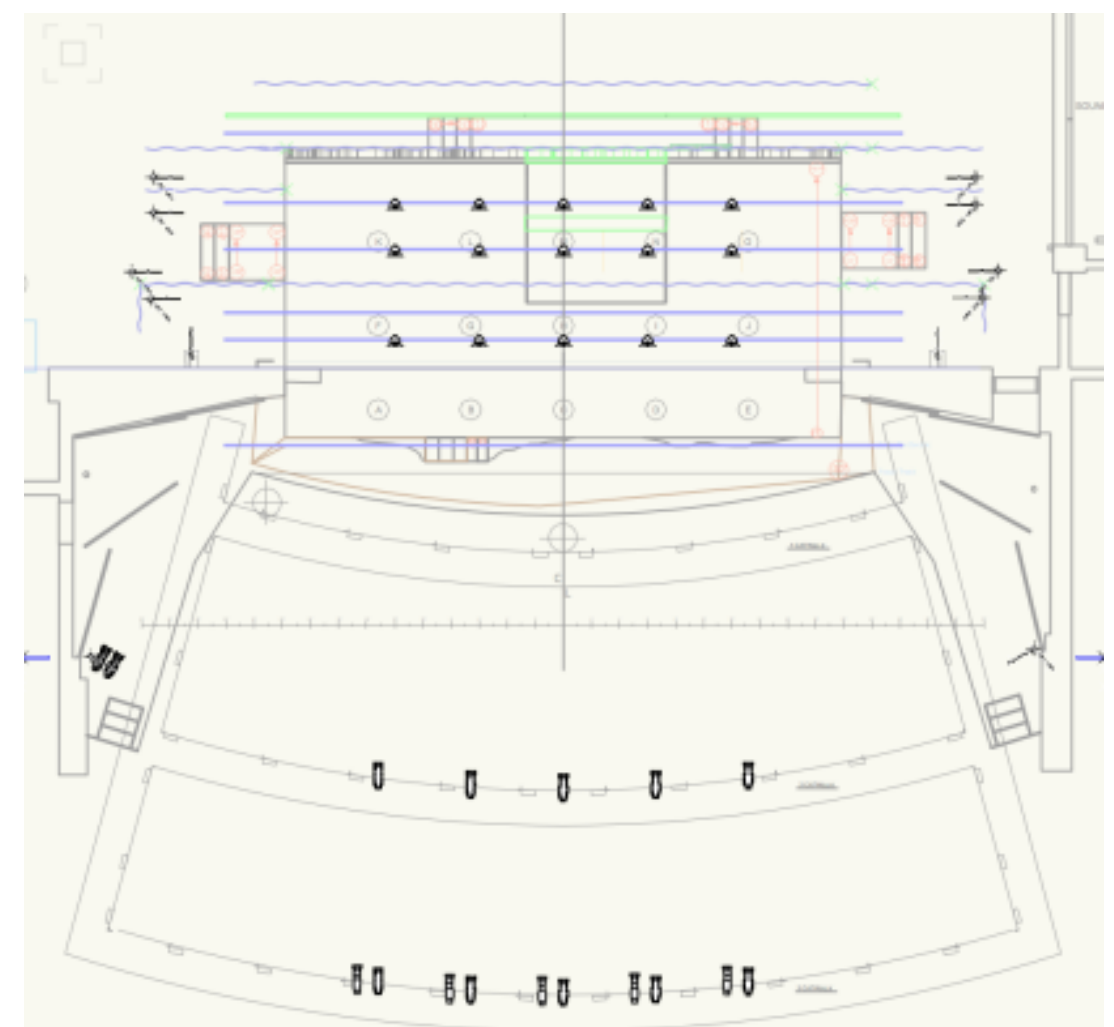

Figure 30. Beginning drafting of front and top light systems. 


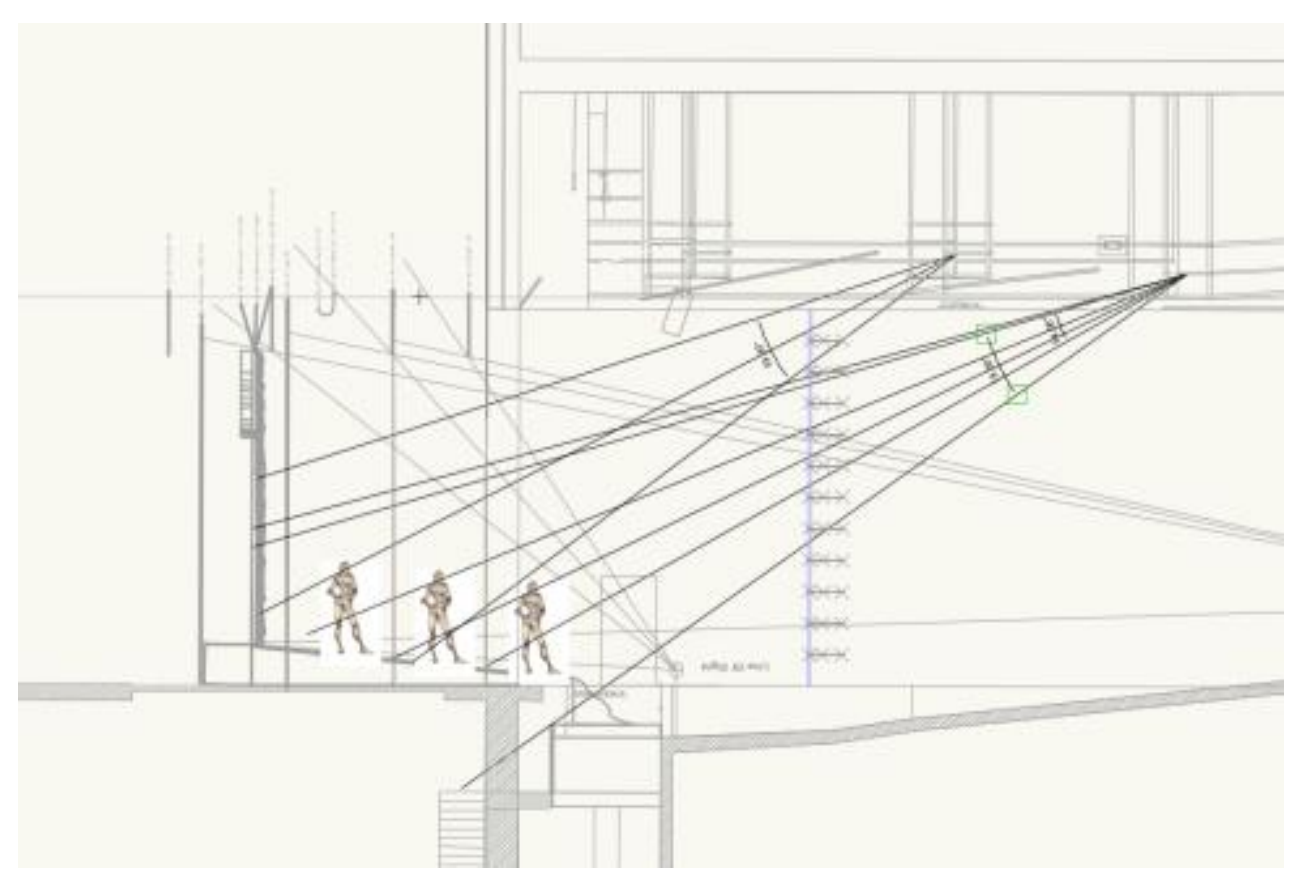

Figure 31. Beginning front light photometric section.

I slowly plotted systems until I had the basics laid out and then moved on to the harder systems, which included the sidelight from the box boom positions and the twenty-one foot booms, wall washes from torms, and specials for the wall crack. One important skill every Lighting Designer needs to have is an understanding of how to use photometrics and apply that understanding to sections to figure out possible positions for the lighting equipment. Unfortunately, this is something I have struggled with quite a bit since I started my career in graduate school. I took it one step at a time and slowly figured out where each light fixture needed to be and the degree it needed to be (see fig. 32-33). I had to rely on my colleagues at one point to double check my photometric work. 


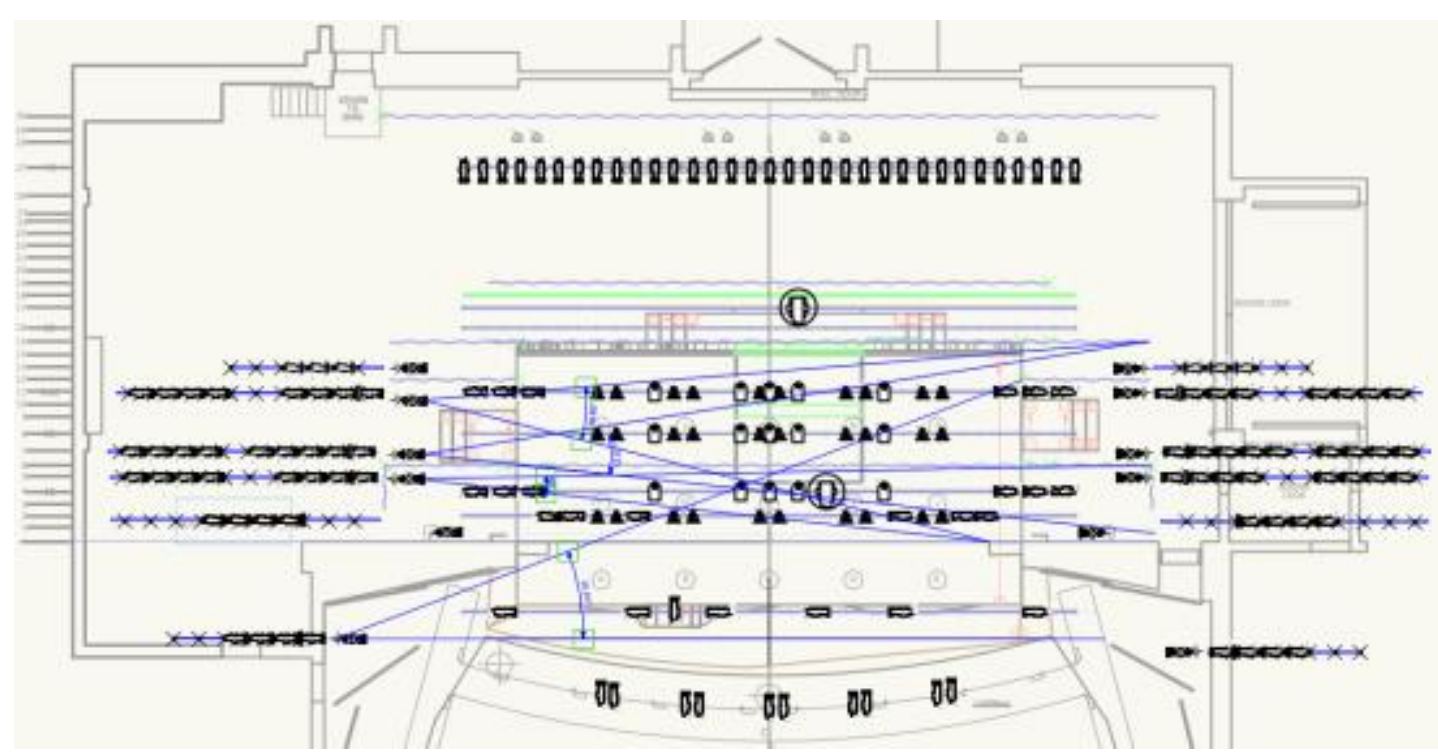

Figure 32. Light plot figuring out boom placement.

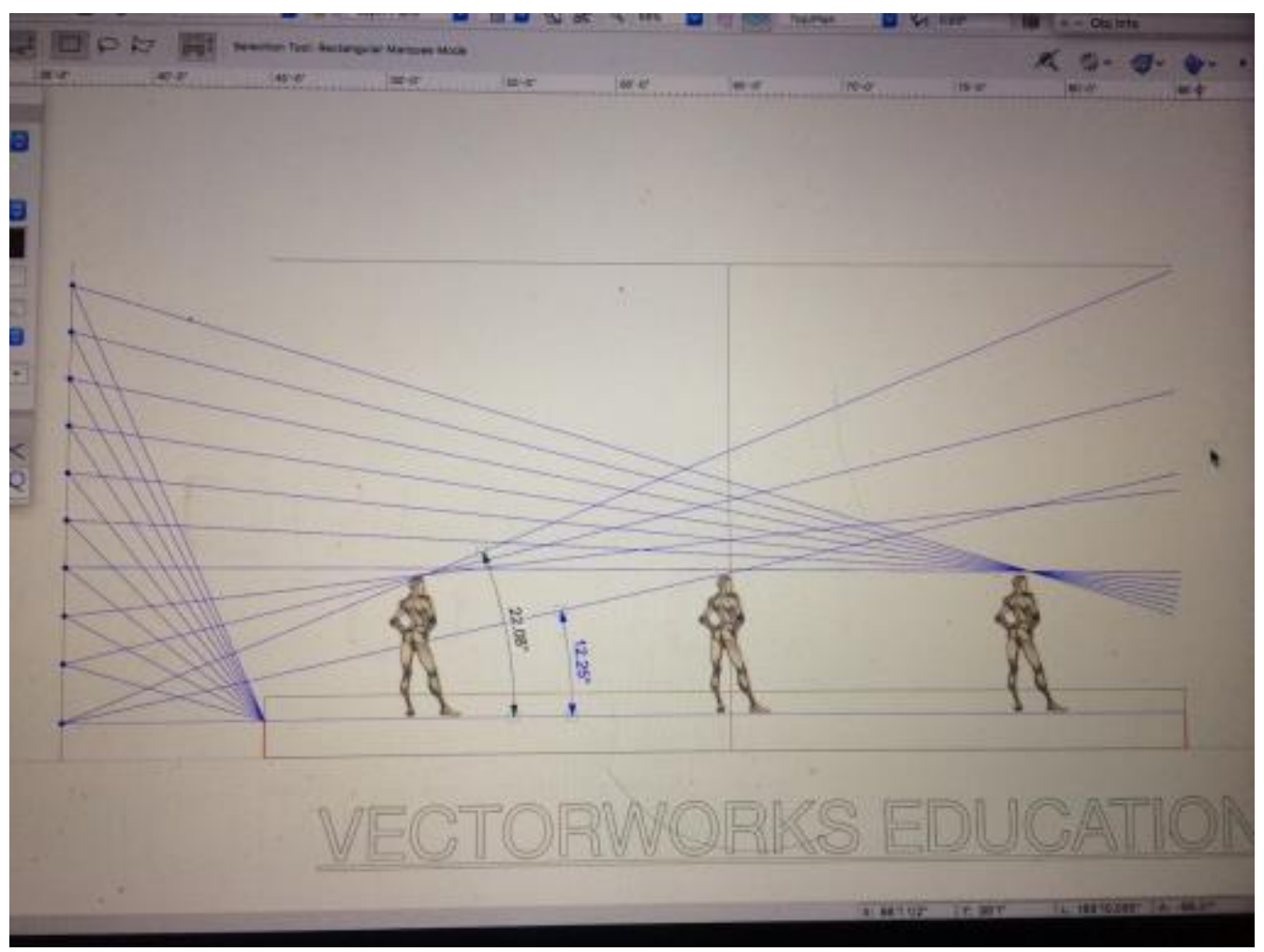

Figure 33. Front elevation of a twenty-one-foot stage boom showing the area of coverage on stage.

I had a light plot done by the time classes resumed, and I was extremely nervous to turn it over to the Master Electrician. I set up a quick meeting with my advisor to make sure I had not overlooked something. He looked and brought up a few concerns. I had too many high side 
systems with which I was trying to cover too much that would end up not reading on the actors if I kept them the way I had them. Having no masking and only side tabs would draw attention because all the booms fixtures would light the curtains. He also suggested I add a second front light system at a greater angle to play more with shadows and options, and I proceeded to make these adjustments (see fig. 34-36).

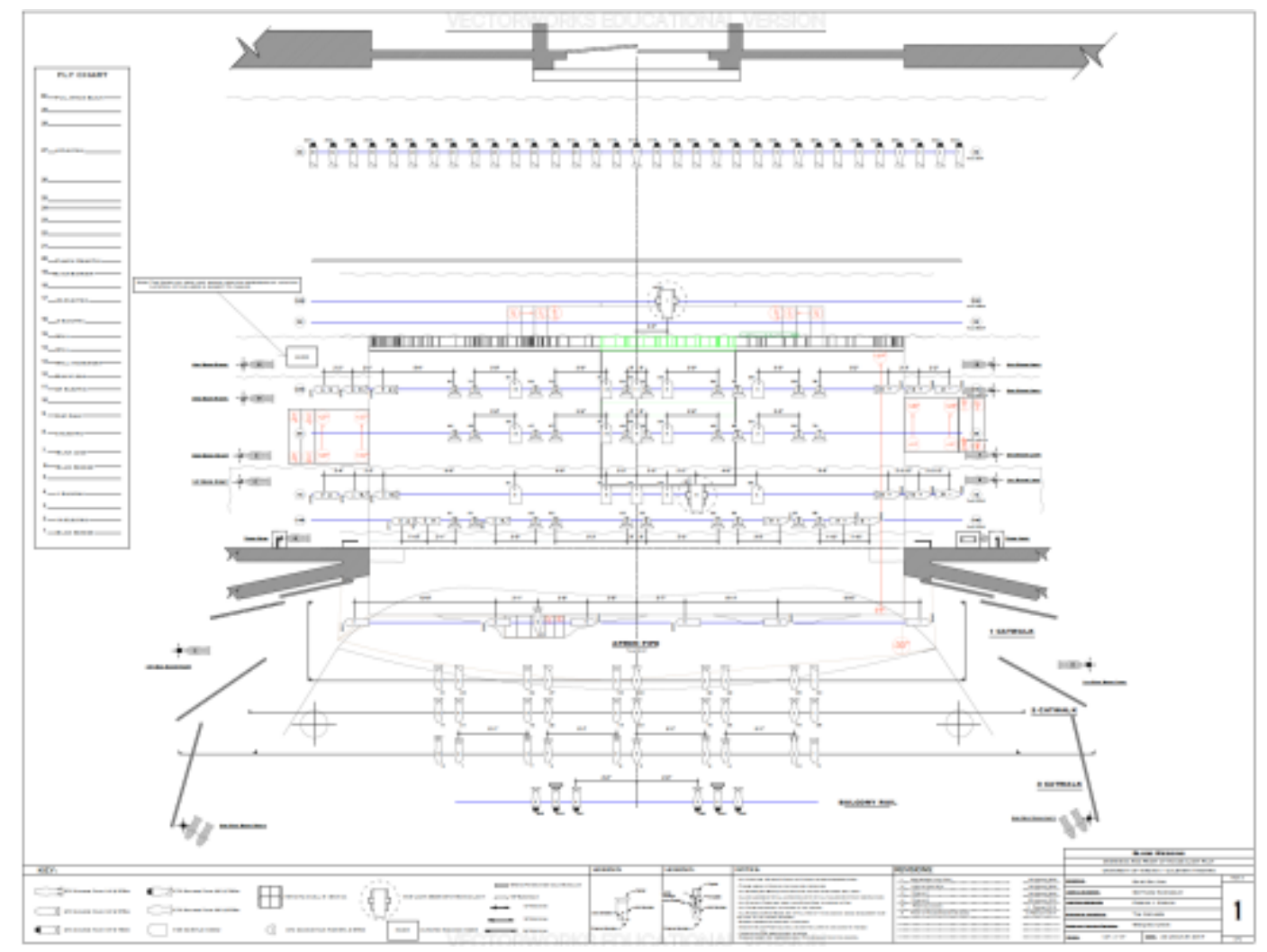

Figure 34. Final over stage light plot. 


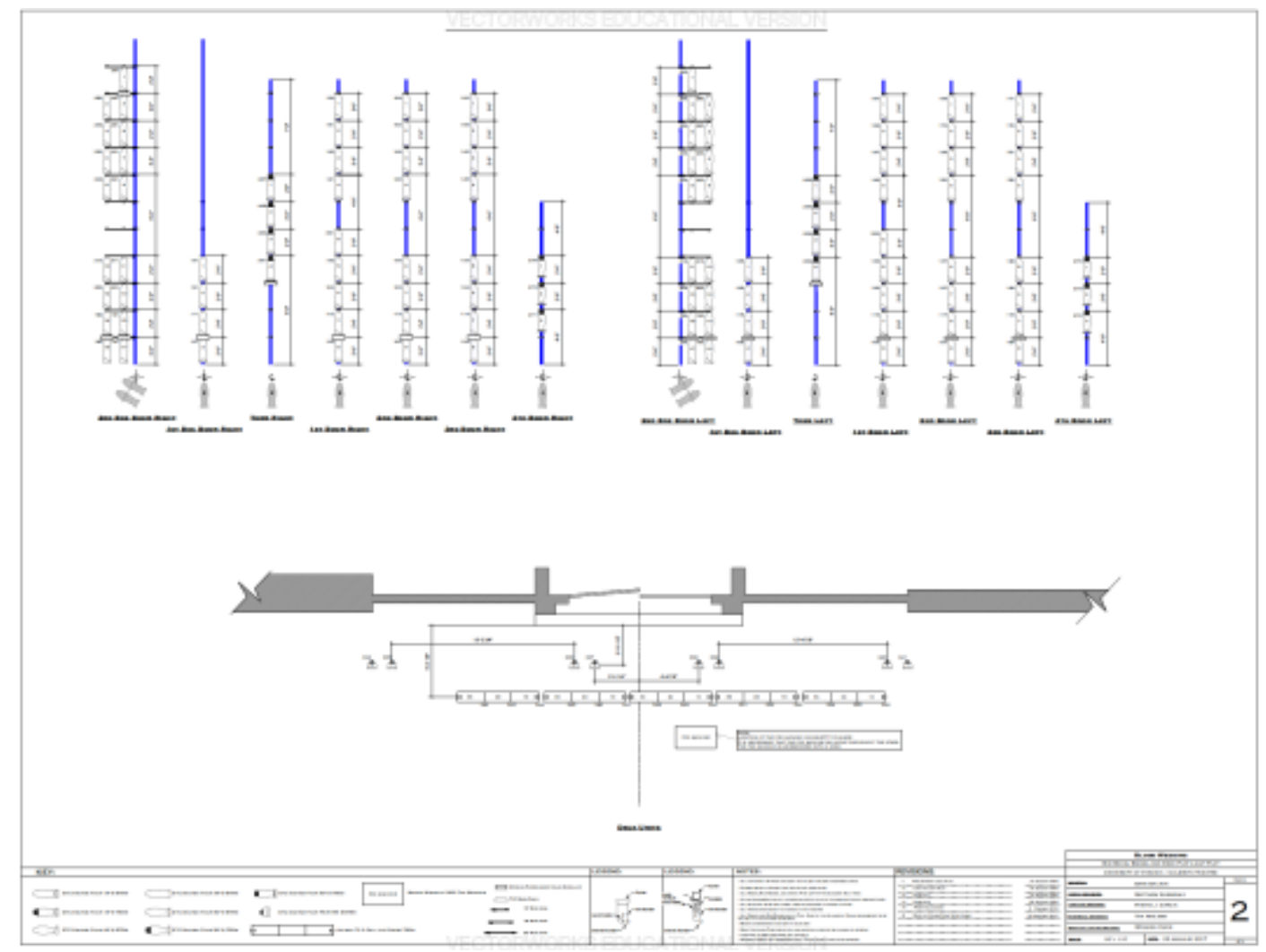

Figure 35. Final deck light plot.

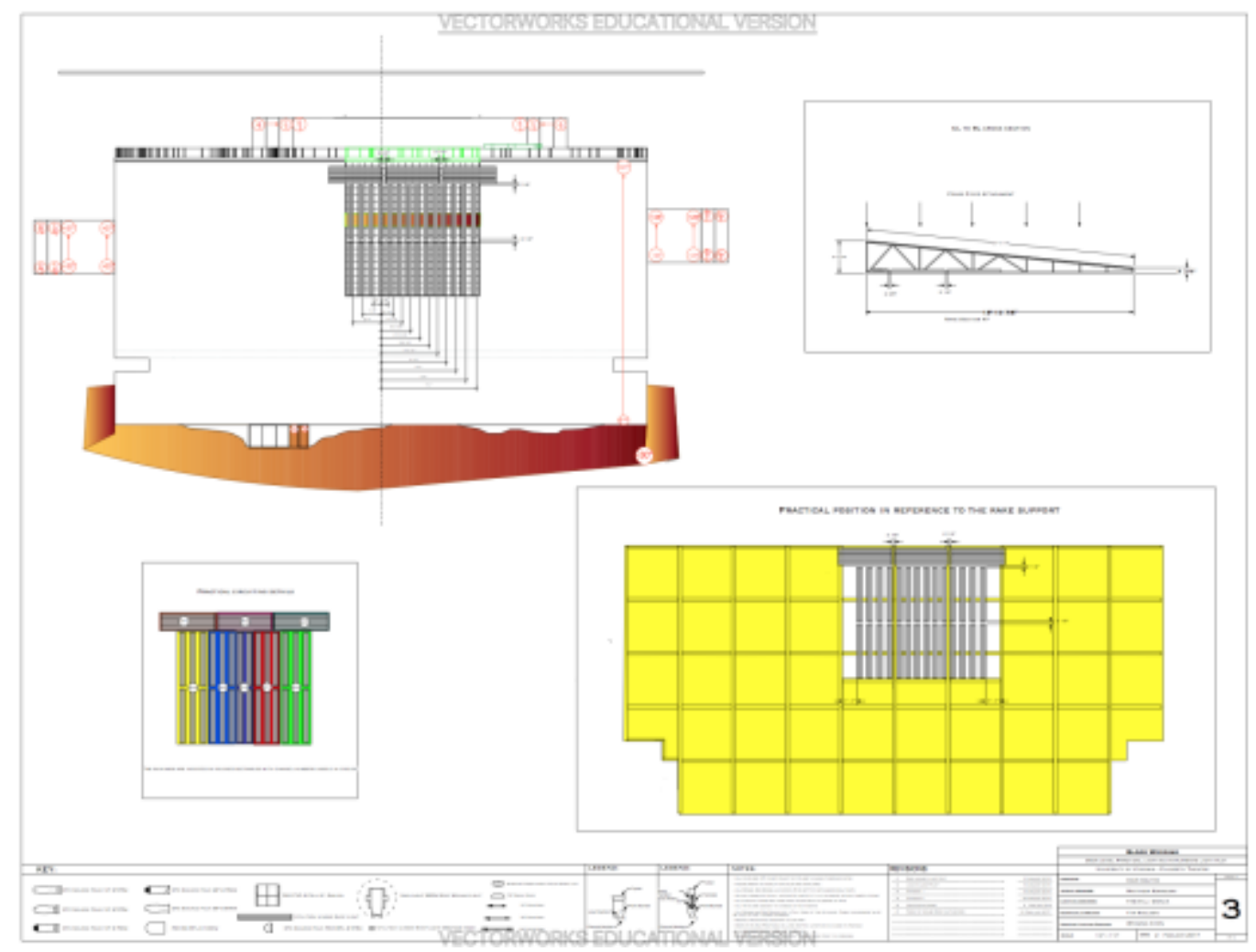

Figure 36. Final deck level practical light plot. 
I cleaned up the plot and prepared it for my Master Electrician to work from. The next few weeks would be a crucial time leading up to tech rehearsals. The implementation of the light plot would begin and I would quickly have to observe and stay in contact with the Master Electrician about it. In the meantime, I had to pick color and patterns for the show, make choices about special effect practicals, attend rehearsal and meetings, finish up any paperwork (see fig. 37-40), and create a cue list for paper tech. The weeks leading up to tech were a blur because of everything happening at once.

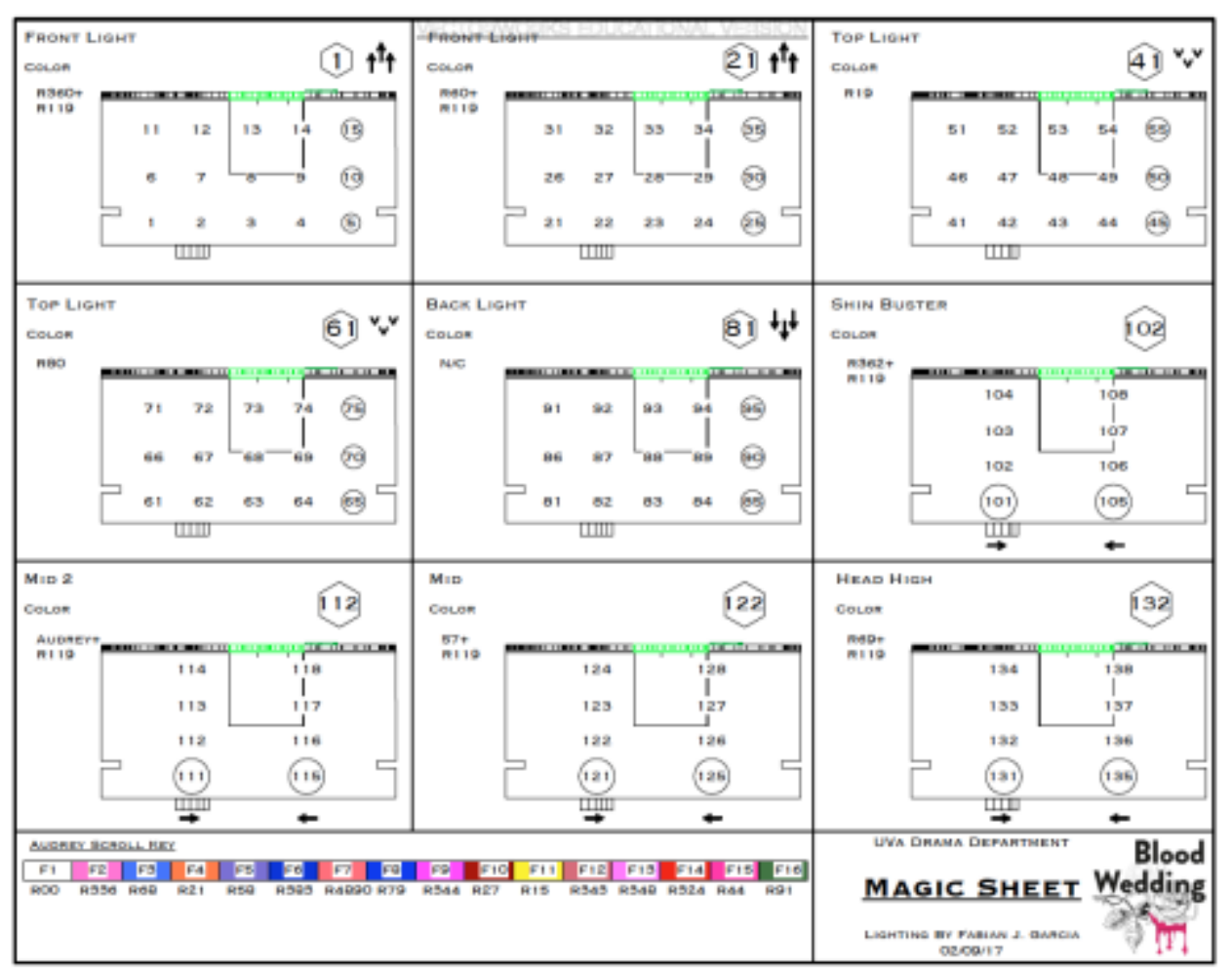

Figure 37. Final magic sheet. 


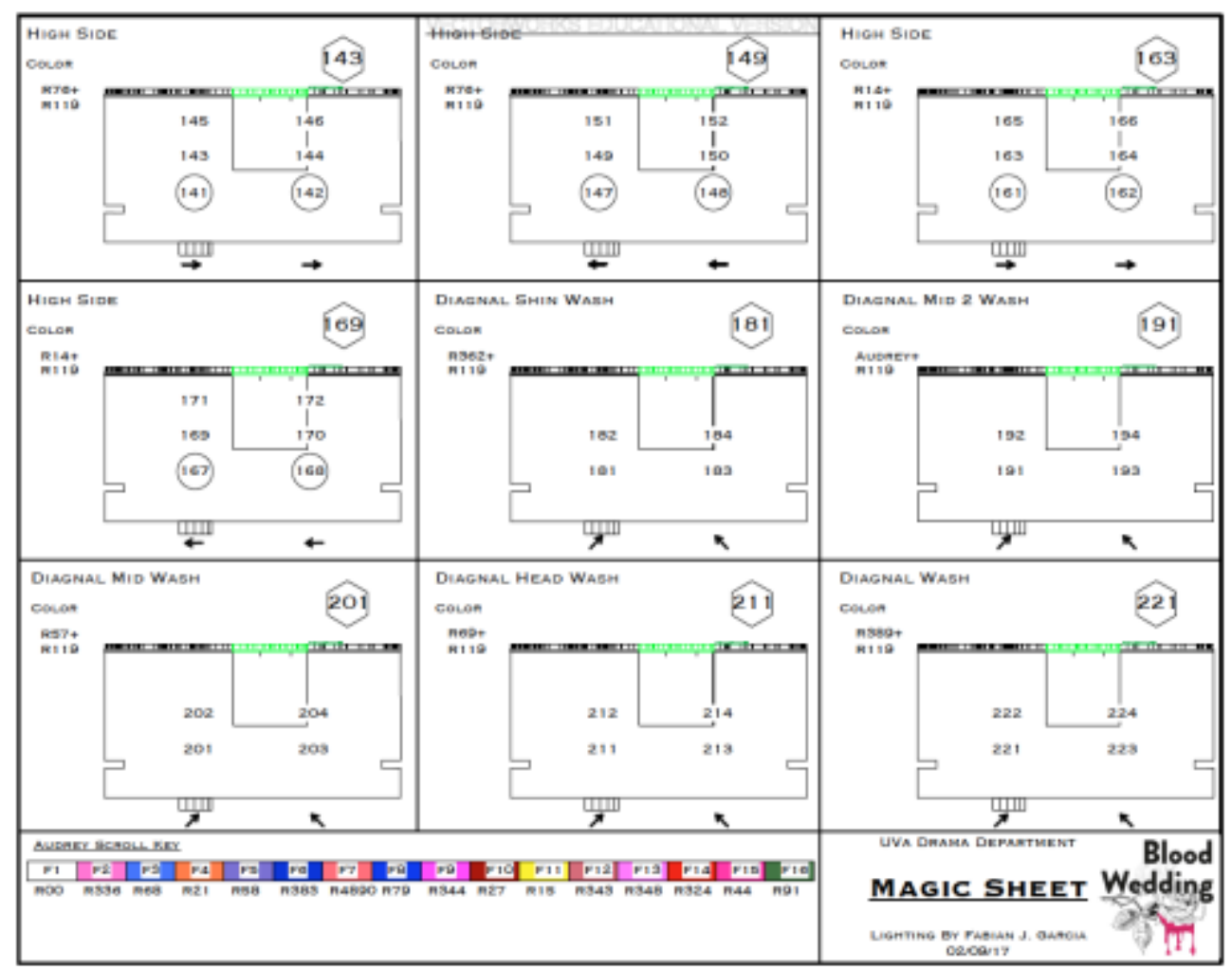

Figure 38. Final magic sheet.

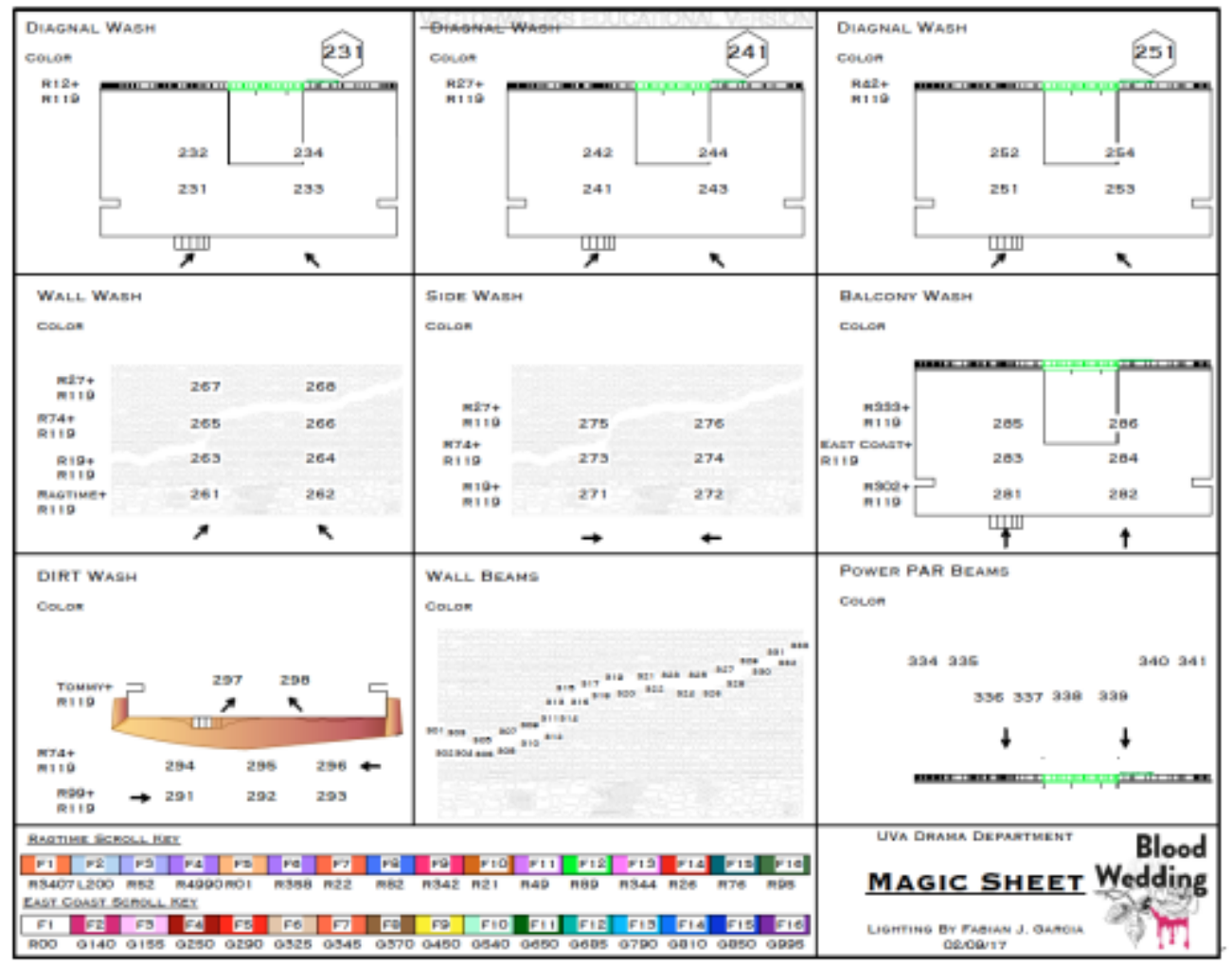

Figure 39. Final magic sheet. 


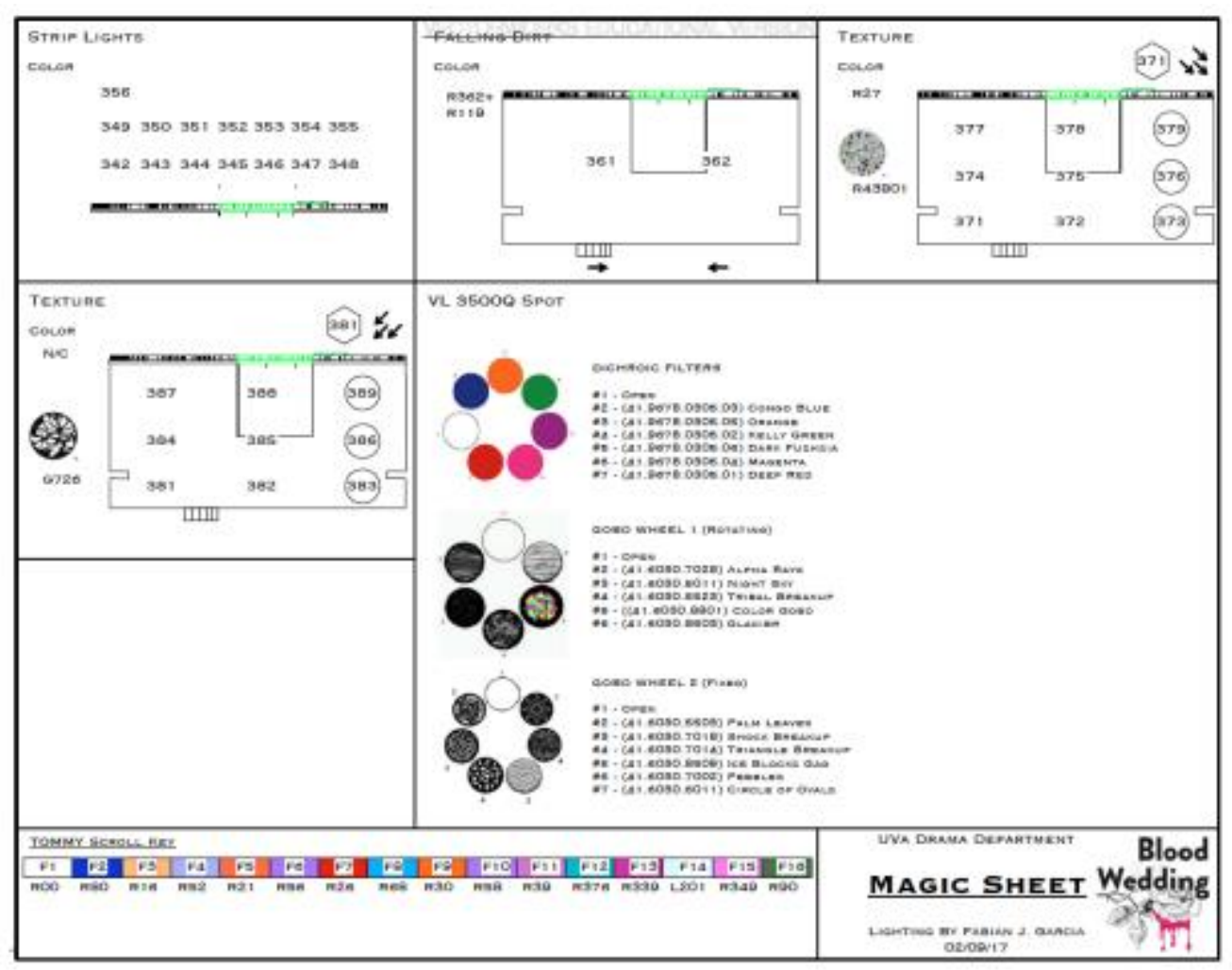

Figure 40. Final magic sheet.

From this blur of activity there are specific moments that jump out at me now as being important. For example, at this point in the process, I hope to see a designer run that is a pretty finished product from the Director so that I know what I need to work on during focus and tech. The Blood Wedding designer run was rough. A lot of the actors were still not off book, and the blocking for the third act had just been finished but the Director was still not set on it completely. I tried to keep an open mind about it, so I just watched and took notes. Another important moment that comes to mind was when the master electrician pointed out I had made a drafting error with a set of legs and booms. I had mistaken the placement of black legs and placed one of the twenty-one foot booms directly under it, which was a careless mistake. Luckily, the Master Electrician was able to just breast the leg downstage and tie it off so that it would not be able move. 
One of the challenges that the design team faced throughout the process was what the ending of the show would look like. We knew we wanted to create a different third world that conveyed doom and loss. For some reason during the third design meeting, I saw a clean white room that was so bright it was hard to even look at. I quickly looked at research and found light boxes that photographers used when they are taking clean pictures of things (see fig. 41-42). You could see that the lighting was coming from all different sides and being diffused with white paper or fabric. This was it. This was what the third world needed to look like. I got extremely excited and presented my findings to the team. I explained the idea of creating a light box that would look clean and bright to help establish something completely different than what the audience had been experiencing throughout the play. The Director liked the idea and wanted to explore it further. The design team talked more about this third world room that we wanted to create and I requested under lighting on the set to add a supernatural element that would make it look like the light box images I presented. The Scenic Designer loved the idea since we could not create our original idea of a falling white wall. Instead we settled with having under-lighting revealed and flying out the center part of the wall while bringing in a white drop that could be illuminated from behind to help create this light box (see fig. 43-45). 


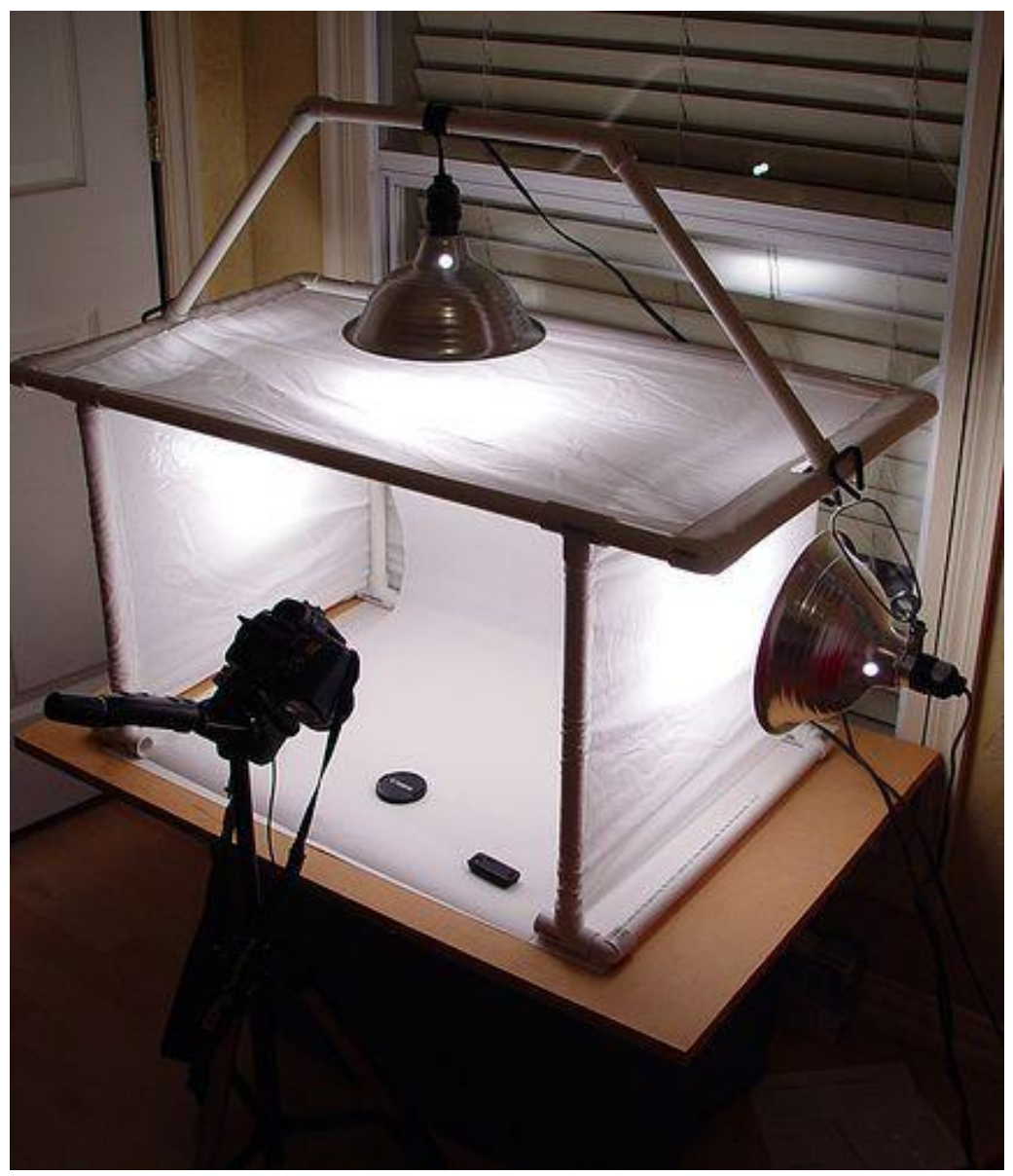

Figure 41. Research of light box from the Lighting Designer. ${ }^{23}$

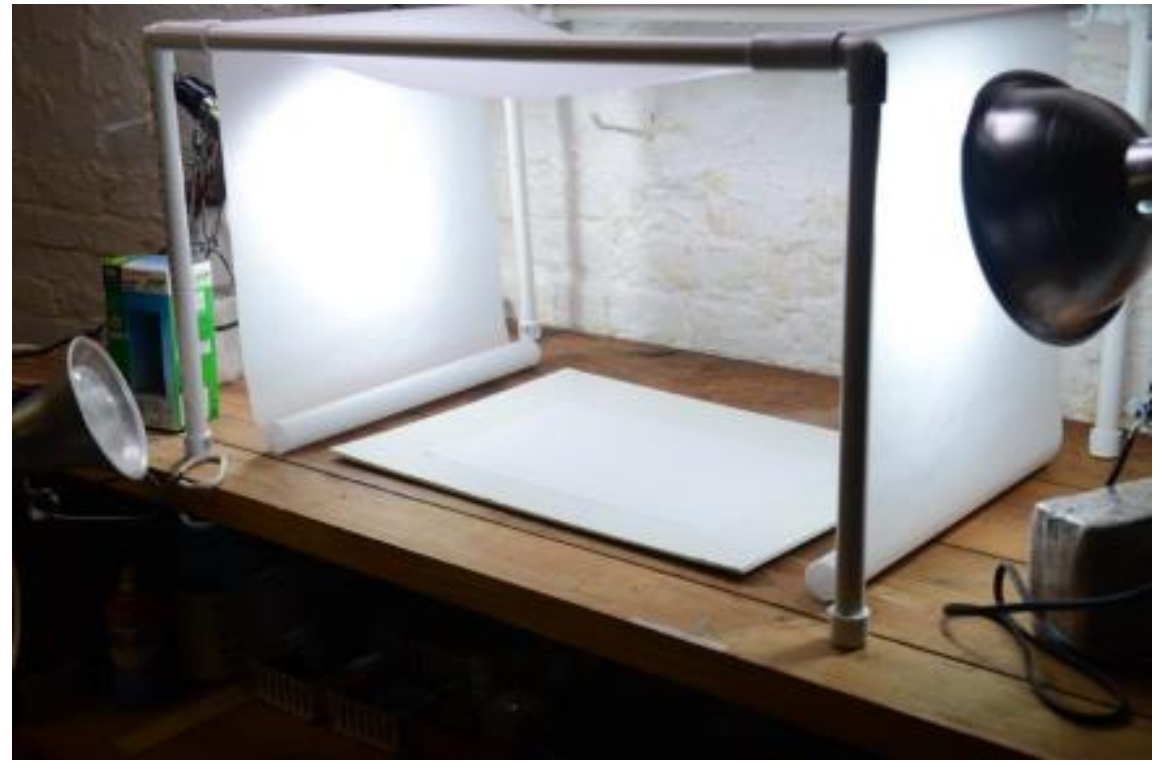

Figure 42. Research of light box from the Lighting Designer. ${ }^{24}$

23 "BEHIND THE SCENES." Pinterest. N.p., n.d. Web. 27 Apr. 2017. $<$ https://www.pinterest.com/rocketlandphoto/behind-the-scenes/>. 


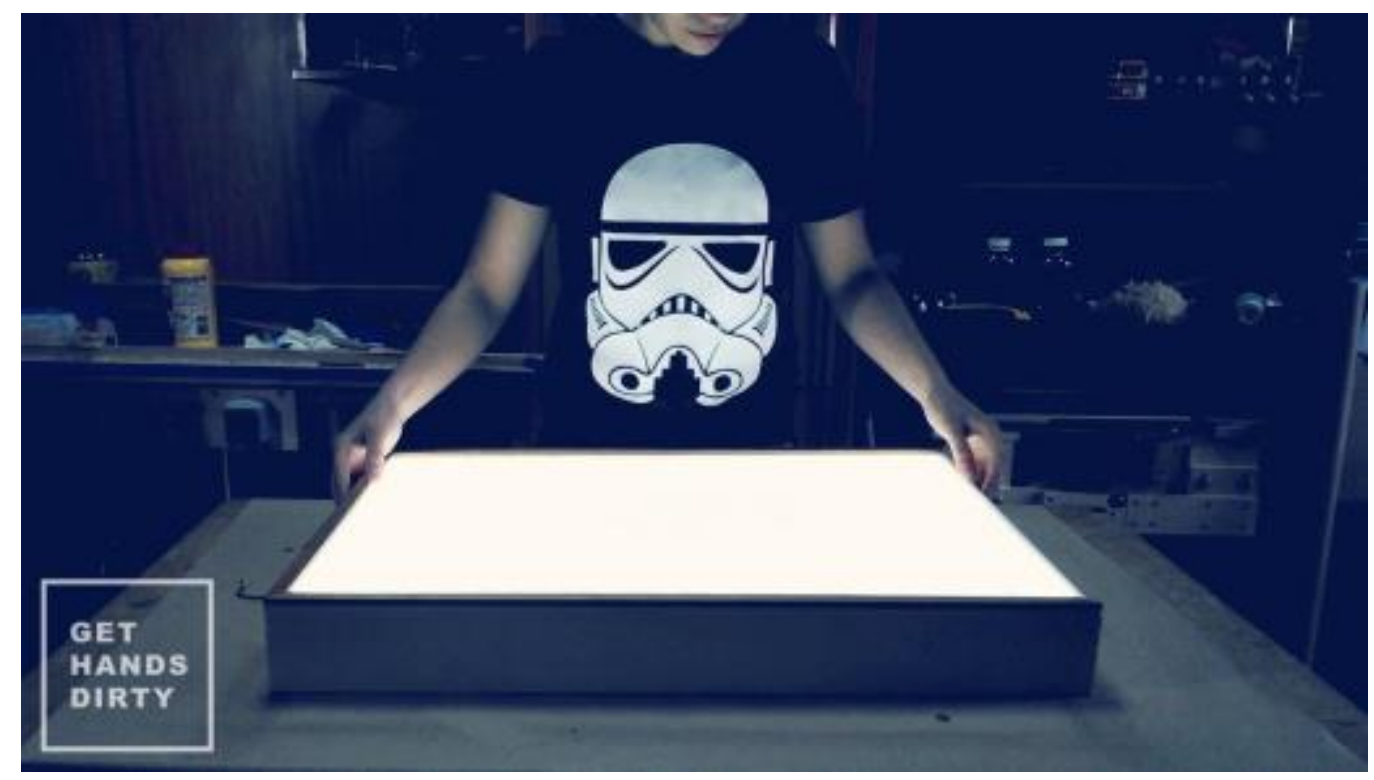

Figure 43. Research of light box from the Lighting Designer. ${ }^{25}$

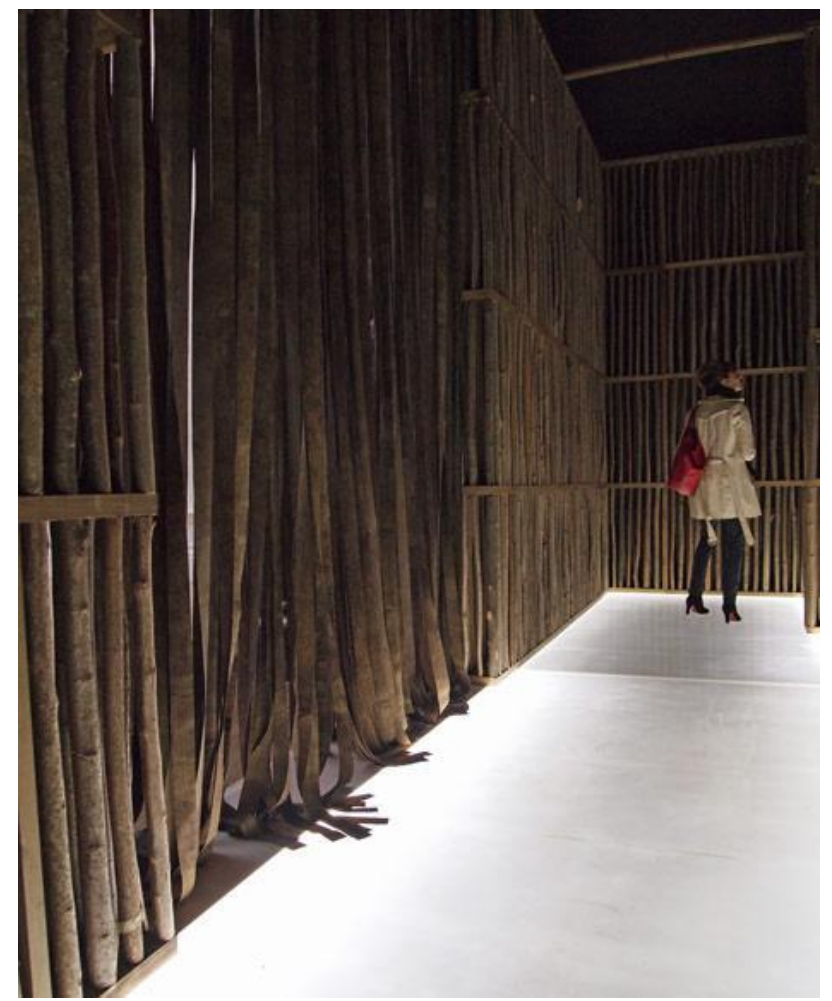

Figure 44. Research of under lighting from the Lighting Designer. ${ }^{26}$

24 "Making a light box." Left on walnut. N.p., 27 Jan. 2012. Web. 27 Apr. 2017. $<$ https://leftonwalnut.com/2012/01/27/making-a-light-box/>.

${ }^{25}$ Savalle, Johann. "DIY - Tracing lightbox project resources." Johann Savalle. Johann Savalle http://jsavalle.com/wp-content/uploads/2015/11/logo-JS2-300x66.png, 07 Feb. 2017. Web. 27 Apr. 2017. $<$ http://jsavalle.com/diy-tracing-lightbox-project-resources/>.

26 "Sensing Spaces Architecture Reimagined - Agenda - Blog - Inner Design." The Design Network For Interior 


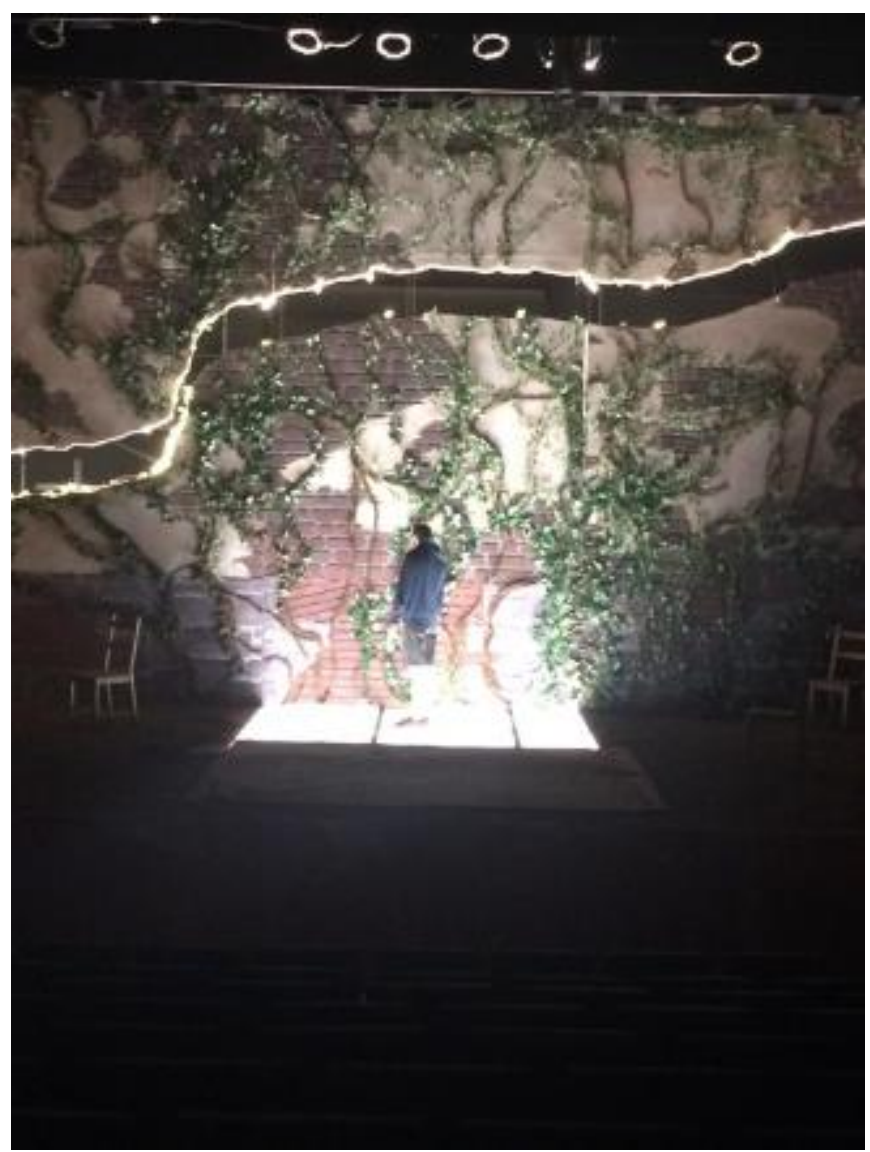

Figure 45. Photograph of under practicals and wall crack lighting.

Everything was fine up to this point, but deciding on what type of drop to use became a challenge. The Scenic Designer loved the idea of having a plastic drop that would be wrinkled so that the drop could catch the lighting and take form and shape. To him, the third world was an extension of the other worlds. I disagreed with him. I felt that the better choice would be a rear projection screen. I believed we needed a clean, white, even drop to contrast all the texture happening earlier in the play. Layering texture on top of texture felt like too much to me. I did the best to explain this to the Scenic Designer but he believed his way worked better. We decided to set up a plastic drop and a rear projection screen to test out the lighting and to see if we could

Design Lovers. N.p., n.d. Web. 27 Apr. 2017. <http://www.innerdesign.com/blog/events/Sensing-SpacesArchitecture-Reimagined>. 
decide which choice would work best. I decided to use two different types of instruments and different distances from each material. I took pictures to document everything and sent my findings to the design team, asking for feedback and explaining which ones I liked (see fig. 46$52)$.

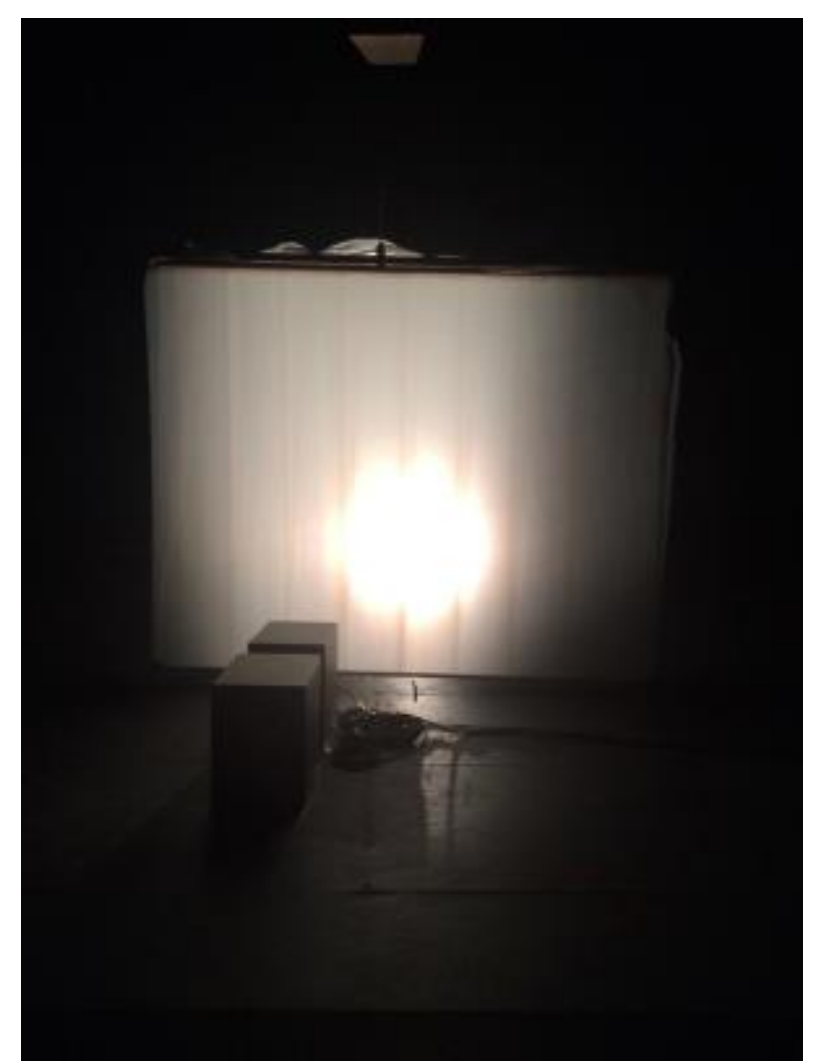

Figure 46. Photograph of a PAR-64 1000w instrument on a plastic drop. 


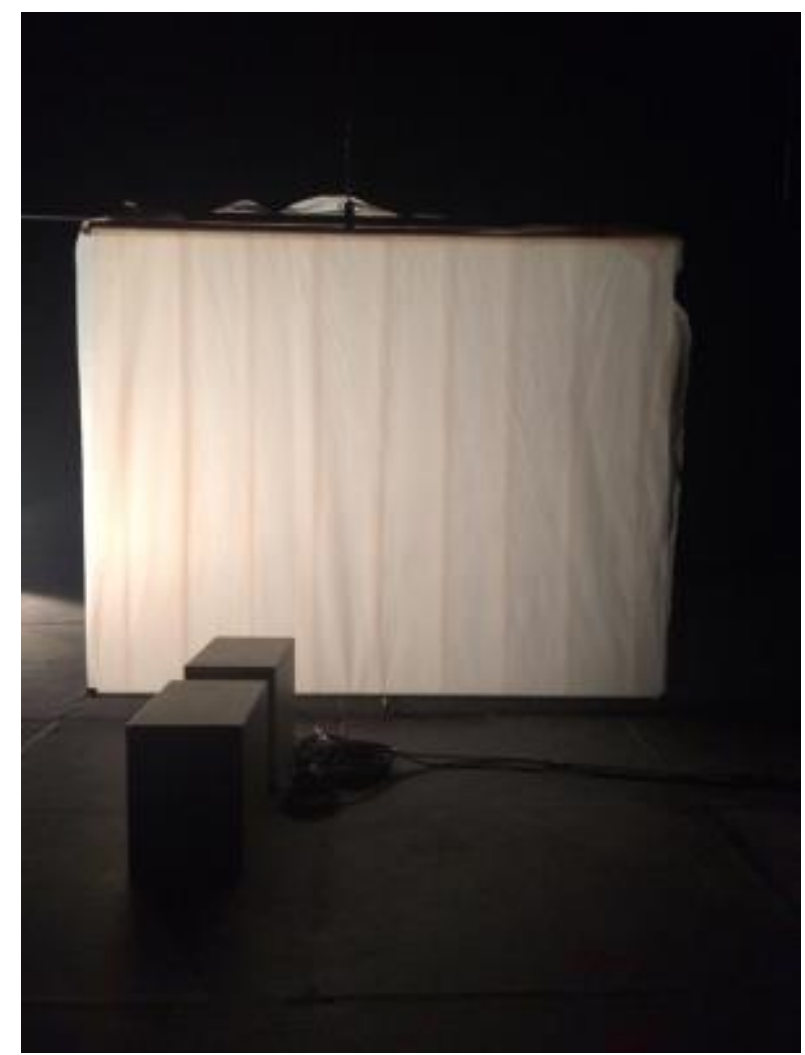

Figure 47. Photograph of a PAR-64 1000w instrument on a plastic drop.

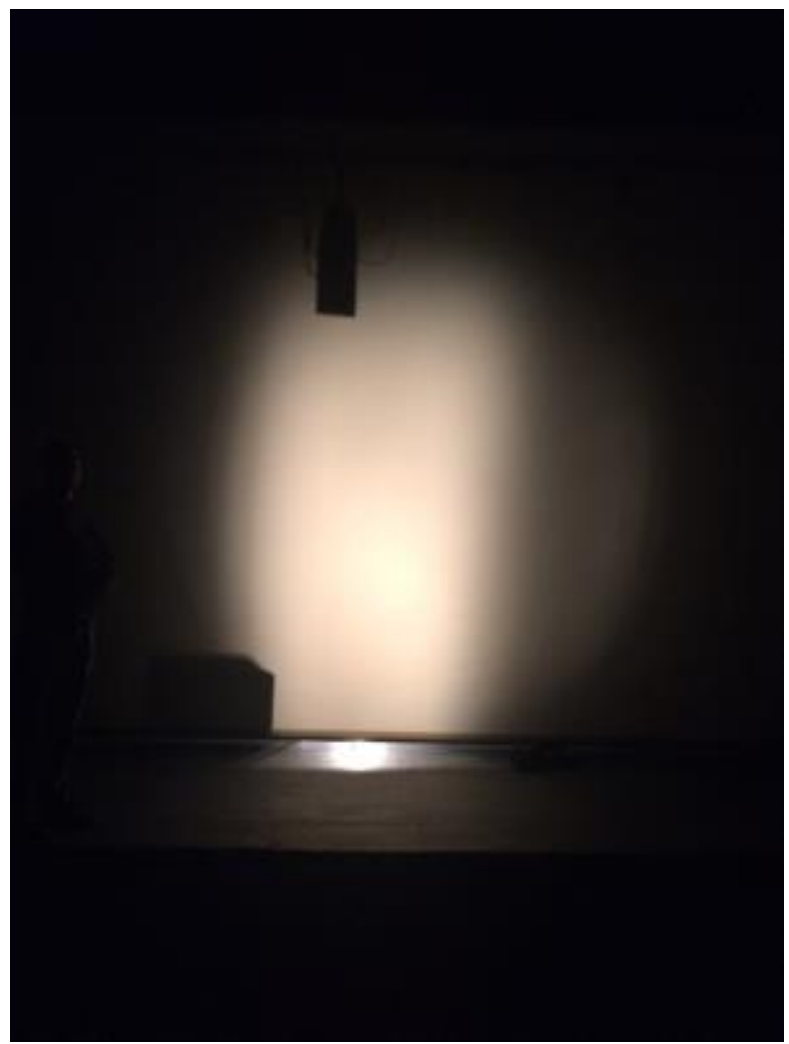

Figure 48. Photograph of a PAR-64 1000w instrument on a rear projection screen. 


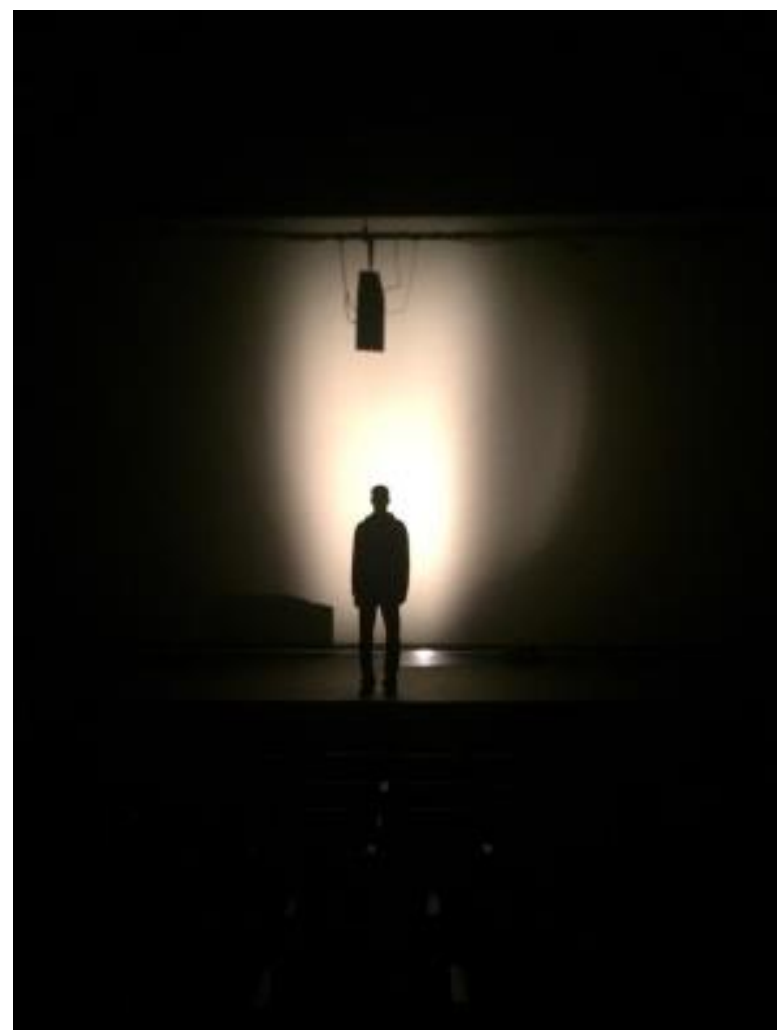

Figure 49. Photograph of a PAR-64 1000w instrument on a rear projection screen with human.

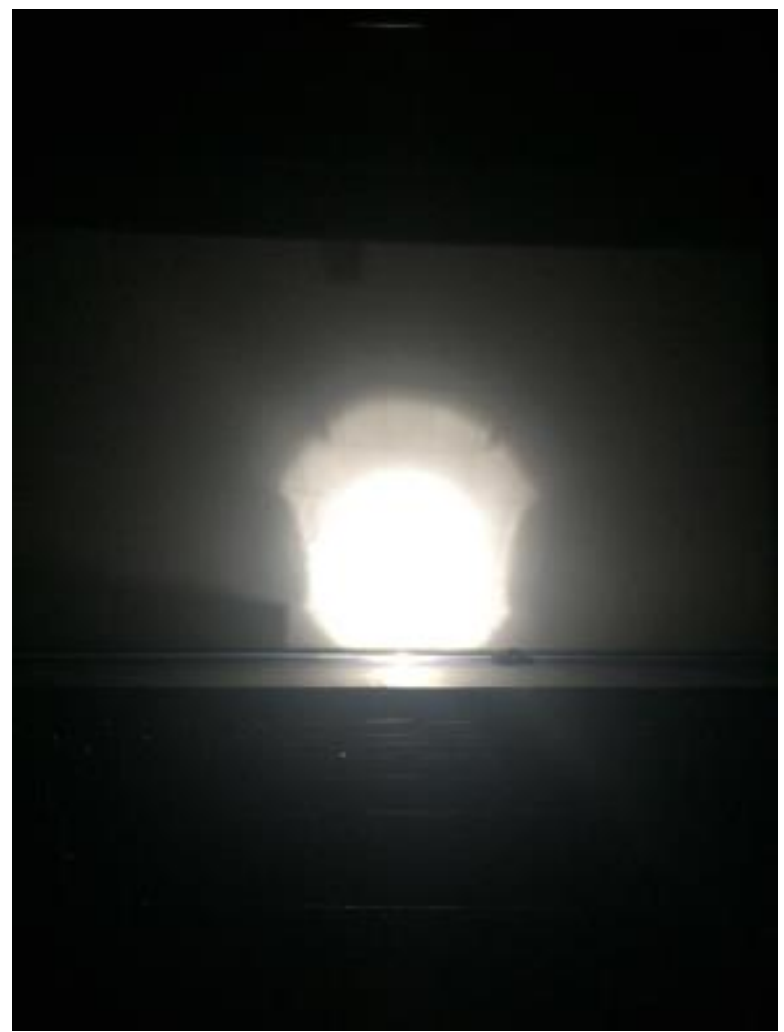

Figure 50. Photograph of a ETC Power PAR 575w instrument on a rear projection screen. 


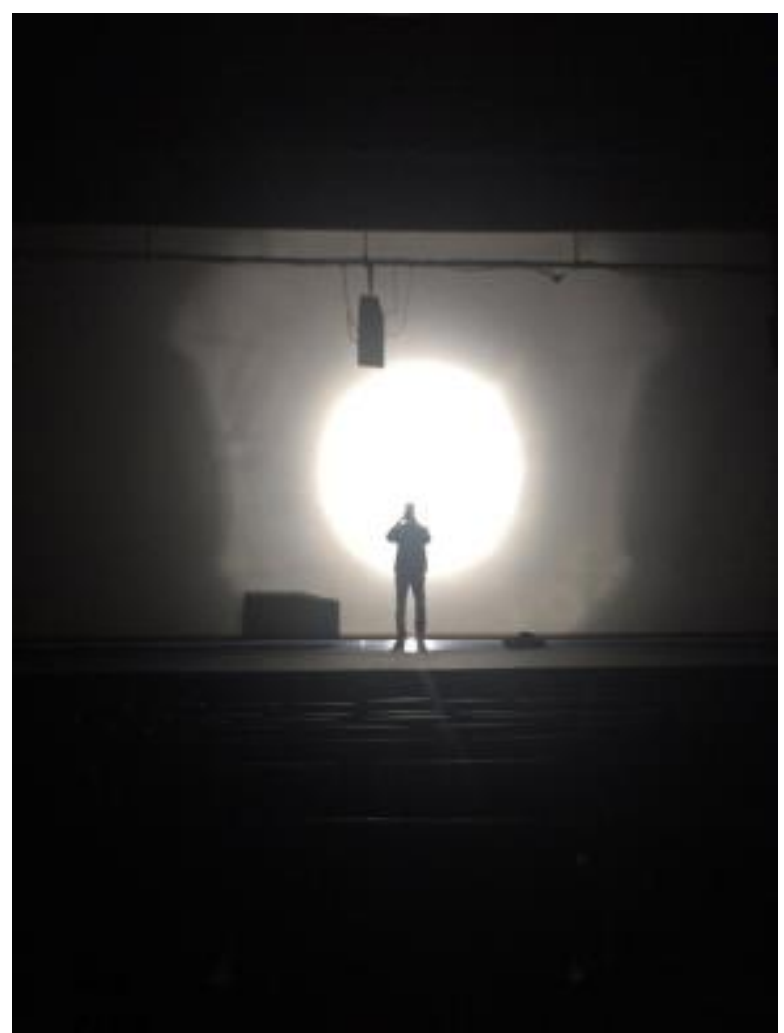

Figure 51. Photograph of a ETC Power PAR 575w instrument on a rear projection screen with human.

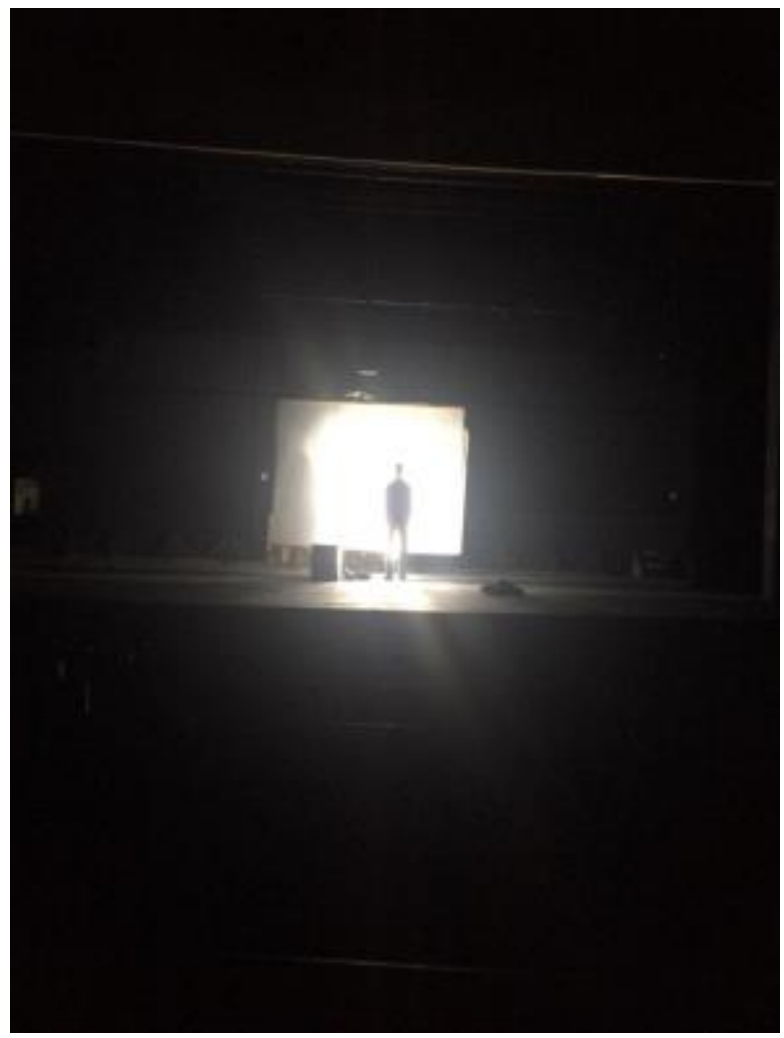

Figure 52. Photograph of a ETC Power PAR 575w instrument on a plastic drop with human. 
I had another meeting with the Scenic Designer, and we discussed which one worked better. Looking at the experiment, I really could not see why he liked the plastic drop because it just looked like a bad shower curtain. During the next production meeting, I brought up the drop discussion and told the Director that we needed to make a decision in order for scenic and lighting to move forward with their work. I presented the images, and the Scenic Designer and I defended our viewpoints. The Director asked for the input of the Costume and Sound Designers and they gave their input. The Director still could not choose which option he liked better because he could see both working in the show. He wanted to see both options during tech to decide. We let him know that unfortunately we didn't have the luxury of having both for tech. In the end, he chose to have the rear projection screen because it was cost effective to the show and he liked it a little more. To this day, I still find that the white rear projection screen was a better choice because it was visually stunning and contrasted the other worlds of the show (see fig. 53). Once a decision was reached, I could move forward and plan how I would light the rear projection screen. Tech week was just around the corner, and I had to start making a plan for the overall look of the lighting for the show given all of the individual elements, decisions, and discussions so far. Blood Wedding paper tech took about three hours to get through. It was a long rough process but we needed the time to figure out exactly how the Director saw the show progressing moment to moment. We spent time talking about transitions and the best ways to go about them, and we walked through the big changes to discuss what exactly the lighting would be doing in those moments. After the three hours had gone by, I had a better understanding of the structure of the show and I could move on to programing specific lighting moments. 


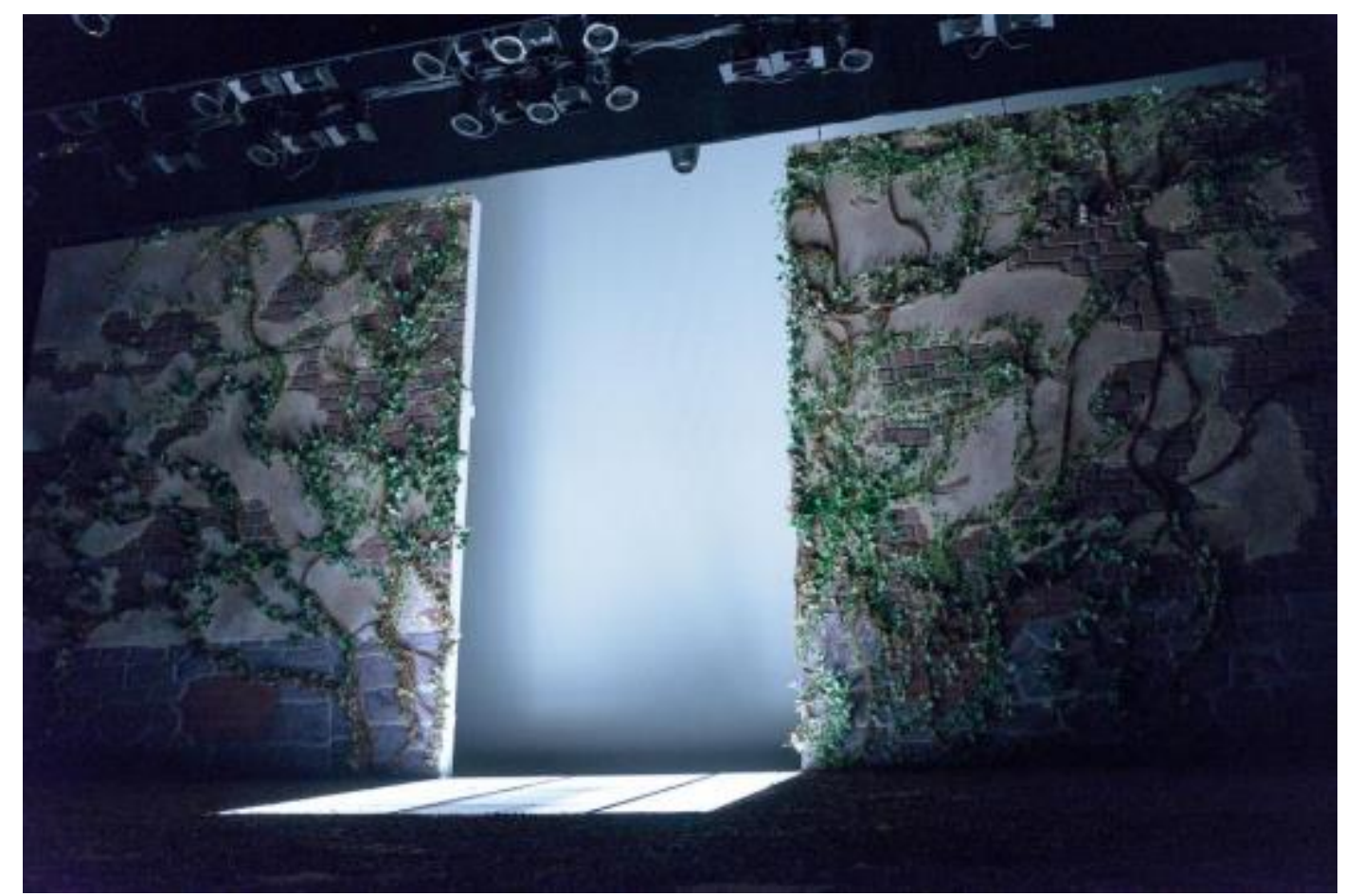

Figure 53. Production photo of the white rear projection screen drop with the set. Photography by Michael Bailey.

Programing is one of my favorite parts of the lighting process as a designer. I have the whole space to myself and can sit quietly and think about the ways I can design a show. Through my time in school, I have programed all of my own shows, but I had my Assistant Designer come in and program this one for me. I felt this would be a great opportunity for us to discuss the choices I would make and whether or not they fit the world the other designers had created. Programing did not go according to plan. My assistant was late to the session, so I took that opportunity to look at all the different lighting systems to see how they interacted as a whole in the space.

At that point, the Technical Director and Scenic Designer decided to come out onto the stage and talk about the set. I was frustrated, but I knew it was not a good idea to kick them out of the space since I was waiting for my assistant to show up. Luckily, we ended up being able to use this time for more collaboration. The Master Electrician was there, and he brought up a work 
note we still needed to finish: focusing the lighting wall crack. I turned the system on and asked him to point all thirty-three instruments at the crack. I then discussed with the Scenic Designer and Technical Director about the spacing of the crack and if we could make it wider than it was. We settled on a two-foot spacing to start with for tech. The Master Electrician roughed the lights in and I looked at it from different seats in the space to make sure it would not blind any of the audience members. We noticed light coming through cracks in the set where was not supposed to, and the Scenic Designer took notes. We also noticed that a big section of the audience could see the thirty-three instruments though the woodcutter's door in the set. As much as we liked to think that the audience would accept this as part of the world of the play, we knew we needed to come up with some type of masking for it. During tech, the Technical Director came up with the idea that a black border that would fly in right before the wall reveal and mask just the bottom half of the instruments. Thankfully this worked wonderfully and not once did the Director notice the instruments through the door.

My assistant eventually showed up and I could get started programing the show (see fig. 54). We only got through Act Two of the show before I called it a night. The third act involved a bit more advanced programing than what my assistant was used to, so I figured I could program it that Saturday morning after the first day of tech. 


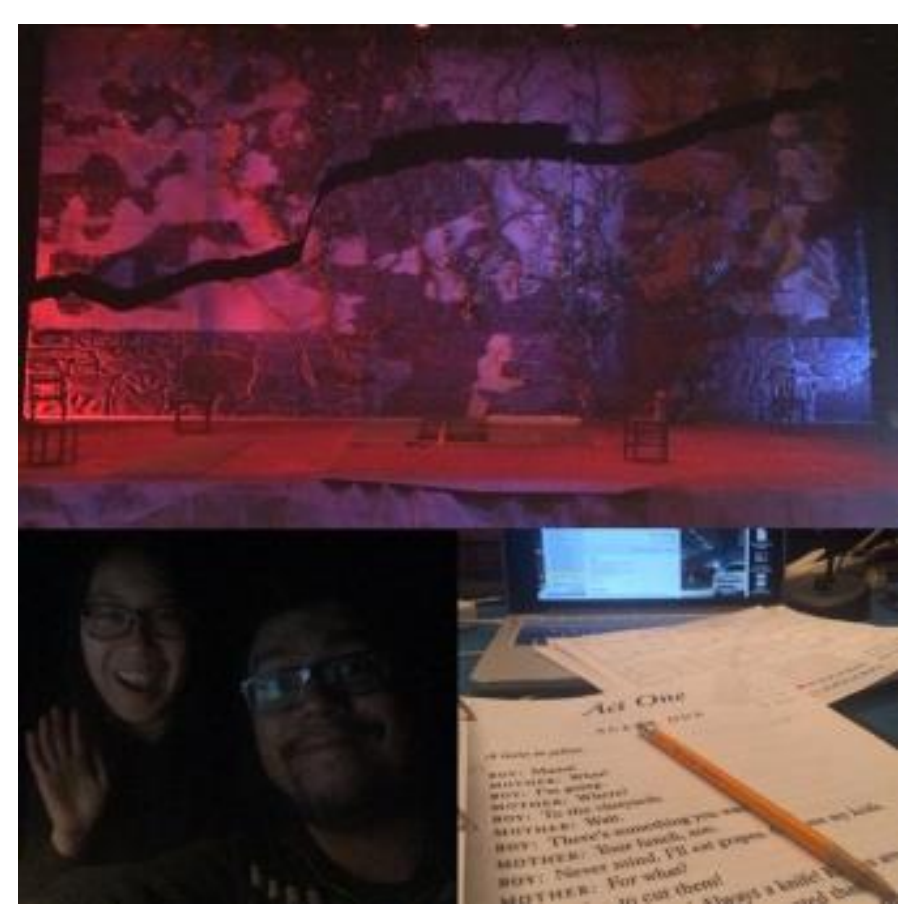

Figure 54. Photograph of programing day with the assistant Lighting Designer.

Next, technical rehearsals began. Tech is the part of the process during which scenic, lighting, sound, music, special effects, and other elements are put together with the acting and rehearsed moment by moment through the show. For a Lighting Designer, this is the most important part of the design process. Up to this point, every decision was a best guess from available information. During the technical rehearsals, I finally get to turn on lights onstage and see how they interact with all the elements of the show on stage (see fig. 55). I was nervous and excited to begin this journey with the design team. The choices I've made have been bolder than anything I had ever done in my career previously. On the one hand, I could overpower the show with my choices if I was not careful, but on the other, part of me thought I was not pushing the design enough. We began tech at $6 \mathrm{pm}$ on Friday. The Director wanted to do a cue-to-cue rehearsal, which means that we move through every technical cue in the show back to back. During my time in graduate school, I have found this structure of rehearsal to be more of a hindrance than a help. I prefer to watch the actors run through the show continuously and only 
stop when technical problems come up. This way, I see the movements of the actors in real time and what parts of the stage they use. In a cue-to-cue, I lose most of that by jumping around in the show, so before we started I asked the Director and Stage Manager if we could change it to a run rather than a cue to cue. I explained my reasoning, and the design team agreed to my suggestion.

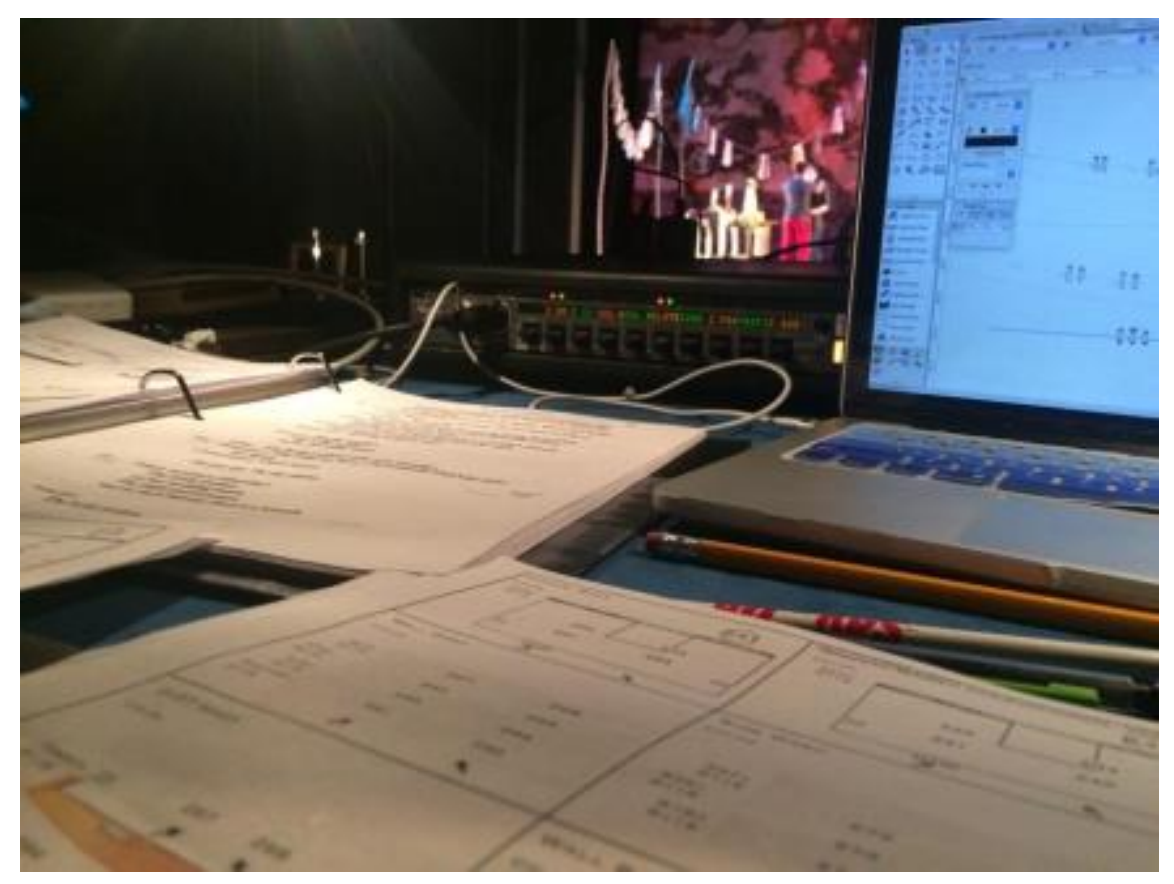

Figure 55. Photograph of a technical rehearsal.

We began going through the show, and I began my process. I watched and analyzed what was going on at each moment in the show, changing levels of lights and completely re-cuing the transitions. The tech process is rarely smooth, and Blood Wedding was no exception, especially when it came to the big wall reveal. We got through half the show the first night and continued the next day. When we came to the wall reveal, we stopped the run and talked through all the elements. The original plan was to go to a blackout at the end of Act Two while an ominous sound cue played that would lead to a clack. I would then turn the crack lights on at full so that once the wall cracked, light would spill out and create a blanket of light that would represent the powerful force of the moon. 
We tried the transition this way, and it was a disaster. The construction of the wall was not perfectly opaque when lit from behind, so even though the wall looked solid when not lit from behind, it had cracks that light could pass through. Lighting behind it while it was still closed destroyed the illusion we tried to make. We finished this version of the transition and paused. The Scenic Designer quickly ran to the Director to discuss what needed to change so that it could look more realistic. They came to the agreement that having the lighting wait to come up with the sound and scenic cues would help. The Scenic Designer came up to me and explained what they had talked about.

Unfortunately, I didn't want to hear what they were saying in that moment. I had been explaining to the design group for weeks how I envisioned this part of the show. I talked about how the lighting needed to be on first so that as the wall opened up, the audience would believe the light had caused it. Everyone seemed to agree and be on board. At this moment, I could not understand why I had bothered to talk about this constantly and why what I saw as scenic issues was now a lighting problem. When I get frustrated or stressed, I shut down. I walk away mentally so that I can have a moment to process everything so that my emotions do not get the best of me. Not surprisingly, the Scenic Designer was not happy that I was not responding to what he was saying. He kept trying to get me to talk, which was only upsetting me more. At that point, he got frustrated and walked away. I took a moment, analyzed the problem, and began quickly working on a solution. I knew that the Scenic Designer and the Director were correct about lighting needing to happen exactly with everything else, so I made bold and stylized choice with the lighting. I created a pixel map that would create an effect of light turning on from Stage Right and travel to Stage Left and stay on. This, along with the sound of a crackling wall and the wall cracking open, created an amazing image (see fig. 56). The design team was happy with the 
new transition, so we perfected the timing of lights and sound and then moved on.

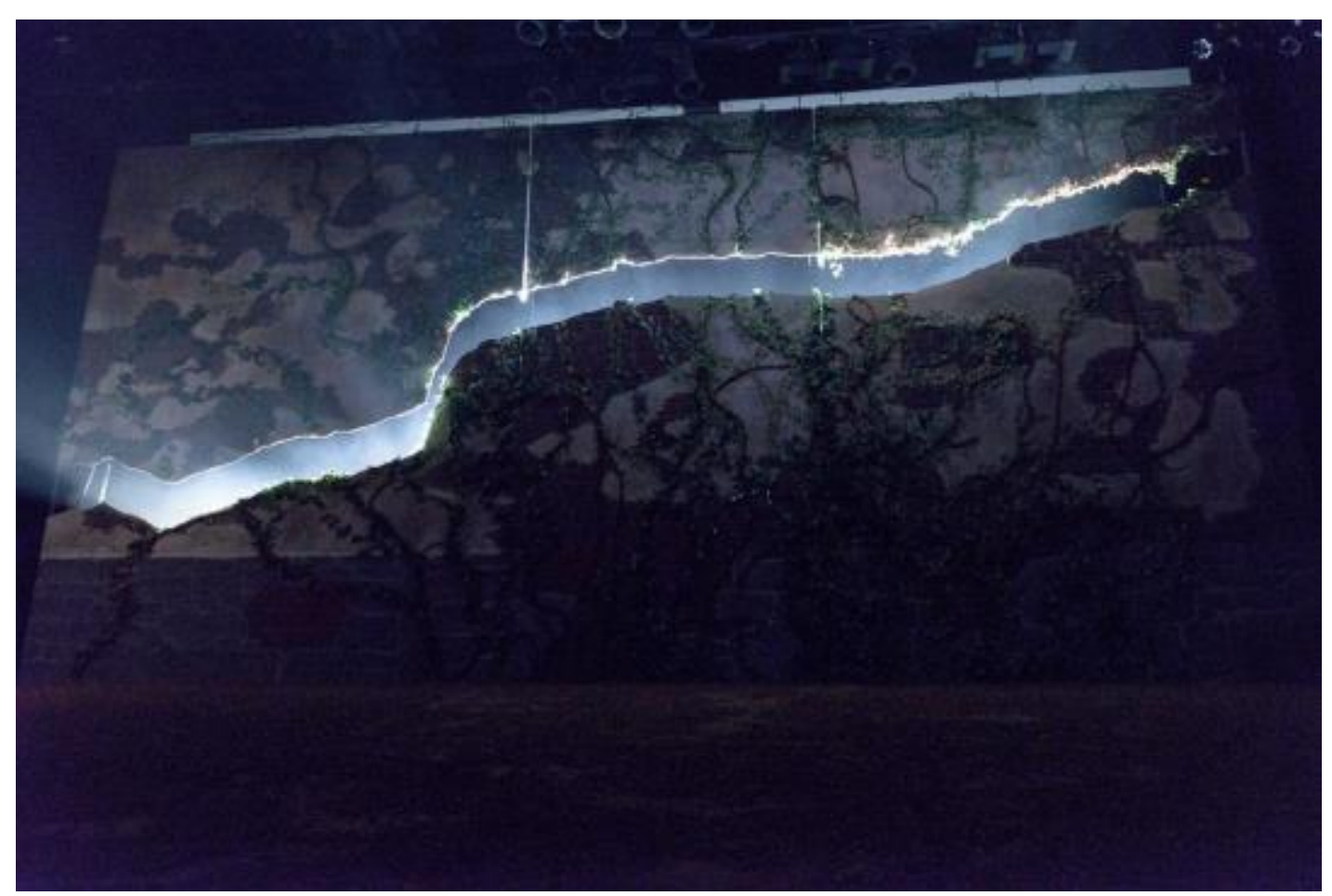

Figure 56. Production photo of the wall crack with haze and fog. Photography by Michael Bailey.

In the next part of the process we added costumes during the dress rehearsals. Adding this element luckily did not create more problems in terms of lighting. The costumes were earth tones and had gradient dyes that could be read under stage lighting if you looked closely. Luckily, the Costume Designer was happy with my lighting design and loved the way the costumes caught the light and how all the elements interacted with each other. I was happy that a few people could not tell if the gradients on the costumes were dye or lighting.

After the first dress rehearsal, the Director came up and talked to me about a problem he was having with the show. The transitions up to that point had been exactly what he wanted. The problem was that they all were too different. He had choreographed dancing in some transitions, scenic changes in others, and he even staged a mini scene because he feared that the audience 
would not understand that the wedding had happened. In my mind each transition called for different lighting looks and I did not have any ideas about how to unify everything. The Director asked if I could possibly put in a blue cue before and after each transition (see fig. 57), to indicate to the audience that it was a transition. A blue cue is usually just a system of blue lights turned on at a glow so that the actors can get into place or set scenery onstage while at the same time indicating that this is a transition in the story of a show. I took his suggestion and ran with it. Instead of doing a glowing blue light, I created an intensified blue wash and it worked.

Making this one change created a more unified transitional element throughout the show. Once the final dress rehearsal came around, I found myself just watching the show and taking final notes on cues. I was surprised that I managed to create such a stunning design.

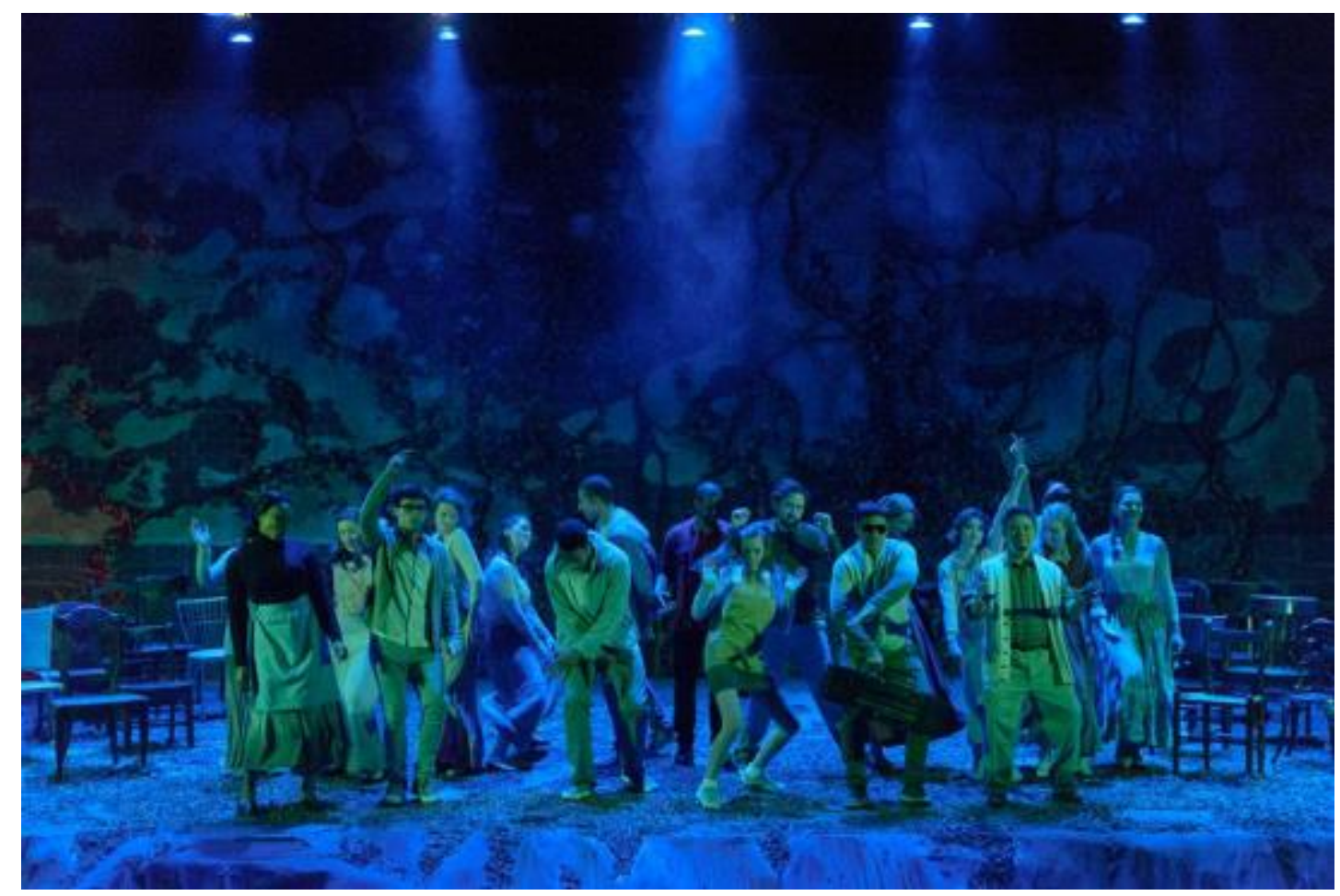

Figure 57. Production photo of the first blue transition in the show. Photography by Michael Bailey.

Blood Wedding opened on Thursday February 23, 2017 at 8:00P.M. The Artistic Team included: Dave Dalton, Director; Matthew Kornegay, Scenic Designer; Kaitlin Sikes, Costume 
Designer; Fabian J. Garcia, Lighting Designer; Matthew Jefferson Ishee, Sound Designer; Monica Blaze Leavitt, Voice, Text, and Accent Coaching; Tim Nielsen, Technical Director; and Kristen Riordan, Production Stage Manager. The Lighting Team included: Celia Chen, Assistant Lighting Designer; Steven Johnson, Master Electrician; R. Lee Kennedy, Lighting Design Faculty Advisor; Natalie Pernick, Light Board Operator; and Olivia Comm, Chelsea Dickens, Patricia Gallegos, Michael Giovinco, Matthew Ishee, Brian Morris, and Katelyn Wattendorf, Electricians.

In the end, Blood Wedding turned out to be one of my strongest designs not just in graduate school but also in my career as a whole. I stressed about and over-thought everything, I struggled through meetings and with understanding all of the design concepts, and at one point I even doubted my abilities as a Lighting Designer, but through it all, I believe I came out stronger than ever. As a collaborator, it took quite a bit of time to visualize a solid approach for the lighting design, but eventually, the pressure of meeting deadlines forced my hand to make choices on the spot. I relied on my instinct and knowledge of lighting to help get me through the process, which was a roller coaster from beginning to end. Looking back now, everything I learned about communication helped make Blood Wedding a successful and visually cohesive production. Constant communication via email and individual meetings with other departments helped keep the production team on the same page. On my end, there were a number of skills that contributed to my overall success as a Lighting Designer. Being knowledgeable about lighting and how it works from the beginning helped to minimize mistakes on my end down the road. I was also able to analyze information and draw conclusions that helped me ask key questions in meetings that might not have been brought up previously. Keeping my paperwork organized and up to date let me quickly find what I needed so that the process continued to run 
smoothly. The listening skills I developed helped me collaborate with others on the design team and accurately assess what they needed from me. Respecting my colleagues and knowing that our common goal was to produce a successful show created a trusting environment in which we all felt comfortable exchanging ideas. Lastly, keeping an open mind helped me be flexible throughout the process and adapt to the many changes as they were made. The final production images (see fig. 58-74) reflect all of the hard work and long hours that went into creating the finalized lighting design for the show. Without successful collaboration and communication, these final images would not have the same visually appealing and cohesive design. The lessons I learned in working on Blood Wedding will continue to help me grow as a designer as I move on from my graduate education into the professional world, and without having had this successful experience I would not be the artist I am today.

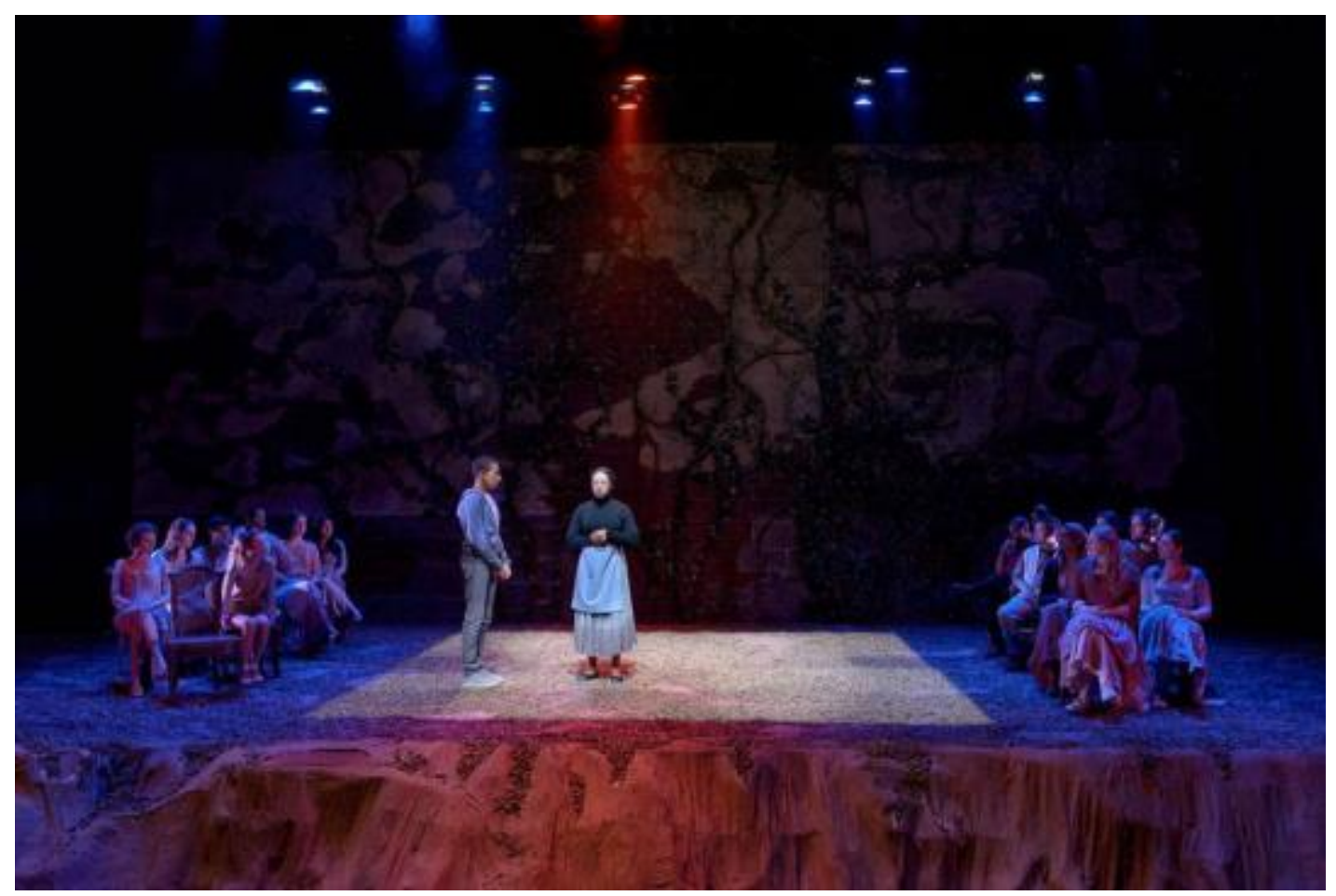

Figure 58. Production photo of Act One Scene One. Photography by Michael Bailey. 


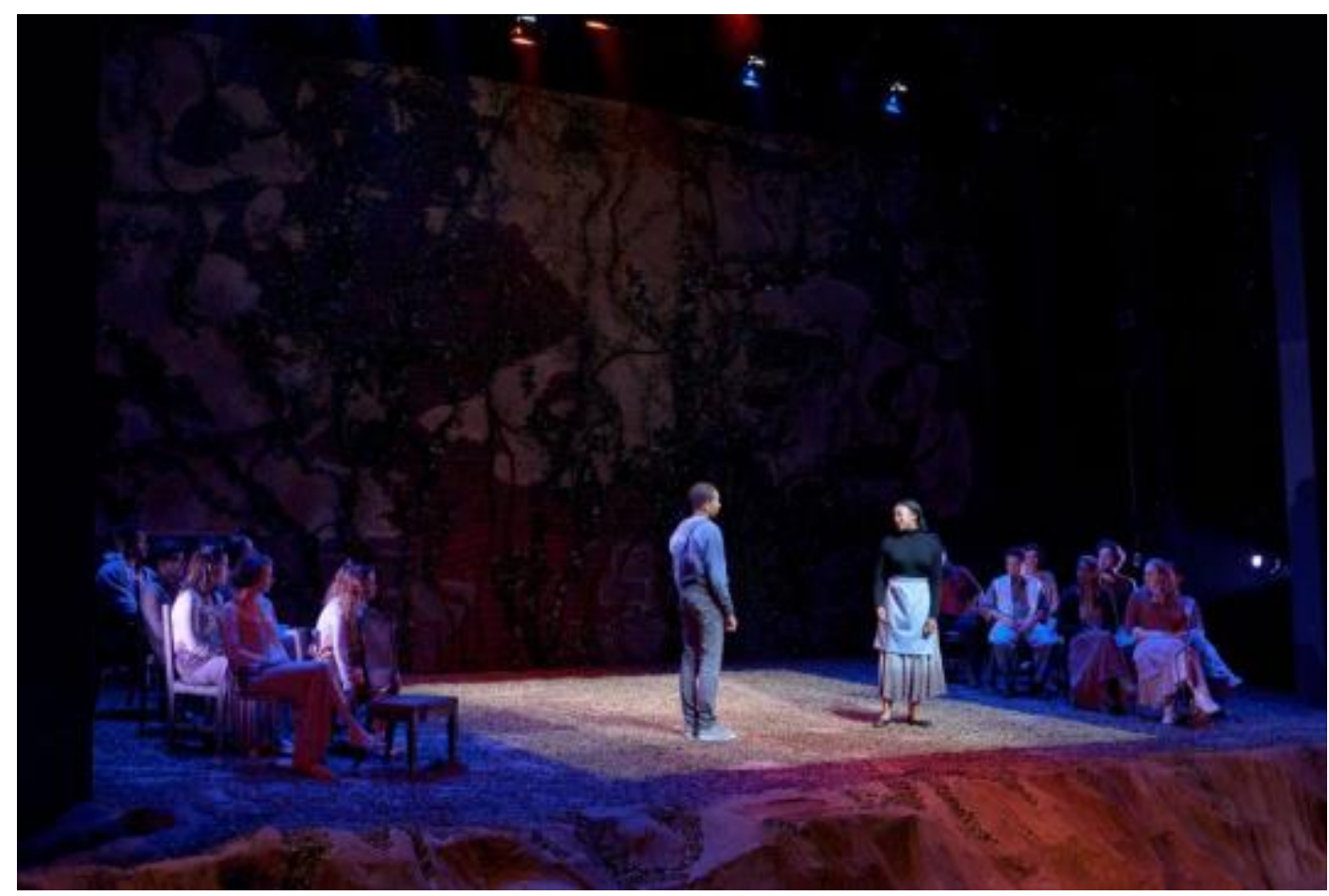

Figure 59. Production photo of Act One Scene One. Photography by Michael Bailey.

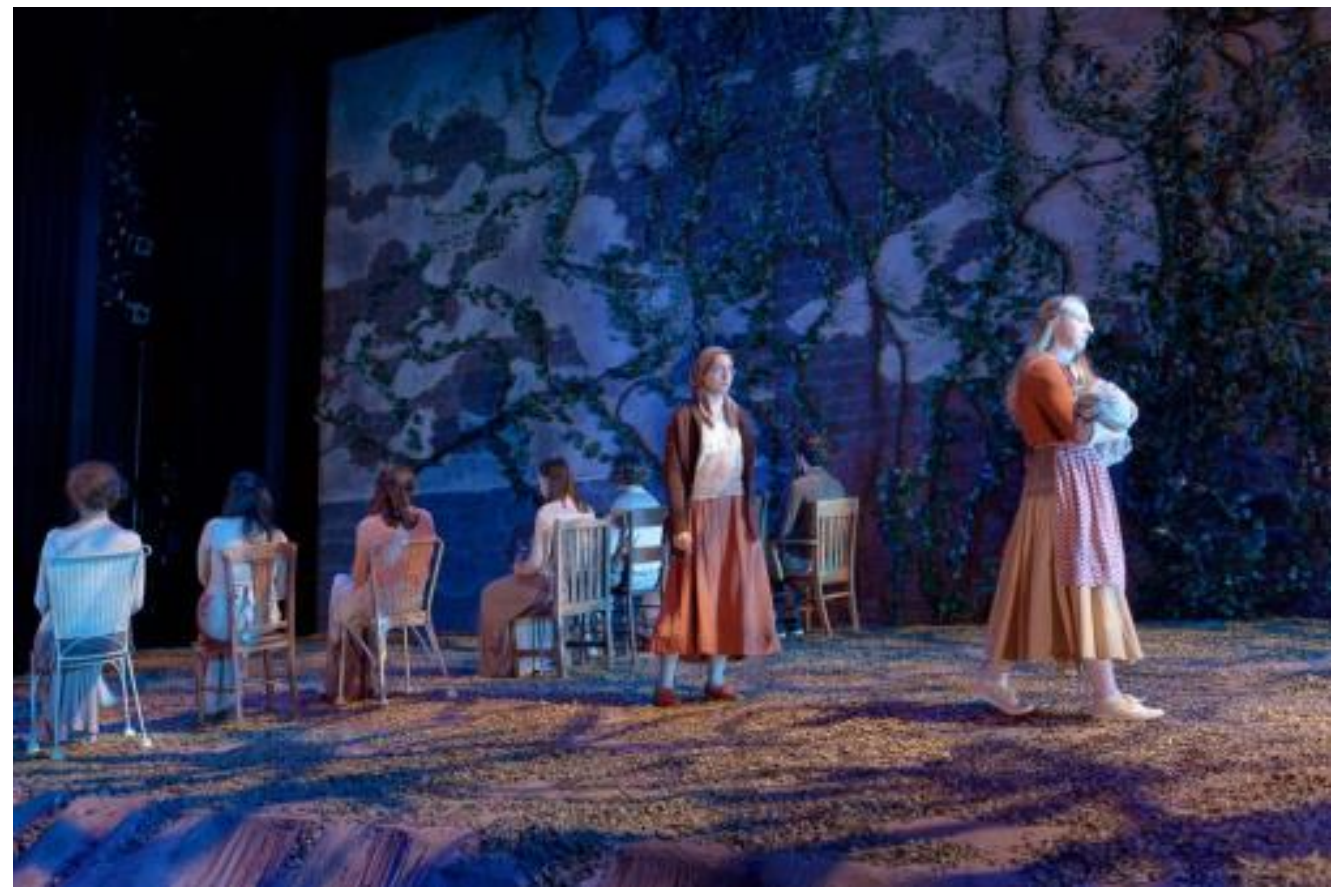

Figure 60. Production photo of Act One Scene Two. Photography by Michael Bailey. 


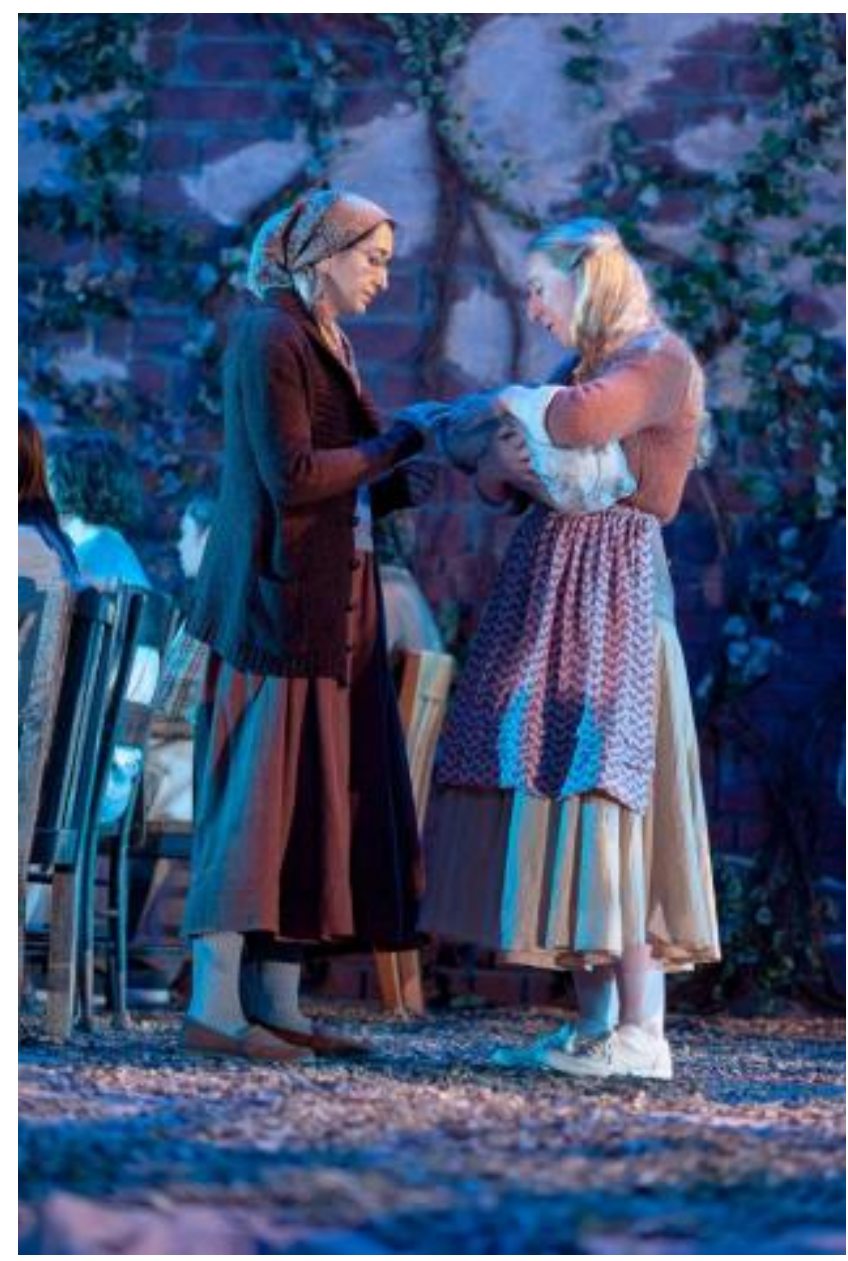

Figure 61. Production photo of Act One Scene Two. Photography by Michael Bailey.

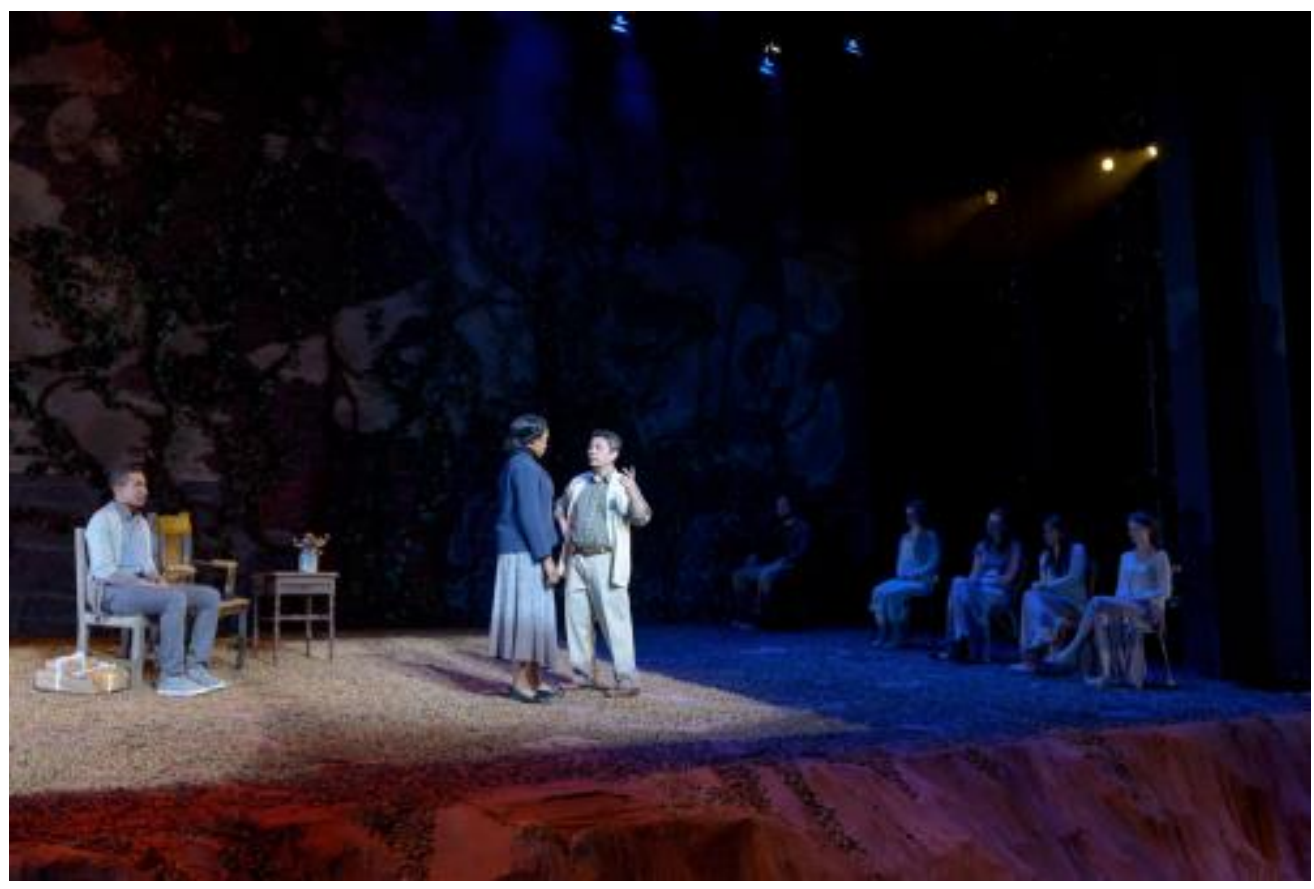

Figure 62. Production photo of Act One Scene Three. Photography by Michael Bailey. 


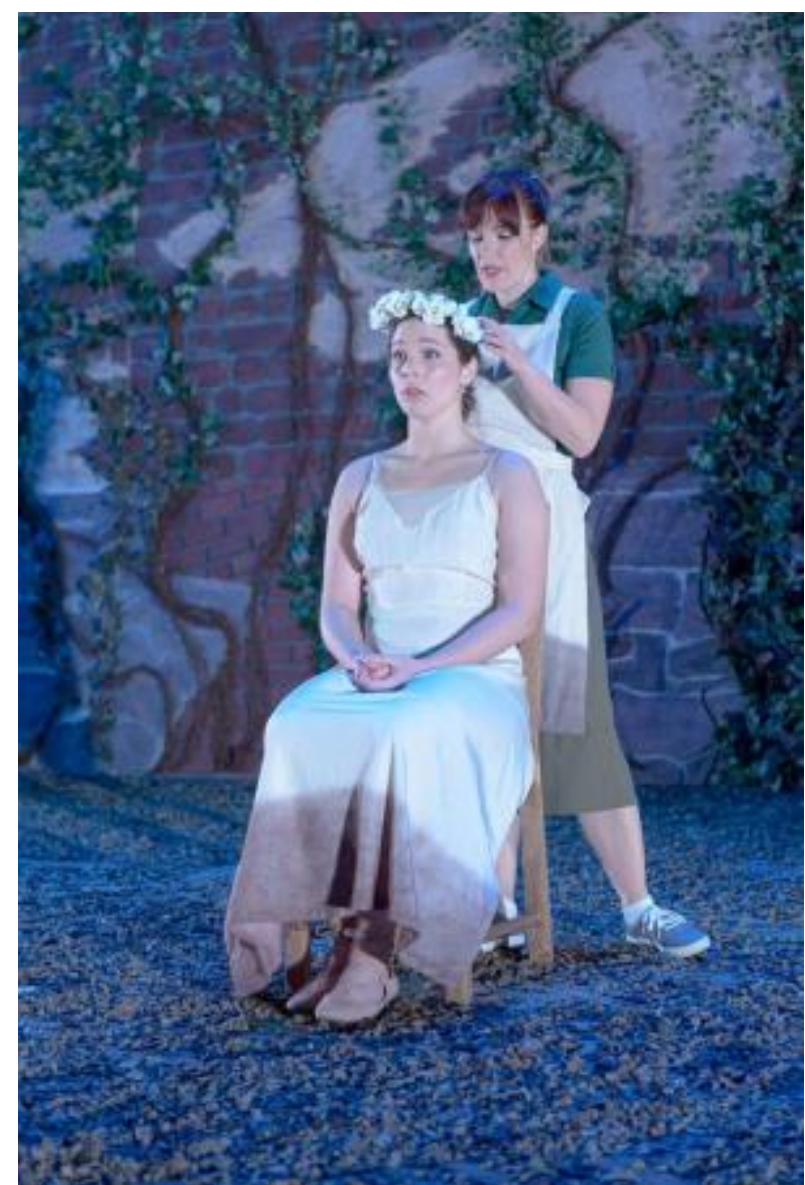

Figure 63. Production photo of Act Two Scene One. Photography by Michael Bailey.

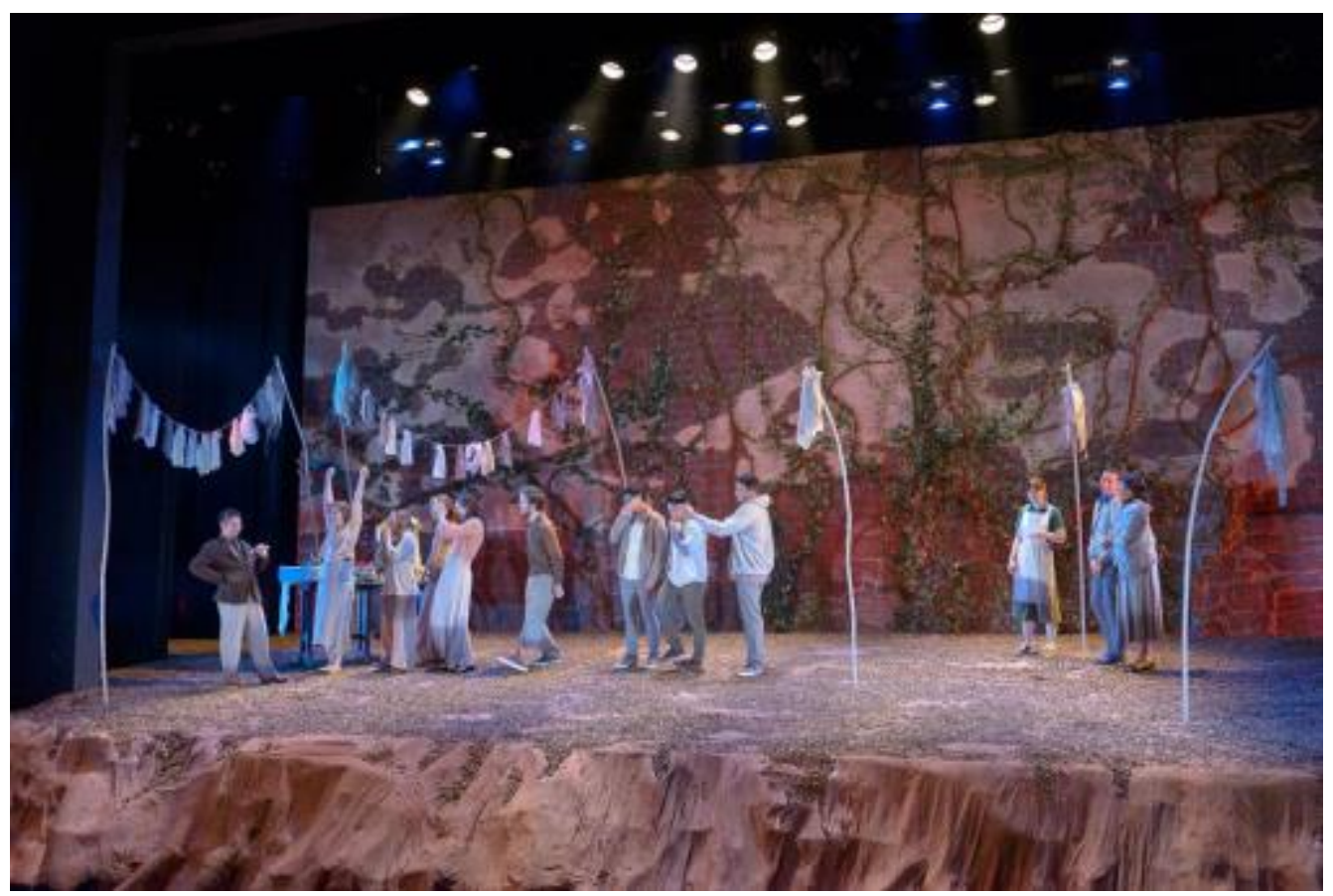

Figure 64. Production photo of Act Two Scene One. Photography by Michael Bailey. 


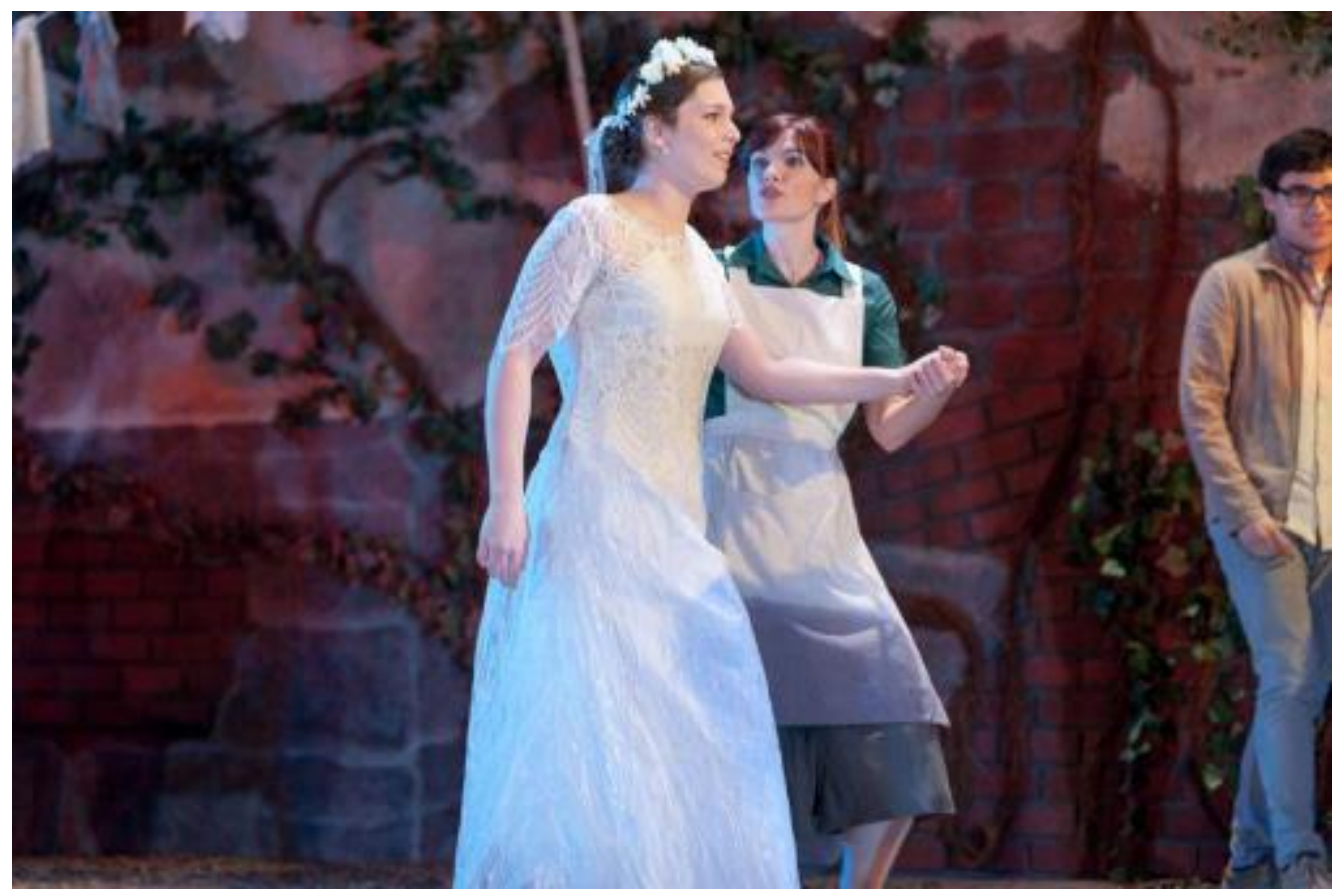

Figure 65. Production photo of Act Two Scene One. Photography by Michael Bailey.

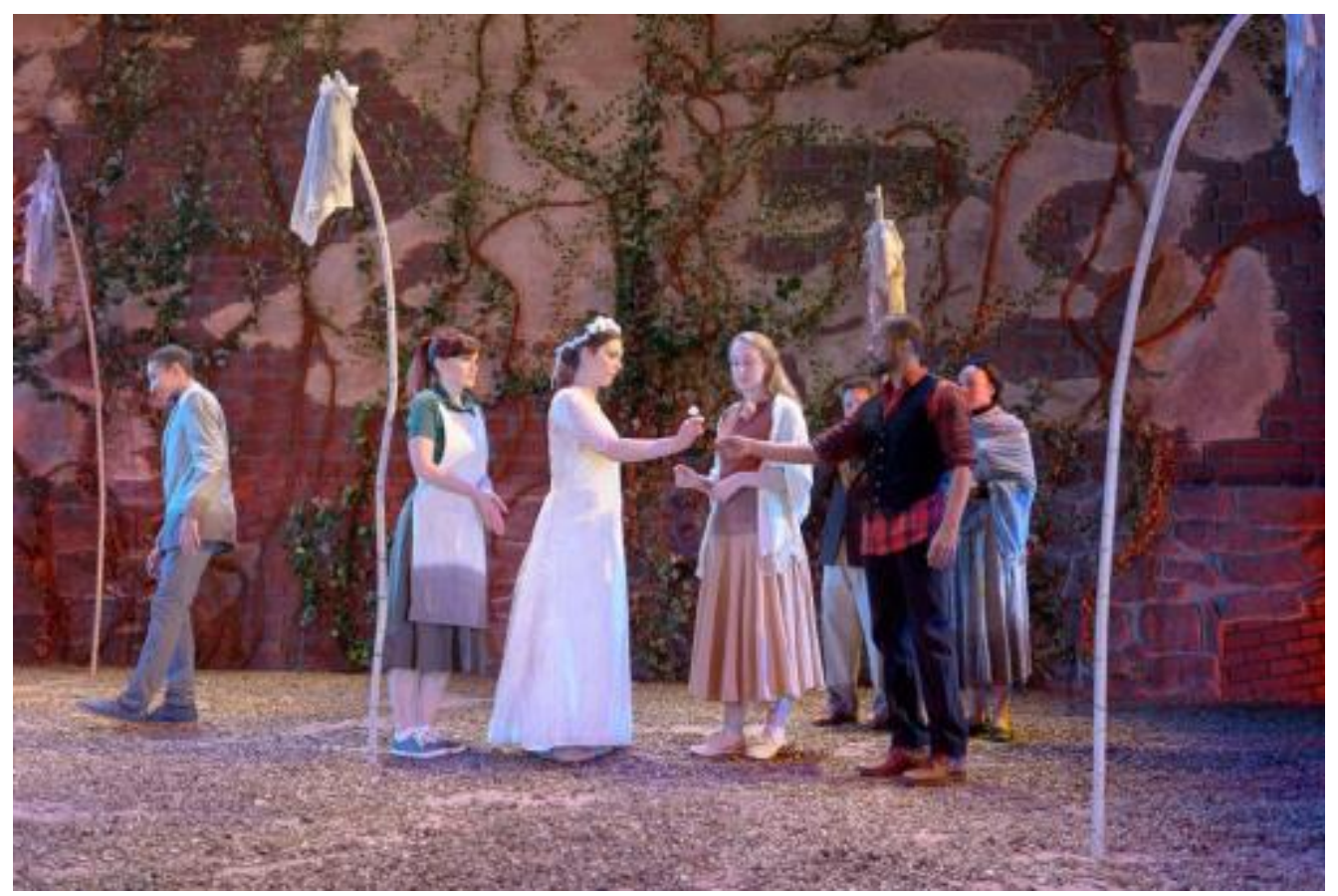

Figure 66. Production photo of Act Two Scene One. Photography by Michael Bailey. 


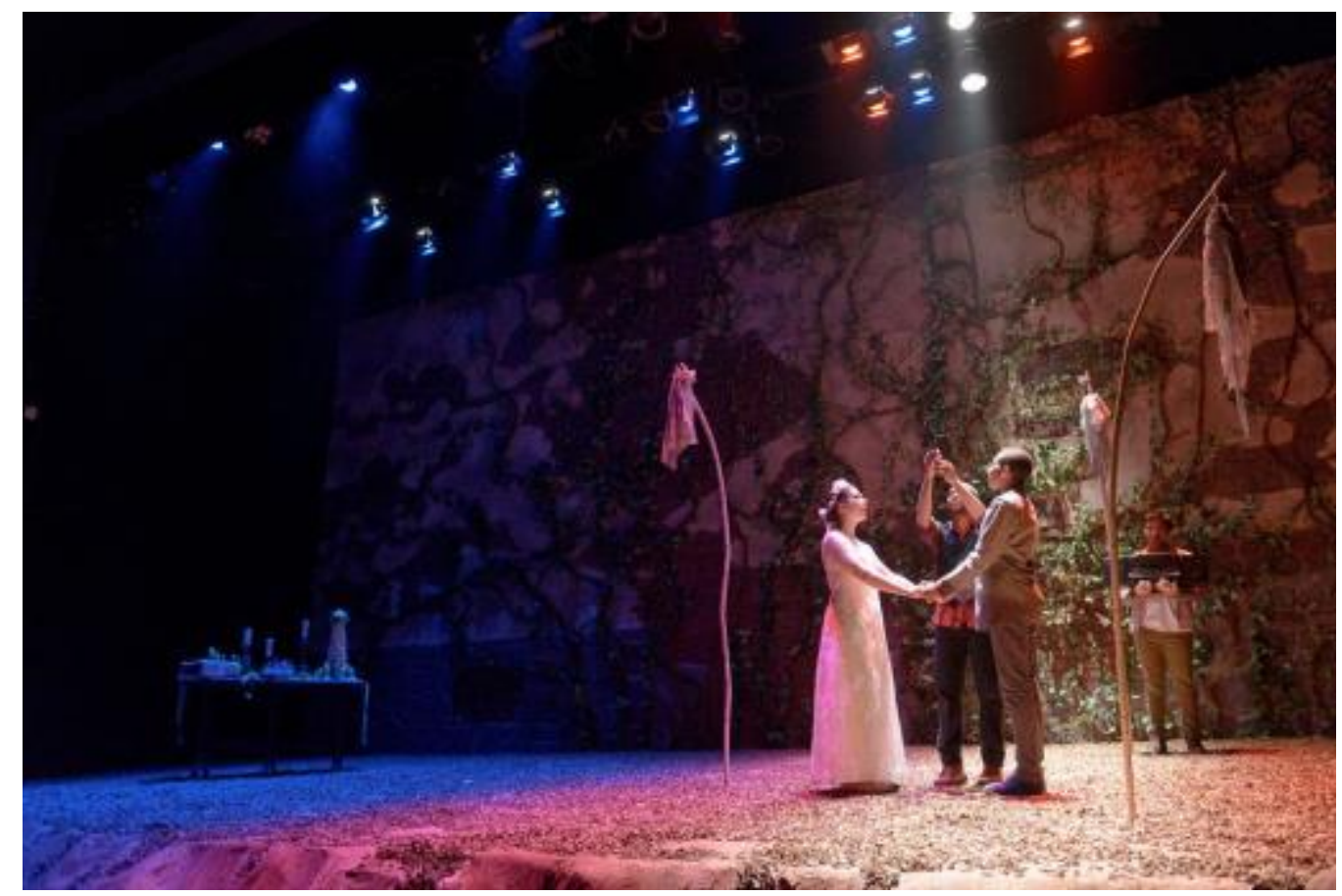

Figure 67. Production photo of Act Two Transition. Photography by Michael Bailey.

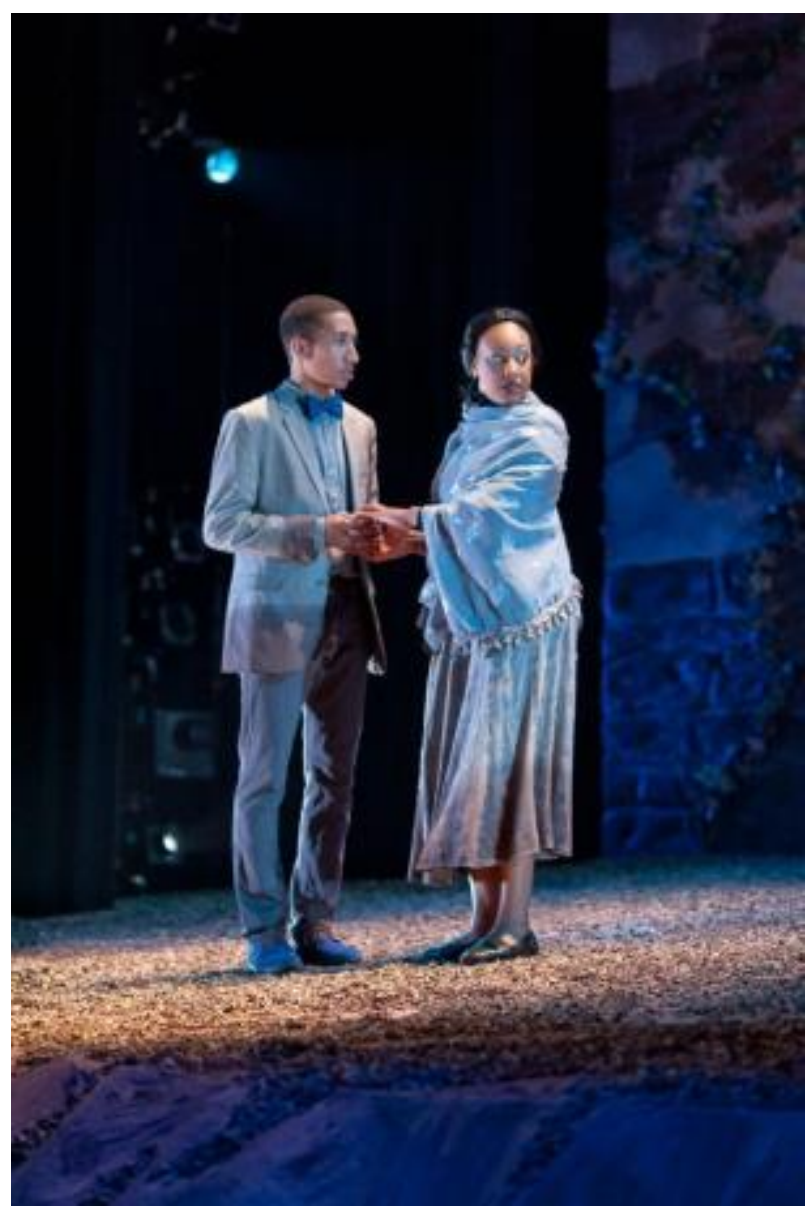

Figure 68. Production photo of Act Two Scene Two. Photography by Michael Bailey. 


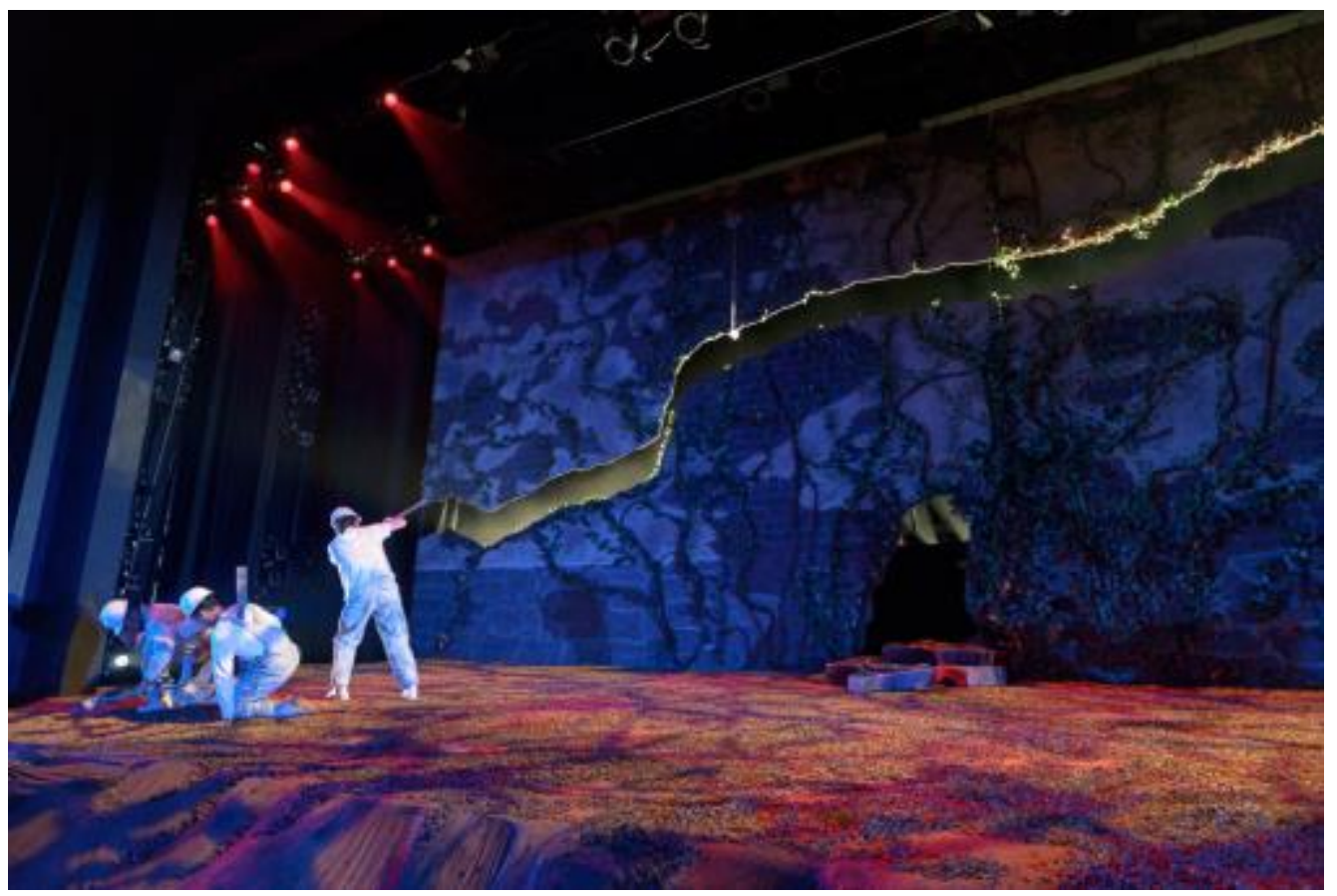

Figure 69. Production photo of Act Three Scene One. Photography by Michael Bailey.

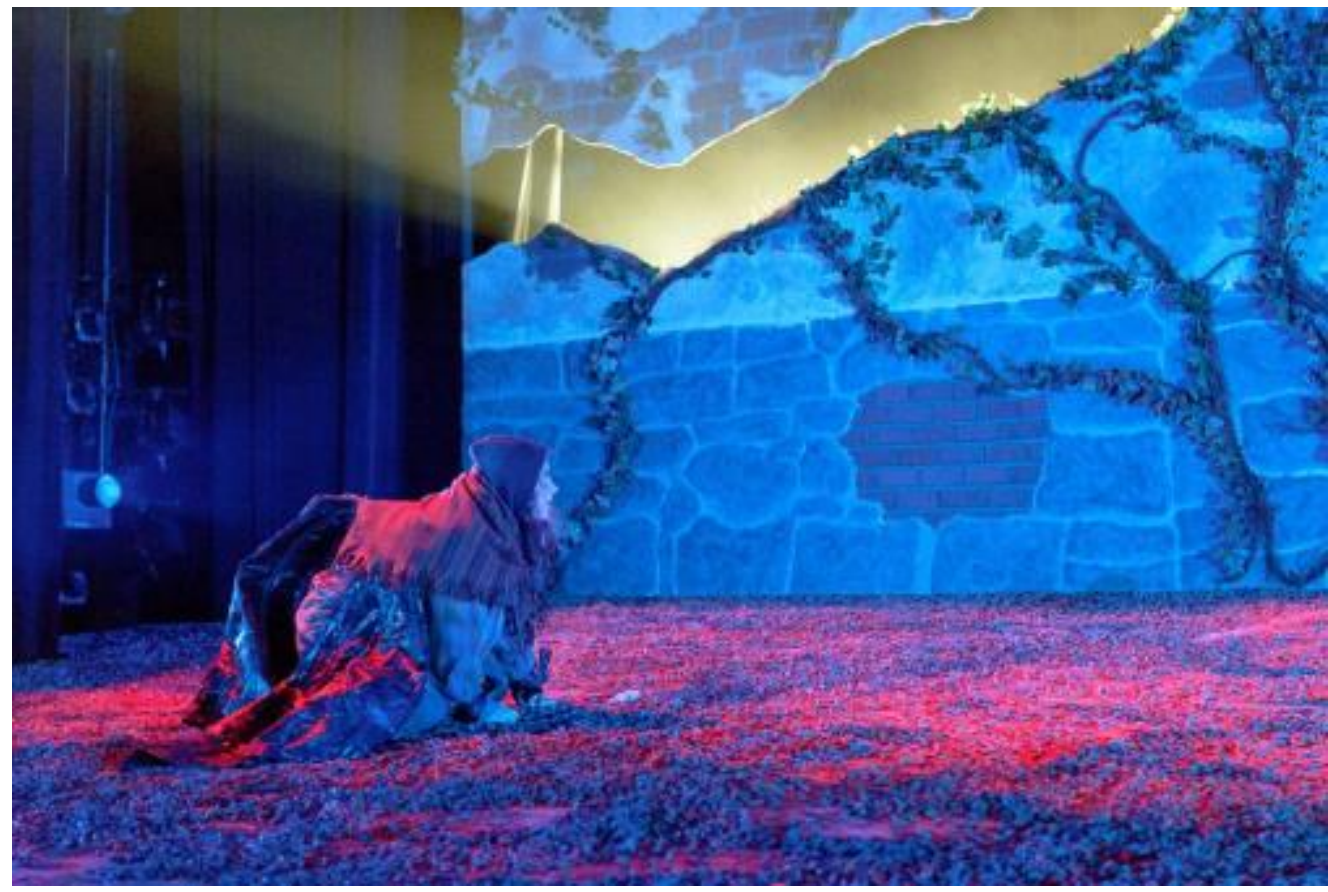

Figure 70. Production photo of Act Three Scene One. Photography by Michael Bailey. 


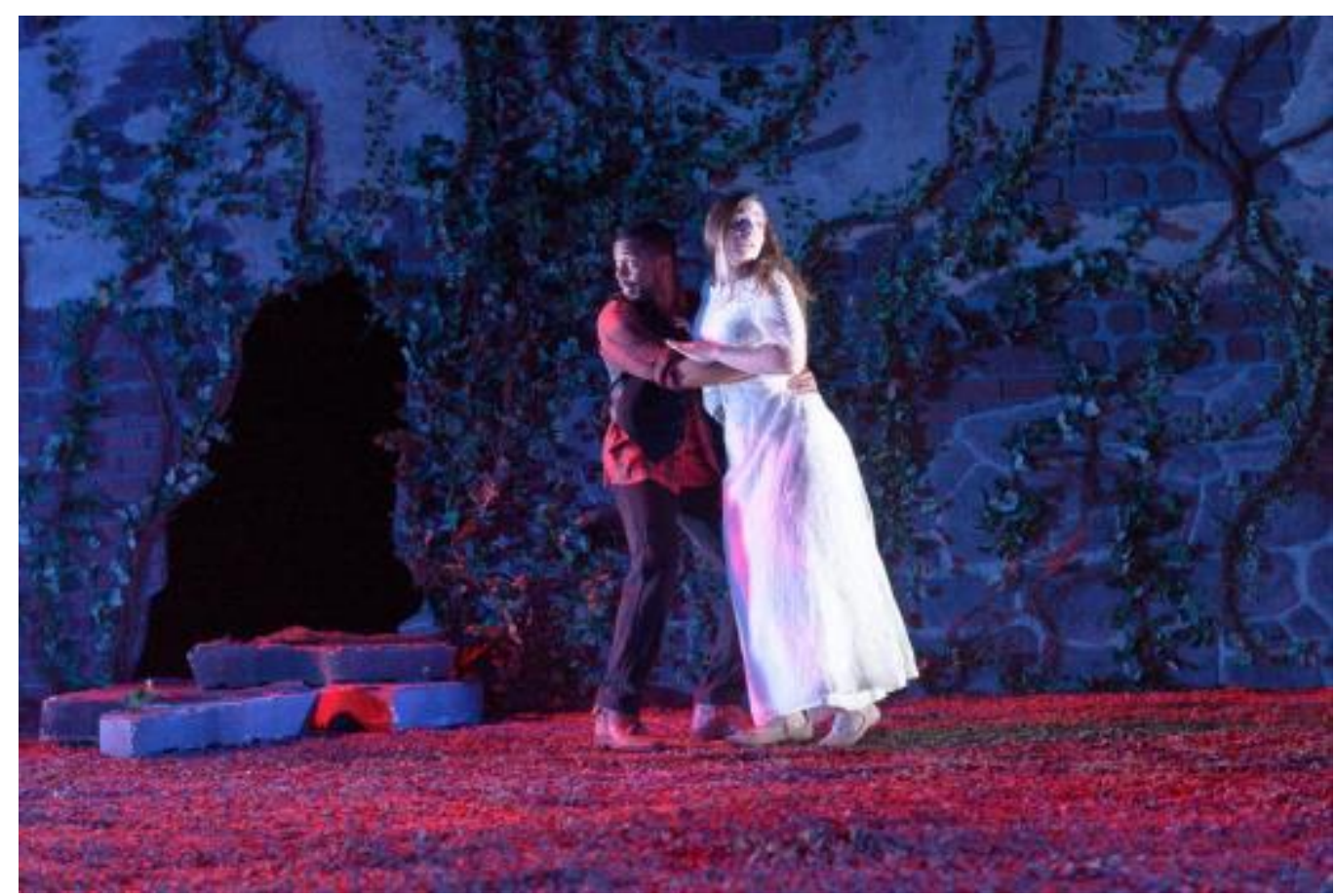

Figure 71. Production photo of Act Three Scene One. Photography by Michael Bailey.

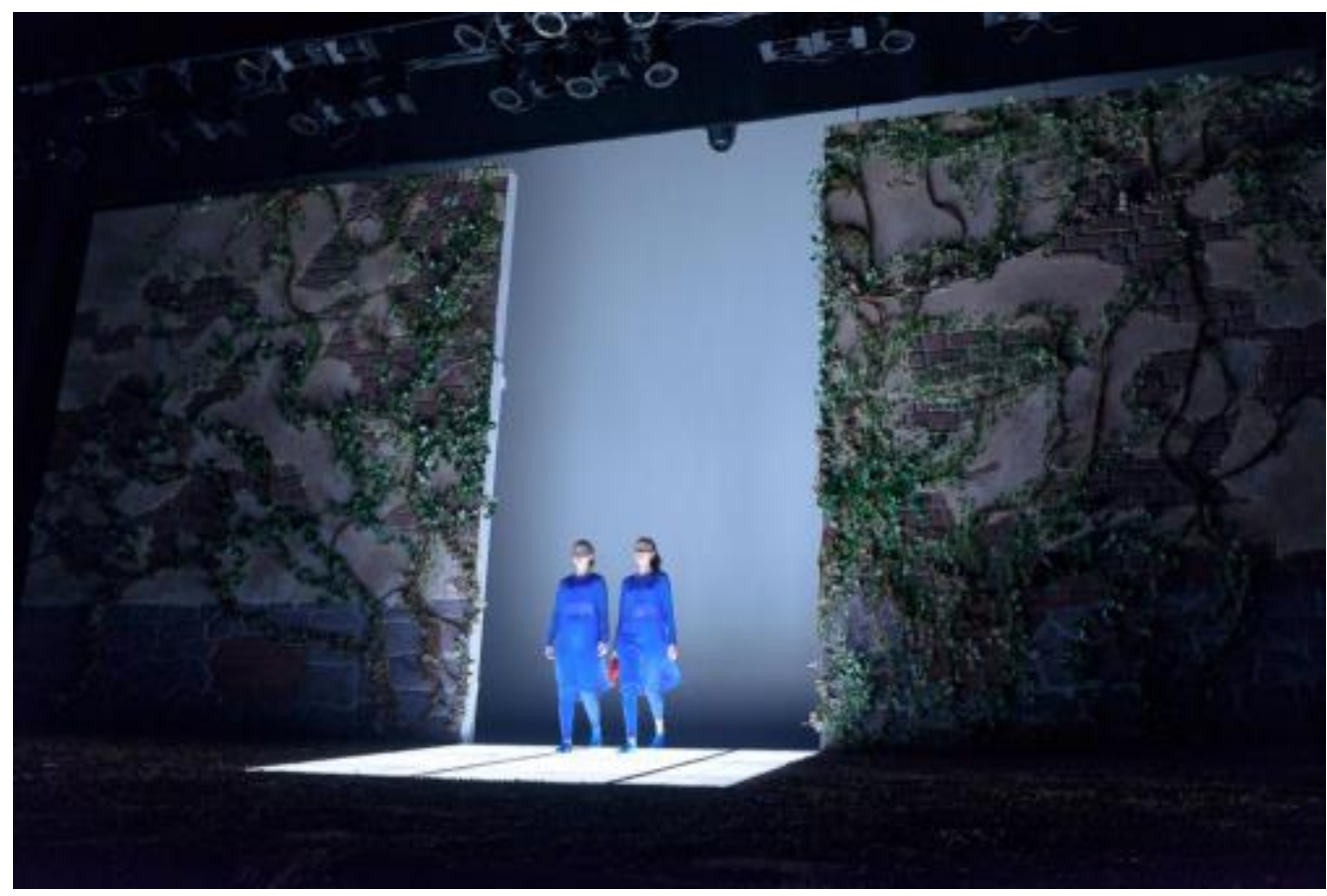

Figure 72. Production photo of Act Three Scene Two. Photography by Michael Bailey. 


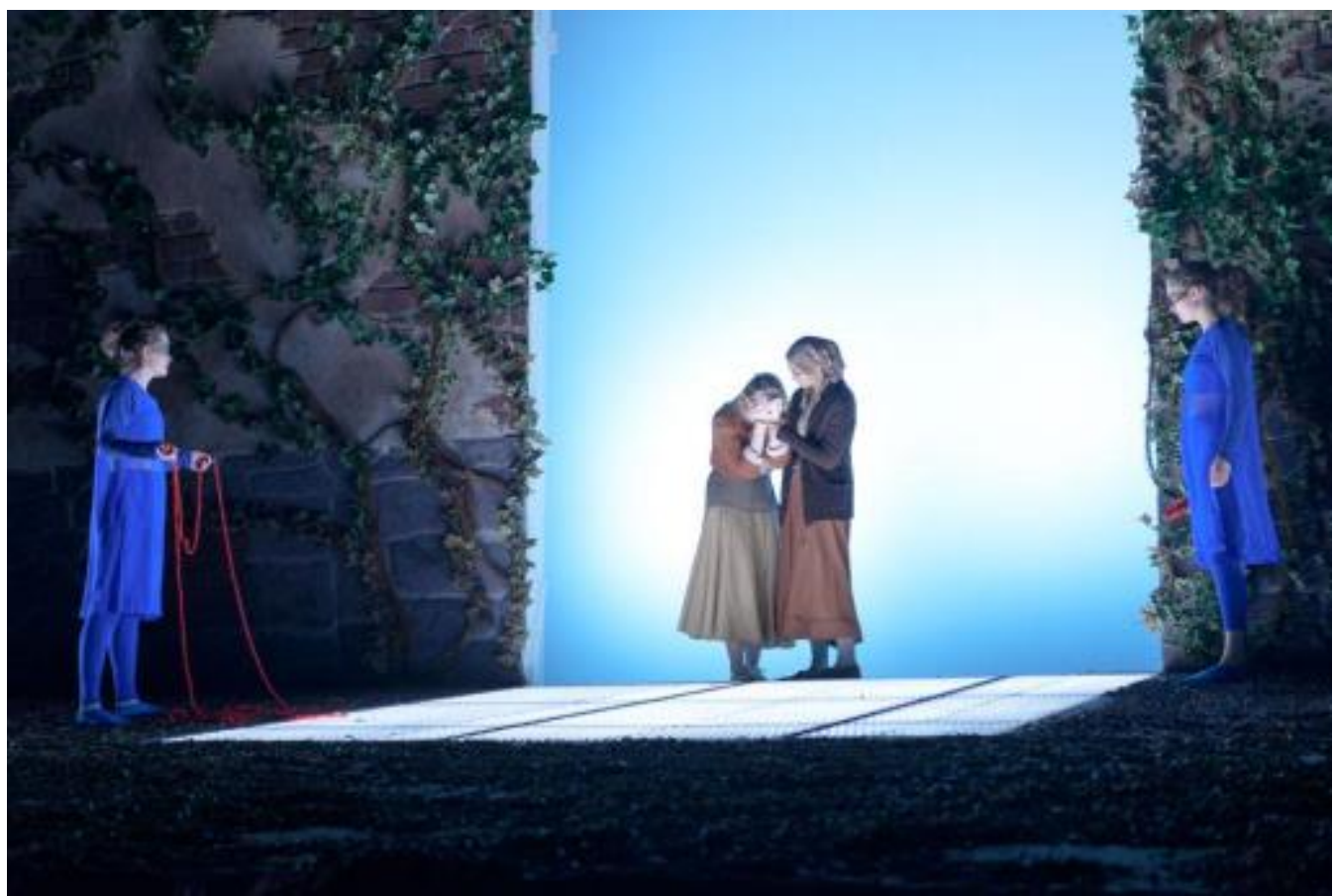

Figure 73. Production photo of Act Three Scene Two. Photography by Michael Bailey.

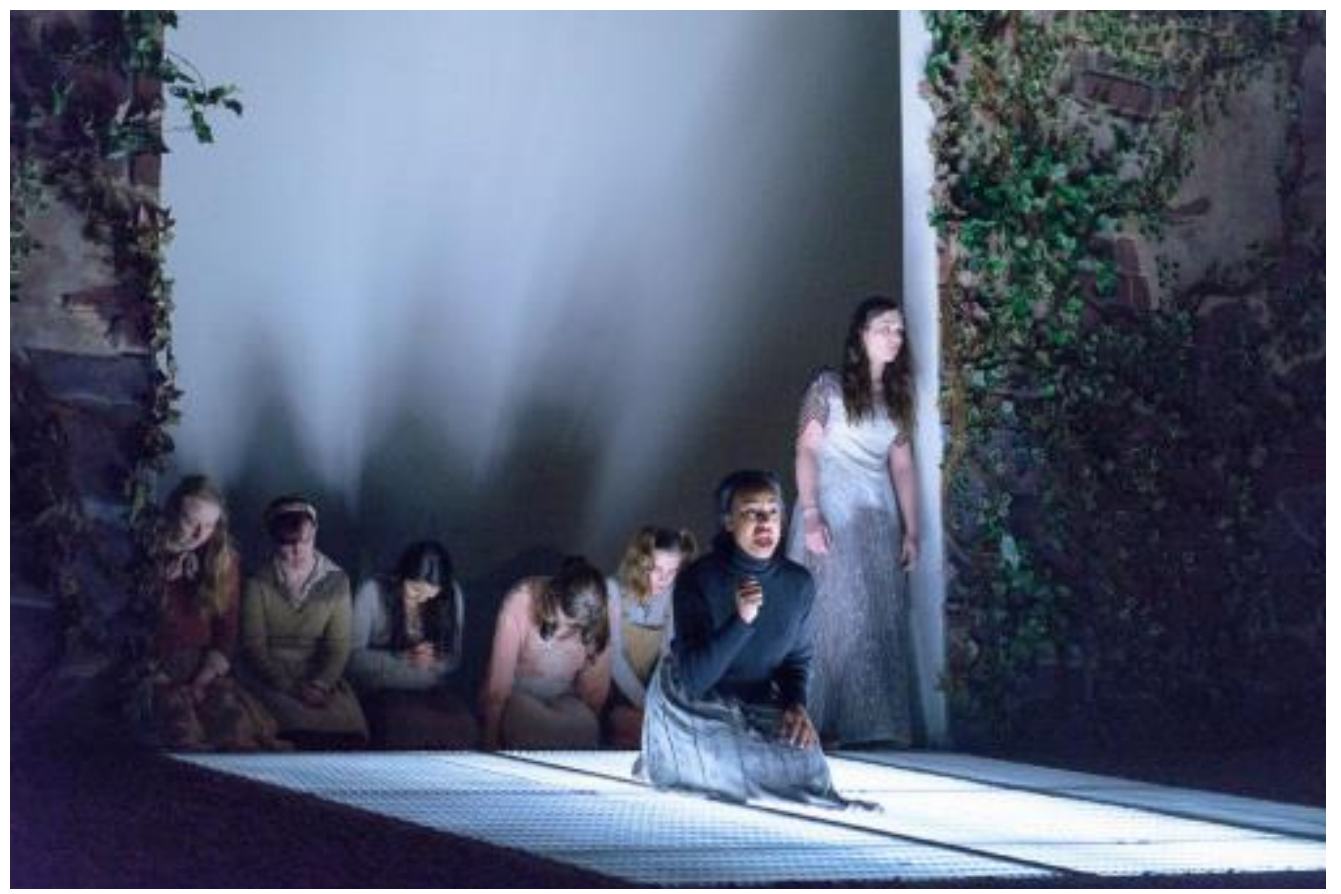

Figure 74. Production photo of Act Three Ending. Photography by Michael Bailey. 